


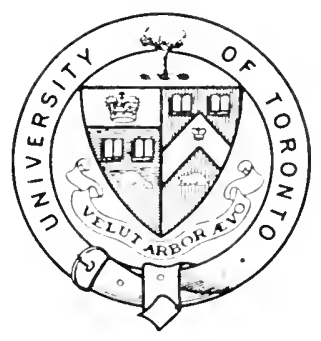

PUP( IIISEI) FOH THI

UNIIERSITY OI TORONTO IIBRARY

$\mathrm{FPONTHE}$

CANADA COUNCII SPECHIL GRANT

$\mathrm{IOR}$

ECONOMIC HSITORY 






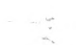




\title{
ABHANDLUNGEN
}

ALS DENI

\section{STAATSIISSEASCHATLICHEN SEMINAR}

\author{
$\mathrm{ZU}$ \\ $S T R A S S B U R G$ i. E.
}

HERAUSGEGEBEN

$\operatorname{rox}$

G. F. KNAPP UND IV. WITTICH.

HEFT XXIII.

OTTO SOLTAU:

DIE FRANZÖSISCHEN KOLONIALBANKEN.

STRASSBURG

VERLAG VON KARL J. TRÜBNER

1907 


\author{
DIE
}

FRANZÖSISCHEA KOLONLALBANKEN

VON

Dr. OTtO SOLTAU, REFERENDAR.

STRASSBURG

VERLAG VON KARL J. TRÜBNER

1907 


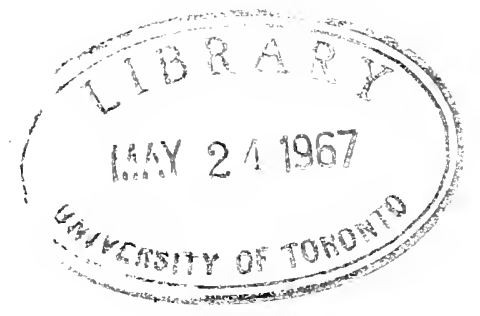

M. DuMont sehauberg, Strafburg. 


\section{LITERATURANGABE.}

\section{Deutsche Literatur.}

1. Dr. Rosendorff: Die französischen Kolonialbanken. Bankarchir L904́ Nr. 10.

2. Zimmermann: Kolonialpolitik. S. 252-262. Leipzig 1905.

3. Weber: Depositen und Spekulationsbanken. Leipzig 1902.

4. Dr. Hauser: Die Deutschen Überseehanken. Jena 1906.

1I. Französische Lileratur.

5. Renand: Les banques coloniales. Poitiers 1899.

6. Denizet: Essai sur les banques coloniales. Paris 1899.

7. Girault: Principes de colonisation et de législation coloniale. Paris 1895.

8. Courcelle-Sénenii: Traité des opríations de banque. Paris 1896.

9. Courtois: Histoire de la banque de France. 1875.

10. Faucher: Banques coloniales. Revme des deux Mondes. 15 dic. 18000.

11. A. Courtois: Les banques coloniales. Feonomiste francais 1874 . $1 \mathrm{er}$ seim.

12. G. Michel: Passé et I'arenir des hanques coloniales. Économiste français 1898, 1er sém.

13. Bouchié de Belle: Renowellement lu privilege des banques coloniales. Journal des ficonmisles. Nov. Is95.

14. Lois de 18501,187 et de 1901 sur les banques coloniales et slatuts des banques. Moniteur universel. Jommal ofticiel.

15. Décrets de 1875, 1888 et $1900 \mathrm{sms}$ la Banque de 1']ndochine et nouveaux statuls de cette banque. Jomnal ofliciel.

16. Lois sur la Banque de l'Algérie, 18.1, 1868, 1880. 1900. Moniteur universel. Journal officiel.

17. Décret sur la Banque de la Nouvelle-Calédonie 187.t. Jomrnal officiel.

18. Décret de 1901 sur la Banque de l'Afrique occidentale. Jommal officiel.

19. J. Leveillé $\left({ }^{2}\right) \quad\left(\begin{array}{c}\text { Rapports sur le projet de hi concernant les banques } \\ \text { coloniales. }\end{array}\right.$

L. Brunet (1) Journal officiel, documents parlementaires de la Isaac (1) Chambre.

Leroy (1) $\left\{\begin{array}{l}1897 \text { p. } 1425,1898 \text { p. } 567,601,920,1900 \text { p. } 17 \text { et } \\ 1901 \text { p. } 1739 .\end{array}\right.$

20. Rapports annuels de la Commission de surveillance des banques coloniales. Journal officiel. 
21. Rapports sur la Banque de l'Algérie. Journal officiel, documents parlementaires:

1851 de Bénoist d'Azy.

1879 de L. Say, Brice et Lucet.

1899 de Peytral, Moigne, Caillawx.

1900 de Moigne et Dubost.

III. Englische Literatur.

22. Summer: A history of banking in the leading nations. Volume III:

The bank of Algeria and the other french colonial banks. 1896. New-York, 19 Beaver Street. 


\section{INHALTSVERZEICHNIS.}

Literaturangabe . . . . . . . . . . . . . V V

Einleitung: Definition. Begrenzung des Themas ....... 1

\section{Erstes Buclu.}

Die fünf alten Kolonialbanken in Nartinique. Guadeloupe. Réunion

Guyane und Sénégal . . . . . . . . . . 3

\section{Erster Abschnitt.}

Zustände ror Errichtung der Kolonialbanken. besonders in den Zuckerkolonien ..............

1. Kapitel. $\$ 1$.

Die Zeit vor der Sklavenbefreiung

Plantagenwirtschaft. Sklaverei, pacte colonial. Kommissionäre als Kreditgeber.

Vorläufer der Koloniaibanken.

2. Kapitel. $\leq 2$.

Die Zeit nach der Sklarenbefreiung . . . . . . . . . 6

Lohnzahlung. Arbeitereinfuhır. Kreditbedürfnis.

\section{Zweiter Abschnitt.}

Die Errichtung der Kolonialbanken: ihr Wesen . . . . . . .

1. Kapitel. \$ 3.

Die Kolonialbankgesetzgebung ron 1849 bis 1905 . . . . . .

Art der Kapitalbeschaffung. Gründung der Banken.

Grundzug der Gesetzesänderungen 18/'

2. Kapitel. $\$ \dot{x}$.

Die Verfassung der Kolonialbanken

Sitz. Kapital. Aktien, speziell actions d'Europe. Reserven. Dividende. Generalversammlung. Verwaltungsrat. Zensoren. Inspektoren. Überwachungskommission. Die Kolonialbanken als privilegierte Privatbanken unter Staatsaufsicht

3. Kapitel.

Ihr Geschäftskreis insbesondere. Leitender Grundsatz . . . . . 
Passivgeschäfte der Kolonialbanken . . . . . . . . . .

1. Die Notenausgabe.

Höhe des Notenumlaufs. Zahlungskraft der Noten. Bedeutung der Notenausgabe.

2. Die Depositengeschäfte.

Depositen zur Verwahrung, zur Verwaltung, zur Verwendnng. Kontokorrent und Giroverkehr. Rícépissé. Scheck.

3. Die Annahme von Zeichnungen auf öfentliche Anleihen.

$\$ 6$.

Aktivgeschäfte der Kolonialbanken

1. Das Diskontgeschäft.

Voraussetzungen der Diskontierung: 2 Unterschriften, Zulassung zum Diskont, Verfallzeit. Ersatz der 2. Unterschrift.

2. Die Darlehen auf Aktien, Rentenbriefe und gewisse andere Wertuapiere.

3. Die Erntedarlehen.

Ursprung und Natur der Darlehen. Widerstreitende Interessen. Sicherung der Bank gegen den Schuldner. Vorgang bei Erteilnng der Emtedarlehen. Zurückzahlung der Darlehen. Risiko der Bank. Reformrorschläge. Bedeutung der Darlehen für die Kolonie.

千. Die Warendarlehen.

Warrant. Lagerschein. Konossement. Beleihungsgrenze der Waren.

5. Die Darlehen auf Gegenstände von Gold und Silber.

Unterschiod zwischen Gold und Silber. Vorteil für die kieinen Leute. Sparkassencharakter.

\section{$\S 7$.}

Die Wechselgeschäfte der Panken . . . . . . . . . .

Der Wechsel als internationales Zahlungsmiltel. Geschätsbeziehmgen der Banken mit dem Miskontkontor in Paris. Stellung des Zentralagenten. Inansprnchnalme des Wechselkredits seitens der kiolonialbanken durch Ausgabe von Tratten und Anweisungen anf das Kontor: Sorge für Rimessen. Envois d'or natif. Tratten des koloniaten Srhatzamts. Rimessemmangel. Die Wechselkurshrage. Beslimmungsgründe desWechselkurses ; seine Regelung durch die Banken. Gewinn und Verlust am Wechselgeschäft. 


\section{- IX - \\ Dritter Abselenitt.}

Die Tätigkeit der Kolonialbanken . . . . . . . . . . . (ift

1. Kapitel. $\S 8$.

Ihre Aufgahen . . . . . . . . . . . . . . . . . . . .

Ordnung des kolonialen Geldwesens. Milderung des Konjunkturenweclısels. Regehng des answärtigen Zahlungsverkehrs. Ausreichende und billige Kreditgewährung.

๖. Kanitel.

Ihre äußere Entwicklung . . . . . . . . . . . . . . 66

\section{s. 9.}

Beginn der Geschäftstätigkeit. Verpfändung und Verkauf der Rentenbriefe. Geschiiftsbeziehmgen mit der Bank run Frankreich, der Caisse de dépôts et consignations und dem Diskontkontor in Paris . . . . . . . . . . . . . 6

$\$ 10$.

Die Kolonialbanken in den Zuckerkolonien . . . . . . . . . . .

1. Periode bis 18ĩo. 2. Periode bis 18s3. 3. Periode bis 1901. 4. Periode seit 1:m1.

$$
\$ 11 \text {. }
$$

Die Bank von Guyane

$\$ 12$.

Die Bank von Sénégal bis zn ihrer Lirniulation 1901 . . . . . . 7

$$
\text { 3. Kapitel. }
$$

Die innere Entwicklung der Kolonialbanken . . . . . . . . . 7

$$
\text { s } 13 .
$$

Die Diskontgeschäfte . . . . . . . . . . . . . . . . 7

Gefahren. Erneverung der Wrechsel. Immolsilisierung des Portefenilles.

Die Diskontgeschäftr. in Martinique. Diskontsatz.

$$
\S 1.4 .
$$

Die Erntedarlehen . . . . . . . . . . . . . .

Beliebtheit. Statutenwidrig hohe Dartehen. Besondere Sicherheiten. Leihzinsfuß. Gewinn (ler Bank infolge Verknüpf tung verschiedener Geschäfle. Risiku und Bankrerluste.

$\S 15$.

Die Warendarlehen

Ihre Bedeutung für den Expont und Import. Verschiedene

Behandlung der Import- und Exportwaren. 
$\$ 16$.

Seite.

Die Wechselgeschäfte . . . . . . . . . . . . . . .

lhre Ausdehnung durch Rimessenangebot bestimmt. Einflub der Produktion der Kolonis auf die Wechselgeschäfte der Bank. Gellsendungen aus Frankreich. Fefährdung des Metallrorrats der Bank durch hohe Wechselkurse. Die Spekulation. Mitte] zur Linderung des Rimessenmangels. Vechselkurs und Geldumlauf der Kolonien. Kassenscheine. Geldnot.

$$
\text { s } 17 .
$$

Der Notenumlauf

Notenansammlung im kolonialen Schatzant. Höhe des Notenumlaufs.

$$
\$ 1 \% \text {. }
$$

Die Depositen . . . . . . . . . . . . . . . . . . . . 9 90

lhr Gegensatz zu den Noten. Höhe der Bankdepositen.

4. Kapitel.

Ergebnisse der Kolonialbankläligkeit. . . . . . . . . . .

$$
\$ 19 .
$$

Das Ergebnis für die Kolonien

Mißerfolg in bezug auf monoculture, absentéisme und Zahlungsbilanz. Erfolge in lyezug auf Gelitumlauf und Zahlungsverkehr, Kreditgewährung und Zinsfuß. Interesse der Kolonien an ihren liolonialbanken.

\section{$\$ 20$.}

Das Ergebnis lür die Banken und ilıre Aktionäre. . . . . . .

Dividenden. Kapital. Verlusle am Wechselkurse. Geldsendmagen aus Frankreich. Upfer zugunsten der Kolonie. Vorschläge.

\section{Zweites Buch.}

Die Banken von Neukaledonien, Indochina und Westafrika . .

$$
\text { Erster Abschnitt. }
$$

$\S 21$.

Die Bank von Nenkaledonien . . . . . . . . . . . . . .

Grïndung. Bankverfassung. Geschäftstätigkeit. Konkurs. Gründe des Mliberfolges der Bank.

$$
\text { Zweiter Abschnilt. }
$$

Die Bank ron lntochina . . . . . . . . . . . . 102 
1. Kapitel. $\$ 22$.

Gründung. Kapital und Kapitalerhöhungen. Filialen und Geschäftsstellen.

2. Kapitel. $\$ 23$.

Gemeinsames mit den alten Kolonialbanken . . . . . . . . . 103

Abhängigkeit vom Staate. Begrenzung des Geschäftskreises.

Übèrwarhıugskounmission.

Aufgaben. Schwierigkeiten. Rechte und Torrechte.

$$
\text { 3. Kapitel. }
$$

Besonderheiten der Bank ron Induchina . . . . . . . . . 105

$$
\S 24 .
$$

Besonderheiten in der Bankverfassung . . . . . . . . . . 100

Modus der Kapitalerhöhung. Gewinnverteilung. Reservebildung. Sitz in Paris. Folgen davon. Vertretung der Aktionäre. Zusammensetzung und Befugnisse des Verwaltungsrates. Stellung der Direktoren. Diskontaussclub

$$
\$ 25 .
$$

Besonderheiten in bezug auf die Geschäfte der Bank . . . . . . 110

Die Notenausgabe. Verzinsliche Depositen. Die Diskontgeschäfte.

Die Darlehensgeschäfte, speziell die Erntedarlehen an Kommunen.

Bankgeschäfte in Paris. Ausstellung von Kreditbriefen. Emissions- und Finanzgeschäfte.

\section{$\$ 26$.}

Besonderheiten in der Geschäftsführung der Bank . . . . . . 122

Hohe Reserven. Behandlung der AuBenstände. Bilanzaufstellung. Lösung der Wechselkursfrage. Verhältnis der Diskontgeschäfte zu den Gesamtrorschüssen sowie der einzelnen Darlehensgeschäfte untereinander. Notenausgabe. Kontokorrentrerkehr.

4. Kapitel.

Die Erfolge der Bank

$\S 27$.

Die den Kolonien erwiesenen Dienste . . . . . . . . 130

Beseitigung der monoculture. Sicherung des inneren Geldumlaufs. Regelung des auswärtigen Zahlungsverkehres. Gewährung von Darlehen an die Kolonien. 
$\S 28$.

Leistmgen an den französischen Staat . . . . . . . . . 132

Service de trésorerie. Errichlung ron unprodukliven Bankstellen.

$$
\text { s. } 29 .
$$

Das Ergebnis für die Bank selbst

Entwicklung der Bankniedrrlassungen. Dividenden. Gründe des Erfolges der lank.

$$
\text { Dritter Abschnitt. }
$$

Die Bank von Westafrika. . . . . . . . . . . 135

1. Kapitel. $\$ 30$.

Gründung der Bank . . . . . . . . . . . . . 136

Entstehung. Kapital. Akitien.

2. Kapitel. $\S 31$.

Verfassung und Geschäfte der Bank . . . . . . . . . . 137

Sitz in Paris. Filialen und Geschäftsstellen. Leitung und Kontrolle der Bank.

3. Kapitel. \$ 32 .

Die Entwicklung der Bank

Ergebnisse und Aussichlen.

\section{Drittes Buch.}

Die Bank von Algerien. . . . . . . . . . . . . . . 1 1 1

1. Kapitel. \$:3:3.

Errichtung und Verfassung der Bank . . . . . . . . . . 141 llue Eigenschaft als Kiblonialbank.

Errichlung durch den Staat. Notenprivileg. Keine Erntedarlehen. Sitz in Paris, aber keine Geschäftstätigkeit in Paris. Bankverfassung.

Vergleich mit der Bank ron Frankreich.

2. Kapitel. $\S 34$.

Entwicklung der Bank von Algerien . . . . . . . . . . . . . 145

Fusion mit der Bank von Frankreich? Leistungen der Bank an den Staat.

\section{Viertes Buch.}

Vergleich der Kolonialbanken mit anderen Banken sowie der kolonialbanken untereinander. . . . . . . . . 150 
1. Kapitel.

I. Das Notenprivileg.

$\S 35$.

ll. Die Begrenzung des Geschäftskreises . . . . . . . . . . . 150

$\$ 36$.

III. Die den Kolonialbanken eigentïmlichen Geschäıte und Geschäftsmethoden . . . . . . . . . . . . . . . . . . . .

Die Erntedarlehen. Wechsel init 2 Unterschriften. Aktiendarlehen. Lange Verfallzeit der Wechsel und Schuldverschreibungen. Diskontsatz höher als Lombardzins. Bevorzugung der Realkreditgesclüfte. Starke Reservebildung. Anlage des Grundkapitals in Rentenbriefen. Regulierung des Geldumlanfs und der Wechselkurse. Heranziehung der einheimischen Kapitalien zu kolonialen Unternehmungen.

$\$ 37$.

IV. Vereinigung von Agrar- und Handelsbank . . . . . . . . . 15 4́ Gründe dafür. Folgen der mangelnden Arbeilsteilung.

\section{$\$ 3$ S.}

V. Der Spekulationscharakter der Kolonialbanken . . . . . . 150

1. Mißverhältnis zwischen Aktiv- und Passivgeschäften.

2. Direkte Abhängigkeit von Naturereignissen.

3. Geringere Sicherheiten. Keine Versicherung gegen Erdbeben ete. Geringes wirschaftliches Verständnis der Bevölkerung.

4. Höhe des Lelhzinses. Schwankende Ergebnisse. Stark wechselnder Metallbestand. IngleichmäBiger Geldbedarf der Kolonien. Die hohen Wechselkurse.

5. Möglichkeit eines Konflikts zwischen den Interessen der Bank und denjenigen der Kolonie.

6. Die Emissionsgesehäfte der Kolonialbanken.

Die Kolonialbanken sind Spekulationshanken mit dem Notenprivileg: ihr Wesen ist bedingt dureh die wirtschaftichen Verhälnisse der kolonien.

\section{Kapitel. \$ 39.}

Die Kolonialbanken in Vergleich mit einander . . . . . 158

Sie stellen versehiedene Entwicklungsstufen dar, die fast bis zur Bank von Frankreich führen. Gruppierung nach diesem Gesichtspunkt. 



\section{DIE}

\section{FRANZÖSISCHEN KOLONIALBANKEN.}

\section{EINLEITUNG.}

Kolonialbanken sind Banken, die in den Koblonien arbeiten; sie sind Institute des kolonialen Kredits. Daf sie eine hesondere Art ron Banken bilden, kommt sehon in der Terminologie der ver'schiedenen Kolonialvölker mehr oder weniger deutlich zum Ausdrucke. England z. B. unterscheidet scharf zwischen den Depositenbanken einerseits, die es rermeiden, außerhalb Englands Filialen zu gründen, und den foreign and colonial hanks andererseits. $\left.{ }^{1}\right)$ In Deutschland nennt man die Banken, welche in der Hauptsache das Auslandsgeschäft betreiben, Überseebanken ohne genauere Unterscheidnng, ob diese nun in fremden Lïnder'n orler in Kolonien des Heimatsstaates arheiten. ${ }^{2}$ ) Anch Frankreich hat in diesem Sinne Übersecbanken, z. B. in Ägypten, Mexiko, Haiti, China und in seinen eigenen Kolonien. Die in den französischen Kolonien tätigen Banken sind entweder Filialen einer gröBeren Bank des Mntterlandes oder es sind Banken, welche ihre ausschließliche oder doch hauptsïchliche Tritigkeit in den Kolonien entfalten, was beispielsweise darin zum Ausdruck kommen kamn, daß die Bank ihren Sitz in der Kolonie hat.

Die französische Theorie ${ }^{3}$ ) bezeichnet nun mit banqques coloniales nicht schlechtweg alle in den Kolonien bestehenden selbständigen Banken, sondern banques coloniales heiben nur diejenigen in den Kolonien errichteten Kreditinstitute, denen

1) Weber S. \{3.

2) Hauser S. 1.

3) Denizet a. a. O., Renand a. a. O.

Soltau, Die französischen Kolonialbanken. 
das Vorrecht der Totenausughe verliehen ist. Sur mit den franzïsischen Kolonialbanken in diesem engeren sinne werden sich mnser" weiteren Ansfïhungen beschäftigen.

Wir haben da droi rerschiedene cimpen vom folonialbanken zu unterscheiden. Die orste Gruppe mmfalit die Banken ron Martinique. Gualdoupe. Rimmion. Guyane und sinfigal. dis sämtlich ihren sitz in den Kolonien haben. Zur zweiten Gruppe grehören die Banken ron Senkaledonien. ron Indochina und ron Westafrikia. Schlieplich bildet die Bank von Algerien noch eine besondere cruppe für sich.

Wir werden dir franzöischen Tolonialbanken nach ihrer historischen Reihenfolge behanteln. Joch soll die Bank ron Algerien, die zuerst ihre schalter offnete, zuletzt betrachtet werden, was später noch zn rechtfertigen sein wird. 
ERT'TES BUCH.

\section{DIE FÜNF ALTEN KOLONIALBANKEN.}

Die nenere franzisische Kolonialgeschichte beginnt mit dem Jahre 1815.1) Der 2. Pariser Friede gab Frankroich nur einen Teil seiner früheren ïherseeischen Besitzungen zurück, nämlich in Amerika die Inseln st. P'ierre, Miquolon, Martinique, (iuadeloupe und die Kolonie Guyane: in Afrika die Insel Remnion sowie Französisch śénégal (St. Louis und Gorée) und in Indien die Nierlerlassungen Pondichéry, Karieal, Janaon, Mahe und Chandernagor.

Das war 1815 der ganze Rest les einst st stolzen franziisischen Koloniahreiches. Daboi waren die indischen Besitznngen unbedentende, weit roneinander liegende Handelskntore und St. Pierre und Miquelon nur kleine Fischereiniederlasingen. Martinique, Guadeloupe, Rémion mol Guyane dagegen waren Plantagenkolonien, und Französisch Sénégal bestand in rler Hauptsache ans zwei Handelskontoren, ron denen aher st. Louis sehr günstig an rler Hündung des Senegalflusises und (iorée auf einter kleinen Insel nahe bei Cap Terde gelegen sind. Bei Betrachtung dieses französischen Kolonialbesitzes erkennt man, dab es kein Zufall war, daß die ältesten französischen Kolonialbanken in Martinique, finadeloupe, Rémnion, Gurane und sénégal errichtet worden sinel.

Erster Absehnitt.

DIE ZUSTÄNDE IN DEN KOLONIEN YOR ERRICHTUNG DER KOLONIALBANKEN MI'T SPEZIELLER BERËCKSICHTHGUNG DER ZCOKERKOLONIEX.

Alle ehen erwähnten Kolonien sind nicht Berölkerungssondern Tropenkolonien. Kapitalien, nicht Menschen, galt es in diese Kolonien zu importieren.

1) Girault a. a. O. S. $195 \mathrm{ff}$. 
Die Antillen (Martinique und Guadeloupe) sowie Réunion werden mit dem gemeinsamen Xamen Zuckerkolonien bezeichnet, weil auf der Zuckerrohrkultur ihre Bedeutung ber'uht. Die Volkswirtschaft in den Zuckerkolonien erhielt während der ersten Hälfte des vorigen Jahrhunderts ihr charakteristisches Ciepräge durch zweierlei: dureh die Plantagenwirtschaft und durch die sklaverei.

\section{Kapitel. \\ $\$ 1$.}

\section{DIE ZEIT VOR DER SKLAVENBEFREIUTr.}

Die Zuckerrohrkultur war fast dic einzige Beschäftigung und Erwerbsquelle der Kolonisten, und zwar herrschte der Großbetrieb in dieser Kultur unbedingt ror, da in cliesen Gegenden der heifen Zone der Europäer und seine kreolischen Abkömmlinge selhst zu körperlicher Arbeit unfähig sind. Der Grobbetrieb erfordert eine grofe Zahl ron Arbeitern, und da war es die Sklarerei, welche den Pflanzern die notwendigen Arbeitskräfte rersehaffte und dadurch den regehmäßigen Betrieb der Pflanzungen sicherte. In hamdelspulitischer Beziehung galt ron 1815 bis 1861 (ler sogenannte pacte colonial, $\left.{ }^{1}\right)$ d. l. die Kolonien durften ihre Produkte nur nach Frankreich rerkaufen und muBten andererseits den größten 'Teil ihrer Einfuhr von dort heziehen. Dieses Schutzzollsystem hatte den Vorzug, dab der Pflanzer immer auf ein sicheres Absatzgebiet für seine Produkte rechnen konnte. Andererseits wurden aber die aus Europa in die Kolonien einseführten Lebensmittel durch den weiten Transport vertenert, und der Wert der fremden, d. h. nichtfranzösischen Wareneinfuhr der Kolonien, die doch nicht zu rerbieten war, soweit sie in Frankreich nicht herstellbare Waren betraf, konnte nielit durch Warenausfuhr gedeckt, sondern nur durch Geldsendungen bezahlt werden. Das war eine Ursache beständiger Celdkalamitiit und einer periodisch auftretenden stümischen Sachfrage nach

1) Girault a. a. 0. S. 168 . 522 f. 
Zahlungsmittedn. Da die ron Frankreich in die Kolonien eingeführten Münzen für den dertigen Gickbodarf nicht genügten, so nahm man anch frende Gold- nnd Silbermünzen in Zahlung, insbesondere spanisch-amerikaniscle Piaster, die man hesonder's gut zu Rimessen verwenden konnte. Doch blieb der Geldmangel eine regelmäBig wiederkehrende Erscheinung, die don Handelsverkehr der Kolonie lähnte. Die Kanflente litten am moisten unter diesen Verhältnissen. Der Pflanzer, der meist in natmra zahite, war durch den Mangel an Zahhnngsmittehn weniger geniort. Nur zur Erntezeit, wenn er seine Ernte rerkaufen wollte, und wemn es galt, die nene Ernte rorzubereiten, dam machte sirh anch bei ihm ein starkes fretd- nud ror allem Kreditbediurfuis geltend.

Wie bereits oben seite 4 erwïhnt, waren es bis 1 sts Sklaven, die das Felı bestellten, die Frucht einernteten und den Zucker zur Verabeitnng in die Raffinerien brachten. Alle diese Arbeiter wurden angekauft, sie muliten genäht und nnterhalten werden. Die Vorbereitumg der Ernte, die Beschaffung und Reparatur der Arbeitsgeräte, der Unterhalt der Sklaven vermrsachten große Kosten, die man mit dem Ertrage der Ernte zu bezahlen hoffte. Da der Pflanzer gewöhnlich nur ïher cin geringes und unzureichendes Betriehskipital verfügte, muBte el' zum Kredit seine Zuflucht nehmen. Wegen der benötigten Vorschïsse wandte er sich an einen sogenannten Kommissionïr oder Wechselagenten, der mit dem rerkanfe seiner Produkte nach Frankreich beauftragt war und durch seinen langjührigen Aufenthalt am Platze Charakter und Arbeitsart eines jeden Pflanzers kamnte. Dieser Kommissionär grwähte Darlehen gegen ein privilegiertes P'fandreelt am Vermögen des Pflanzers. Falls der Kommissionär selbst keine Kapitalien ausleihen komnte, wulite er dem Pflanzer Darlehen ron einem Kaufmam in Marseille. Bordeaux, Nantes oder Le Have zu rerschaffen. Dieser verlangte aber von dem Pflanzer außer einem Pfandrecht an dessen Vermögen noch die Verpflichtung, dem Kaufmann dic herorschufte Ware zum kommisionsweisen Verkanfe zu ïberlassen, für den dann noch eine besondere Kommissionsgebühr erhohen wurle. 
Alles in allem kamen diese Vorsehïsse dem Pflanzer auf 16 bis 1s Pruzent zu stehen: Der gamze Ertrag der Ernte konnte somit durch die Zurïckzahlung lex Vorschïsse anfgezeht werden,

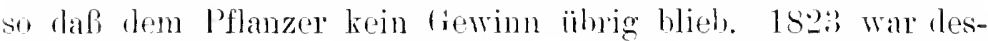
habl) in Risunion und 1526 anch in Cinadeloupe eine Noten- und Darlehenshank errichtet worden in der Absicht, die Pflanzer lem Wucher zu entreifen. Beide Banken machten aber so sehlechte Geschäfte, daß sie schon 1831 linuidierten, ohne ilır Ziel erreicht zu haben. ${ }^{1}$ wie die cinen sagen, infolge Festlegmng dur Bankkapitalien in Hypothokengeschäten, ${ }^{2}$ ) andere führen als Grund ihres Miberfolges an, dab es den Banken nicht gelang, die alten Gewohnleiten der Pflanzor so bathl zu änlejn. Das ist alles nicht rerkehrt; aher tie rolle Wahrheit ist wols, dab bei der Cieldknappheit anch die Banken lohen Zins nehmen und obendrein nuch heschwerliche Normatirbestimmungen erfüllen und auferlegen muliten, otwa Rückzahlung der Darlehen innerhalb bestimmter liurzer Frist. Daf unter solchen I'mstänlen die Pflanzer trotz des W'ucherzinses das Geschäft mit dem Kommissionär dem Verkehr mit ciner Bank rorzogen, ist erklärlich. Bei ten geringen Handelsverkehr der Kolonie fohlte es der Bank an lohnender Besehaiftigmng und danit an der Existenzberechtigung.

Ein rölliger Umschwung trat hierin ein, als durch Dekret rom 2-7.t.1sts die sofortige und röllige Abschaffung der sklaverei in den französischen Kulonien angeordnet wurde. Diese humanitäre Mabregel, die anfangs die koloniale Landwirtschaft zugrunde zu richten drohte, schuf jetzt andererseits die Existenzhedingungen für Kolonialbanken.

2. Kapitel.

sุ.

DIE ZEI'T NACH DER SKLAVEXBEFREIUNG.

Mit der sklavenbefreinng trat an stelle des Arbeitszwanges der freie Arheitsvertras. Das hatte zwei helentsame Folgen:

1) Leruy 5. Bericht [\$:00.

2) Courtois. Histoire de ia Bangue de France S. 190. 
erstens mußte der Pflanzer fortab regchmabig den Lohn in crold zahlen, während his ang der Noger in natura abgelohnt worden war; zweitens wurle es sehr schwierig und kostspielig, die zum Betriebe der Pflanzungen nötige Zahl von Arbeiter'n herbei zn schaffen, da die Neger sich nur äuferst langsam daran gewöhnten, freiwillig. d. h. olne Zwang, zu arbeiten. Der Übergang ron dem Arbeitszwange zur freien Arbeit rollzog sich in Róunion, wo die sklaren stets gut hehandelt waren. $\left.{ }^{1}\right)$ leichter als in ten Antillen oder in Guyane. So versehieden sich aber anch die Arbeiterfrage in den einzelnen franzisischen Kolonien stellte, ïberall wurde die Einfuhr fremter Arbeiter (Neger, Hindous oder Chinesen) sowie die (irïndnng eines Lohnfonds nötig. Die Notwendigkeit regehmäfig Lohn zu zihlen, steigerte natürlich den Geldbedarf der Pflauzer betrïehtlich. Andererseits rerursachte die Beschaffung der nötigen Arbeitskiäfte solche Mehrausgaben, daß für den Pflanzer der bislang an den Kommissionär gezahlte Zins ron geradezu wucheriseher Höhe absolut unerschwinglich wurde. Der Fortbestand der Pflanzungen war bedroht, wenn es den Ptlanzern nicht gelang, hilligeren Kredit in ausreichendem Maße zu erhalten.

Aber wer sollte ihnen diesen hredit gewähren: Da riele Pflanzer aus Mangel an Arbeitskraiften den Betrieb ihrer Pflanzungen einstellen mubten und da anderen Pflanzern dasselbe Schicksal drohte, so waren die Kommissionire, die bistang in del Hauptsache ja den Agrarkedit gewährt oder vermittelt hatten, jetzt erst recht nicht geneigt und vielleicht anch gar nicht in der Lage, den Leihzinsfuls für ihre Darlehen zu ermäligen. Der Leihzins war leshalb so hoch, weil meist zwei Personem - der Kommissionär und der Kanfmamn eines französisehen Hafenplatzes - an den Vorschuggeschift verdienen wollten, sodam, weil die Entfernung des Ciläuligers rom Schuldner das Risiko des ersteren erhöhte. Eine Bank, die an Ort und stelle sowie direkt, d. h. ohne Zwischenhand, Danlehen gewährte, komnte deshalb ohne weiteres den Leihzins beträchtlich herabsetzen,

1) Girault a. a. 0. \$. $283 \mathrm{f}$. 
ohne geringeren Gewinn zu erzielen als der Kommissionär oder franzöische Kanfmann, und sie war jetzt sicher, einen starken Kundenkreis zu finden. Eine Bank konnte also helfen, ja nach dem Cresagten mußte sie helfen, wenn nicht alle Gesehäfte still stehen sollten. Allein eine reine Privatbank hätte, wenigstens für den Anfang, das große Risiko des Kólonialkredits nicht tragen können. Auch hätten ilır die nötigen Betriebsmittel gefehlt. Wirkliche Hilfe rersprach in dieser Lage nur die Errichtung einer staatlich unterstiitzten Nutenbank, die zugleich Diskontund Darlehenshank sein mußte, wenn sie allen Geldbedürfnissen und Kreditansprüchen der Kolonic genügen sollte.

In diesem sinne ist der flanzösische Ciesetzgeber auch vorgegangen. Wie grob die Tot war, zeigt die Tatsache, daß in den Antillen nicht gewartet werden konnte, bis die französische Nationalrersammlung die Errichtung ron Kolonialbanken beschlossen hatte. Die Generalkommissare der französischen Republik in den Antillen sahen sich riehnehr genötigt, schon im Oktoher 1849 in Martinique und Guadeloupe sowie in Rémion Warenlombardbanken einzurichten und sie zur Ausgabe von Kassenscheinen mit Zwangskurs zu ermächtigen, die gedeckt walren durch Anweisungen des kolonialen Schatzants, in Rémion dureh Hinterlegung von Waren. Nichts illustriert den Wandel der Verhiiltnisse seit $18: 31$ deutlicher als dieses.

bic eben erwähnten Institute hatten nur provisorischen Charakter, ihre guten Erfolge zeigten aber, daß man mit ihnen anf dem rechten Wege war.

\section{Zweiter Abschnitt.}

DHE ERRICHTUNG DER KOLONIALBANKEN; IHR WESEN.

1. Kapitel.

$$
\$ 3 .
$$

DIE KOLONIALBANKGESETZGEBUNG TON 1849-1905.

Als man 18t9 an die Errichtung der französischen Kolonialbanken ging, war zuerst die Frage zu lösen, wie man das 
den Koloniabanken nötige Betriebskapital herbeischaffen sollte. Man verfiel auf folgendes sinnreiche Mittel. Der franzïsinche Staat hatte angesichts der groben Notlage der Pflanzer, die durch die Sklavenbefreiung fraglos hervorgerufen war, ctwa ein Jahr nach Aufluehung der Sklaverei, nämlich durch fiesetz vom 30.4. 184! den Pflanzern für jerlen freigelassenen Sklaven cine Entschäligm von $500 \mathrm{fr}$. bewilligt, und zwar sollte an die Entschïlignunsberechtigten gezallt werden:

1. eine cimmalige Summe rom sechs Millionen franes in bar,

2. eine fortlaufende jührliche Rente im Betrage ron sechs Millionen francs die, zn fünf Prozent kapitalisiert, als Rentenbriefe auszugehen waren.

Gleichzeitig wurde angeordnet, dab ein Achtel der auf Martinique, Guadeloupe nut Réunion entfallenden Rente zurïckbehalten und zur Errichtung einer Diskont- und Darthensbank in jeder dieser Kolonien rerwentet werden sollte. (Fiir) die Kolonien Guyane und sénécal war tliese Vorschift nu. fakultatir, nicht obligatorisch wie in den Zuckerkolonien.) Nur die weniger als $1000 \mathrm{fr}$. hetragenden Entschädligungsansprüche sollten von dem Zwange ausgenommen sein. Jeder Entschïligungsberechtigte sollte für den auf ihn entfallenden 'Teil der' zurïckbehaltenen Rente den entsprechenden, d. h. mit fünf Prozent kapitalisierten Betrag in Aktien der zu griundenden Kolonialbanken erhalten. Das Aktienkapital dieser Banken war also zu bilden durch Apports ron Rentenbriefen, welche die ansschließliche Bestimmung hatten, zur Deckung der Banknoten zu dienen, zu deren Ausgabe die Kolonialbanken ermächtigt wurden. Deshalb waren die Rentenbriefe anfünglich unpfündbar und unreräıßerlich.

Die Entschärligungsberechtigten wurden also zwangsweise Altionäre einer noch zu errichtenden Bank.

Kraft der soeben mitgeteilten Gesetzesbestimmmmg erhielt jede der drei Banken ron Martinique, Guadeloupe und Rémion Renten ron jährlich $150000 \mathrm{fr}$. überwiesen. Da diese Renten zu fünf Prozent kapitalisiert wurden, repräsentiesten sie ein Kapital ron je drei Millionen francs. Demgemäß wurde das Kapital für jede der drei benannten Banken durch Gesetz rom 11. 7. 1851 Art. ?2 
auf drei Jillionen franes festgesetzt. Dieses Giesetz. die loi orgunicue der Kolonialbanken, rief die Kolonialbanken erst ins Leber, nachdem sehon das Cresetz rom 30. 4 . 1849 ihre Errichtung angeordnet und den Weg dafür gewiesen hatte. Dem Gesetze ron 1851 sind Statuten beigefügt, die einen Teil des resetzes bilden, also nur durch Gesetz abgeänlert werden können. Es "rdnete auch die Grindung einer Bank ron binvane an durch Zurütekbehaltung ron 35000 fr. Rente die ein Kapital ron $700000 \mathrm{fr}$. (eraben. $\left.{ }^{1}\right)$ Das Gesetz rom 11. 7. 1\$51 sprach noch njeht ron einer Bank ron Sénéral. Doch wurde durch Deliret rom 21. Dezember 185: auch in sénégal eine Diskont- und Darlehensbank gogrundet und ihr Kapital ron 230000 fr. ebenso wie bei den vior ersten kolonialhanken durch Zurückbehaltung von einem Achted der den Entschädigmusberechtigten in Sénégal zukommenden Entschädigungssumme und dnrch die bis dahin anfgelaufenen Zinsen der Rentenbriefe znsammengebracht. Ferner wurden die Bestimmungen rom 11. 7. 1851 austrücklich anf rie Bank ron

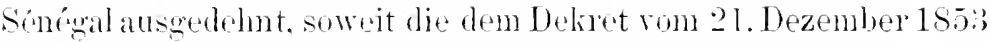
folgenden Statuten nichts Abweichendes enthielten.

Da die Banken ron (iuyane und Sénégal unter wesentlich anderen d. h. kieineren Verhältnissen zu arbeiten hatten als die Banken der Zuckerkolonien, so wurden gar bald einige statutenändermngen für jene nötig. die hauptsäehlieh die Herabsetzung der Zahl der auf der Cienerahersammlung stimmberechtigten Aktionäre, ferner die Präienzziffer anf rer Generalrersammlung und den obligatorischen Aktienhesitz der Terwalter und Direktoren der Bank betrafen. Nur liurz zu streifen ist hier das Dekret rom 1\%. Yorember 1s52. das die Sehaffung einer Zentralgesehaiftsstelle für alle fünf Kolonialhanken und zwar in Paris vorsal. Näheres darïles folgt woiter unten.

Das P'rivileg der Banken von Martinique. (inadeloupe. Réunion und Giuyane, tas $18 i 1$ erloseh, wurle durch Dekret rom

1) Das Kapital der Bank ron Guyane wurde durch Dekret rom 1. Il. Lis' auf 300000 fr. herabgesetzt. noch bevor die Bank ihre Geschäfte begomen hatte. 
11. September Lis anf zwo Jahre verlängert. Turch Dekret rom S.8. 18 s3 erhielten alle fünf Banken ihr Privileg auf oin weiteres Jahr ernenert, rom 1.9. 1sis an gerechnet. Der (irumb für diese kurzen Verlängernngsfristen war, laf man in Frankreich infolge des Krieges mit Dentschland keine Zeit fand zu einer näheren Prüfung der Kolmialbankfrage. Erst 1864 elying unter dem 2-4. Juni ein nenes Gesetz, welehes das Privileg der fünf Lolonialbanken um zwanzig Jalne verlängerte und danchen einige Statutenändermngen brachte, die sich auf Grund zwanzinjühriger prakticeher Erfahrungen als wünschenswert erwiesen hatten. Zunächst ist zu bemerken, laf das liesetz rom 2.4. ‘. it für alle fünf holonialbanken grilt, also anch für die im Gesetze ron 1\$51 noch nicht erwähnte Bank ron Nénégal. Alle sich auf diese Bank beziehenden Dekrete sowie die rerschiedenen in Laufe der' verflossenen 23 Jahre für die Kolonialhanken erlassenen nenen Bestimmungen sollten 1854 inhaltlich in das nene Gesetz aufgenommen werden. Das machte schon eine neue Redaktion des Gesetzes ron 1851 nötig. Danchen galt es anch Liicken im Gesetze auszufüllen, z. B. Bestimmumgen zu treffen äbur den Iodus bei einer Kapitalerhöhung oler -rerminderung oder äber das Terfahren bei der Übertragung ler Aktien der Kolonialbanken nach Frankreich und iber die Vertretung der emropäischen Aktionäre auf derin den Kolonien stattfindenden (ieneralrersammlung. Sodann war es das Bestreben des resetzgebers, den Kolonialbanken gröfere Freiheiten zu gewähren. soweit sie mit der Sicherheit der Bank rereinbar waren. Dahin gehörte die Gestattung ron Darlehen gegen Hingabe ron Aktien der Kolonialbank als Pfand, ferner die Erlaubnis zu Zeichnungen auf öfentliche, in den Kolonien eröfnete Anleihen. Fortan durften die Banken auch Handel mit Edehetallen treiben, obschon ihmen im übrigen jeder Warenhandel rerhoten war. Diskontiert wurden bislang ron den Kolonialbanken Effekten mit zwei Unterschriften, deren eine obendrein durch ein Pfand ersetzt werden komnte. Die Zahl dieser Pfänder wurle 1874 um zwei rermehrt (titres mobiliers und Dépoits von gemünztem oder ungemünztem Gold und Silber). Sodamn wurde 1874 die Beleihungsgrenze für Gegen- 
stände ron Gold und Silber von vier Fünftel auf fünf Fünftel ihres Wertes und ebenso für Waren ron zwei Drittel auf drei Drittel ihres Wertes erhöht, letzteres nnter Generalisierung der durch Dekret rom s. 1. 1 s 60 der Bank ron Réunion erteilten Frlaubnis, Waren bis zu ihrem vollen Werte beleihen zu diurfen. Sehr wichtig war sehließlich die Ermäehtigung zur Ausgahe ron 5 fr.-Soten, welche 1851 noch rerweigert worden war.

Alles in allem zeigte der (iesetzgeber $187 t$ eine gewisse Liberalitit; das war erklärlich: rlenn die Kolonialbanken hatten in den letzten Jahren ror Emenerung ilıres Privilegs gute Dividenden ${ }^{2}$ ) erzielt, ohne ihr Totemecht zu mißhrauchen. Da sie anch den Kolonien unleughare Dienste erwiesen hatten, so stand die Emenerung des Kolonialbankprivilegs 1874 auBer Frage. Wesentlich anders lagen die Verhältnisse 1 s.94 am Ende der zweiten Periode der Kolonialbanken. In den seit 1874 verflossenen zwanzig Jahren hatten sich arge Mifstände heransgehildet; die Kolonialbanken hatten sich schwere Statutenverstobe zu schulden kommen lassen; sie hatten schwere Krisen durehgemacht und - was die Laune des Gesetzgebers besonders ungiunstig beeinfluBte - die Lage der Kolonialbanken war recht unbefriedigend, teilweise sogar hedrohlich geworden. Eine eingehende Untersuchung schien am Platze zu sein, ebenso eine breite Erärerung der ganzen Kolonialbankfrage. War es überhaupt richtig, lauter kleine koloniale Lokalbanken am Leben zu erhalten, die infolge ihres begrenzten räumlichen Tätigkeitsfeldes ron jeder Konjunktur direkt betroffen, won jerler der in den Tropengegenden so zahhreichen Krisen in Mitleidenschaft gezogen wurden? War nicht das ganze system dieser staatlich beanfsichtigten umd privilegierten Privatbanken ein Fehler, da alle Staatsanfsicht grobe Statutenwidrigkeiten nicht hatte verhindern können?

Die Gegner der kolonialen Lokalbanken wollten eine einzige grobe Kolonialbank in Paris mit Filialen in den rersehiedenen französischen Kolonien an die Stelle der fünf alten Kolonialbanken

\begin{tabular}{ccccccc}
\hline$\left.{ }^{1}\right)$ & Jahr & Martinique Guadeloupe & Rémion & Guyane & Sénégal \\
Dividende & $1870 / 71$ & $1.14 \%$ & $13.8 \% \%$ & $8.46 \%$ & $10.2 \%$ & $10.35 \%$ \\
Dividende & $1871 / 72$ & $17.45 \%$ & $11.6 \%$ & $8.14 \%$ & $9.6 \% \%$ & $5.76 \%$
\end{tabular}


setzen.1) Die nene Kolonialbank hätte, da sie ihren Sitz in Parris haben sollte, dio reichen Kiapitalien des Mutterlandes den Kolonien dienstbar machen können. Aher lie Anhänger einer solehen Zentralbank rergalien, dak dio kolonien schon das Maximum dessen, was sie an kredit hranchen komiten, erhalten hatten und daß bei den beschränkten Mitteh und Berlürfnissen der. nicht mehr sehr entwickhngafühigen kolonien Martinique, Ginadeloupe und Rẻunion eine stark vermelnte Kapitalzufulur eine unproduktive Kreditgewiihnng bedientet haben wïrde. Zuden war noch zu berïcksichtigen, dali die Entschäıligungsherechtigten 1851 zwangsweise Aktionïre der Kolonialbanken geworden waren; sie hatten somit ein gewisses historisches liocht auf eine eigene Bank, d. h. Koloniabank und kolonie gohiirten zusammen, umsomehn, als zwischen den einzolnen kolonien keine odter geringe Interessengemeinschaft bestand.

Man war sich also bald dariber einis, dah die kolonialbanken Lokalhanken bleiben muliten. Abor olme das Notenrecht waren sie nicht imstande, ihre Aufualren zu erfïllen. Und das Notenrecht zog wiederum mit Nohwenligkeit cine gewisse Stantsaufsicht nach sich. Die ganze Fage der Roform der hónonialbanken konzentrierte sich daher in dem l'rohlem. wio es zu erreichen wäre, die Aufsicht des statutes ïher die Kolonialbanken wirksamer zu gestalten, ohnedurch zu cuge statutenbestimmungen die Bewegungsfreiheit der Banken einzuschüuken und ihnen damit die Lebensader zu unterbinden. Die Kontrolle des Staktes über die Kolonialbanken sollte bestehen bleiben. War das aber nicht auch möglich olme Einmischung dus states in die innere Bankleitung: Nach den statuten ron lsis und 18 st hatte del Präisident der französischen Repuhlik den Direktor der Kolonialbanken zu ernemnen. You den vier Verwaltern, dio zusammen mit dem Direktor den Verwaltungsat der Bank bildeten, war einer kraft Gesetzes ein kolonialer Finamzbeanter (trésorier de la colonie). Unter fünf Mitgliedern des Verwaltungsrates gah es also zwei Beamte, die in unnittelbarrer Abhängigkeit von dor Regierung standen. Damit war ein 'T'eil der Verantwortung fül

1) Denizet a. a. $0 . \triangle 236 \mathrm{f}$. 
die Leitung der Bankgeschäfte auf die (framzïsische) Regierung ahgewälzt. Dis durfte nicht sein, schon im Interesse der Aktionäre. Der koloniale Finanzheamte war nicht nur sesetzlicher Verwalter, er war zugleich anch gesetzlicher Zensor' (der Zensor' entipricht etwa unseren Aufsichtsrat). Also Leitung und Kontrolle der Bank warl hier in einer Hand rereinigt. Es war das ein Milstand, der unhedingt beseitigt werden mubte. Die Losung komnte nur lanten: Zurückdïmmung des Regierungseinflusses auf die Bankleitmng unter Verschärfung ihrer Aufsichtspechte. Ein Blick anf die Gesetzgebnng zeigt, dab dieser Reformweg schlieblich heschritten wurde, freilich nicht in der vollen wïnschenswerten Konseyuenz.

Nach eingehenden Beratungen seitens einer auBerparlamentarischen Kommission 1 s.9t und seitens reschiedener parlamentarischer Kommissionen, lie von 1s!s bis 1900 in fünf groben Berichten eine genane Darstellung aler Entwickelung ater Kolonialbanken auf Crund des amtliehen Quellenmaterials gaben, wurde 1901 endlich das nene Kolonialbankgesetz in der Fassung des letzten Kommissionsentwurfes angenommen und unter den 1:. Dezember 1901 verkündet. Ion 1894 bis 1901 hatte man das Privileg der Banken fortgesetzt um ein Jahr ernenem müssen. Un mun die ciöltigkeit der nur durch Dekrete erfolgten Verlïngerungen des Privilegs in zweifelfreier Weise festzustellen, wurden im Artikel 16 des resetzes ron 1901 die Bestimmungen der verschiedenen von 1894 bis 1901 erlassenen Dekrete ausdrïeklich aufrecht erhalten.

Das Gesetz rom 13. Dezember 1901 betrifft nur die (rier) Banken ron Martinique. Cruadeloupe. Rémnion und Gurane. Die Bank ron Sínégal hatte am 25. 1. 1901 in einer aulierordentlichen Generalrersammlung die Liquidation der Bank und ihre Fusion mit eincr nenen Bank ron Westafrika beschlossen. Anch 1901 galt es, einige Gesetzeslïcken anszufüllen, z. B. das Liquidationsverfahren zu regeln. Die Hauptsache war aber die prinzipielle Reform im Gesetze. Der Schatzmeister der Kolonie hörte anf, gesetzlicher rerwalter der Bank zu sein. Da er aber stark interessiert ist an der Notenausgabe der Bank, weil die Noten 
Kassenkurs besitzen, so soll er fortan jeder Sitzung des Vorwaltungsrats beiwohnen dïrfon: er kamn sich da ein völlig unabhängiges Urteil bilden, weil ar nicht mehr Verwalter ter Bank, also nicht mehr wie früher selbst Partoi ist. Die ungünstige Lage, in der sich einzelne Kolonialbanken gogen Ende der 90er Jahre befanden, war zum Teil dic Folge einer Reihe statutenwidriger Handlungen. Um die Beohachtung der Statuten zu erzwingen, soll in Zukunft hei einem statutenverstol der Bank jede Dividendenverteilung für die lanfende Geschäftsperiode rerboten sein. Die Inspektion der Kolonialbanken, die friilner rein fakultatir war, ist jetzt obligatorisch und hat alle zwei Jahre zu erfolgen.

Um die Einheitlichkeit ler Bankleitung zu sichern, ist dem Direktor der Kolonialbanken das Ernemmugsiecht beziiglich der Bankbeamten gegehen worden. Der Direktor selhst wird nach wie vor ron dem Prösidenten der französischen Republik emannt. Auch die Aufrechterhaltung der Vor'schrift, daß keine Dividendenrerteilung stattfinden kann ohne Zustimmung des Gonverneur's der Kolonie, zeigt, daß man sich ron dem alten Berormundung'ssystem noch immer nicht hat freimachen künnen.

Im Gegensatze zum Jahre 1874 überwog 1901 beim Gesetzgeber die Neigung, der Tätigkeit der Kolonialbanken engere Grenzen zu ziehen. Demgemäß wurde die Beleihungsgrenze für einzelne Pfänder herabgesetzt und den Banken das Recht genommen, ihre Kapitalien in kolonialen Kommunalanleihen anzulegen, weil damals die Bezahlung der Annuitäten seitens del Kommunen infolge ihrer schlechten Finanzlage stockte und dies eine anormale Festlegung der Aktiva der Bank zur Folge hatte. Auf der anderen Seite sind manche Vorschläge. die im Interesse der Banken gemacht waren, z. B, den Kolonialbanken die Annahme verzinslicher Depositen oder die Ausgabe langfristiger Obligationen zu gestatten, ${ }^{i}$ ) unberïcksichtigt geblieben. 'Trotz alledem bedentet das Kolonialbankgesetz ron 1901 gegenüber den früheren Gesetzen einen entschiedenen Fortschritt.

Nachdem wir im Vorhergehenden einen Überblick über

1) Denizet a. a. 0. S. 212. 
die mehr als fünfzigjührige französische Kolonialbankgesetzgebung gegeben haben, ist es Zeit, auf das Wesen der Kolonialbanken nüher einzugehen.

2. Kapitel.

$\leqslant$

\section{DIE VERFASSUNG DER KOLONLALBANKEN}

Gemä̈ Artikel 2 der Statuten sind die Lolonialbanken Diskont- und Darlehensbanken. und zwar Aktiengesellschaften. Ihr sitz ist Fort de France ${ }^{1}$ ) auf Martinique, Point a Pitre auf cimadelompe, St. Denis anf Rémnion, Carenne in finyane und St. Louis in Sinnwal. Die Banken können auch an anderen Punkten ihrer Kolonie Niederlassmgen gründen. Doch ist die Genehmigung res Kolonialministers einzuholen.

Das den Kolonialbanken rerliehene Notenprivilug macht eine Bestimmung iiber die Daner der Bank nötig. Der Konmissionsentwulf 1595 schlug dem alten Branche entsprechend cine Verlingerung des Privilegs mm abermals zwanzig Jahre ror. Dieser Zeitrium erschien der Kommission 1900 zu grob mit Rücksicht auf die Verïndermngen, die in den wirtschaftlichen Ferhältnissen der Kolonien in dieser Zeit eintreten könnten. Das Privileg der vier Kolonialbanken wurde deshalb nur nm zehn Jahre verlingert: es lïuft am 31. Dezember 1911 ab.

Das Kapital der Kolonialbanken beträgt je drei Mtillionen francs für die Banken ron Martinique, Cinadelonpe, Rémion und $600000 \mathrm{fr}$. für die Bank ron linrane. Anch die Bank ron Sénégal hatte zuletzt ein Kapital ron $600000 \mathrm{fr}$. Das Bankkapital zerfüllt in Aktien ron je $500 \mathrm{fr}$. Doch hat der Nominalwert der Alitien verschiedene Wandlungen durchgemaeht. Wie man sich erimnert, wurde das Kapital der Kolonialhanken durch Apports ron Rentenbriefen gehilret. Naturgemäb ergab nicht immer ein Achtel der Entschädigmg, die cinem jeden Pflanzer zukam, eine durch 500 teilbare summe. IIan multe daher 1851 bestimmen, daf die

$$
\text { 1) Ris } 190 \overline{\text { war }} \text { es St. Pierre. }
$$


Aktien in Nominalwerte ron $500 \mathrm{fr}$. bei ihres ersten Ausalue in Teilaktien ron je $50 \mathrm{fr}$. zorlegt werden könuten. 10 solcher Teilaktien konnten in einer Hamul reroingt bis zum 1. Jannal 1855 (in Gurane und Senegal his zum 1. Janual 1s.57) gegen eine Tollaktie ron $500 \mathrm{fr}$. Hmgetanscht werden. ${ }^{1}$ )

1899 beschof die Bank ron Rémion, ihr Kapital, das seit $18 s t$ auf vier Millionen franes erhöht war, auf drei Millionen franes herabzusetzein. Sach den Statuten durfte das nicht durch Terminderung der Zahl der Aktien geschehen; man hätte dadurch die Aktionäre einer wilden Spekulation anscesetzt. Eine Kapitalrerminderung solte viehmehr erfolgen durch Barriickzahlung eines Teils der anf jede dktie ǧemachten Einzahlungen. Dis hätte die Bank ron Réunion 1 s.99 hei ihrem sehr knappen Metallrorrat in cine kritische Lage gebracht und zugleich eine Einschräkung des Yotenumlaufs nötig gemacht in einem Angenblicke, wo der Geldbedarf der Kolonie sehr grof war. Auf Torschlag les Direktors fler Bank ron Réunion beschlol taher die Generalrersammlung, die $125 \mathrm{fr} .$, welche auf jetle Aktie zurickzuzahlen waren, nicht in bar anszuzalulen, sondern dem Reservefonds zuzuschreihen. ${ }^{2}$ ) Seitdem haben die Aktien der Bank ron Rérmion einen Xominalwert ron $110 \mathrm{r} 35 \mathrm{fr}$.

Eine Änderung in der Höhe des Bankliapitals kamn nur durch Dekret ausgesprochen werden. Wird das Kapital erhöht, so bestimnt der Generalversammlungshesehup den Teil des Reservefonds. der zu den Einzahlungen anf die nenen Alitien rerwendet rerden darf. Bei einer Vermindermng des Kapitals darf die Zurïckzahlung 125 fr. pro Alitie nicht übersteigen. ${ }^{3}$ ) Das Aktienkapital war ursprünglich vertreten durch Rentenbriefe. deren Verpfändung und Veränßerung verboten war. Als dies Verbot 1851 aufgehoben wurde, haben die rerschiedenen Banken nacheinander ihre Rentenbriefe rerpfändet oler gar reränBert. ${ }^{\text {y }} 1862$ besaß die Bank ron sénégal keine Rentenbriefe mehr; ihr Alitien-

1) Art. 7-8 der Statuten 1851.

2) Renaud a. a. O. S. $37 \mathrm{ff}$.

3) Art. 2 Gesetz 1901.

4) Vergl. Bericht der Überwachungskommission (Ü. Ko.) 1861/63. 
kapital war ein reines Betriehskapital geworlen. das durch den Metallgeldrorrat der Bank rertreten warl. Seit der \%eit beginnt eine Rïckntwickelung. Die Banken kanften ihre Rentenbriefe wieder an mud behielten sie anch damn noch, als die ursprüglich 5 prozentigen Renten nacheinander in $4^{1}$ ə prozentige und 3 prozentige verwandelt und fïr amortisabel erklät wurlen. Damit war das Kapital der Kulonialhanken wierler ein Garantiekapital geworden. Anch ein 'Teil der Reservon der Banken ist in Rentenbriefen angelegt.

Die Aktien der Kolonialbanken sind Yamenaktien. Zur Eigentumsühertragung immerhalh der Kolonie genügt eine schriftliche Abtretungserklärnng des Anteikeigners oder stines Berollmächtigten and Eintragung in das Aktienbuch der Bank. ${ }^{1}$ ) Soll eine Aktie nach Frankreich übertraen werlen, so muB ihr Eigentümer sie bei der Bank hinterlegen, wobei diese iln eine Anweisung an den Zentralweschäftührer der Kolonialbanken in Paris aushändigt Der Zentralgeschäfsfiihner stellt dann gexon Torwejung ale Anweismo einen nenen Aktienschein ans, der aber nur in Paris ibertrabar ist.2) Der alte Aktienschein wird ron der Bank remichtet. In der eben angegebenen Teise kïnnen die nach Frankreich ïbertragenen Aktien dort weiterbogeben uder wieder in die Kolonie zuriek übertragen werden. Durch die Übertrabarkeit der Aktien nach Frankreich wurde den in Frankreich wohnenden Aktionären der Kolonialhanken ein grober Dienst erwiesen. Sie komnten nun ilns Aktien in Frankreich haben, dort die Dividenden erheben und am sitz der Zentralgeschäftsstelle ihren Alitienhesitz ühertragon. Diese Torteile kamen einem großen Teile der Aktionäre zugute. Denn infolge der Differenz zwischen dem Landeszinsfube in Frankroich und demjenigen in den Kolonien waren schon 1854 heispielsweise in Martinique 2925 ron 6000 Aktien nach Frankreich ïbertrasen. ${ }^{3}$ ) Auch behielten dic Kreolen, die wohlhabend geworden waren und sich in ihren alten 'Tagen nach Frankreich zuriickzogen, ihren Aktien-

1 Statuten 1901 Art. 7, 8.

2) Dekret rom 17. Norember 1852 Art.9.

3) Vergl. Bericht der Ü. Ko. 185355 . 
besitz bej, da sic noch grofe Interessm in den kolonien hatten. So kam es, dab 1892 mehr als die Hälfte der Aktien der Banken von Martinique und (iualeloupe sich in Frankreich bofanden, d. h. sogenannte actions ('Europe waren. $\left.{ }^{1}\right)$ In Réunion und Cuỵane dagegen machten die actions d'Europe nicht riel mehr als ein Drittel aller Aktien ans. Die Aktien der Bank ron Sínégal sind nie nach Europa ïbertragen worden. Sic wurden auch in der Kolonie selbst nicht geluanlelt, sondern blichen meist in denselhen Händen. Denn sie gehörten zum großen Teil franzïsischen Kanfleuten, die in Sénégal grobe Handelsinteressen hatten und daher den mit dem Aktienbesitz rerbundenen wirtschaftlichen Einflub sich zu erhalten wïnschten.

Gemäß Art. 25 der Statuten ron 1901 werden alle 6 Monate (am 30.6. und an :31.12.) die Bïeher und Konti der Bank ahgeschlossen, bilanziert und das Ergehmis festgestellt.

Die ausstehenden Forderungen, I. h. solche, die an Verfalltage nicht heglichen worden sind, dürfen dabei höchstens zu einem Fünftel ihres Nominalwerts in die Aktiva der Bankbilanz eingestellt werden. Von dom wihluend des s'emesters erziolten Reingewinn soll zunächst eine Summe $=1_{2}$. Prozent des eingezahlten Grundkapitals dem Reservefonds zugewiesen werden. Jede Aktiengesellschaft hat nach dem frimzösischen Aktiengesctz ron 1867 einen Reservefonds zu bilden, dessen gesetzliches Minimum ein Zeluntel des Grundkapitals heträgt. Der Spekulationseharakter der Kolouialbanken rumbulite den Gesetzgeber dieses Minimum für die Kolonialbanken auf die Hïlfte ihres Grundkapitals zu erlöhen. Dieses Minimum von 1/z des Grundkapitals war aber bis 1901 zugleich ein gesetzliches Maximum, da Art. 27 der Statuten bestimmte, dab, sobald der Reservefonds die Mialfte des Grundkapitals erreicht hätte, jede weitere Zuwendung an ihu unterbleiben sollte. Das Gesetz ron 1901 gestattet dagegen in diesem Falle die Begründung außerordentlicher Reserven und zwar 1) zur Amortisation der Immobilien und des Mobihars der Bank, 2) zur Ergänzung der Diridente anf fünf Prozent, falls der er-

1) Vergl. Bericht der Ü. Ko. 1892/93. 
zielte Reingewinn nur eine geringere Aussehüittmg zuläBt, und 3) zur Bildung einer Pensionskasse für die Bankangestellten. Die unter Nr. 2 erwähnte Reserve rerdient eine besondere Beachtung. Aus dem Reingewinn soll nach Abzug einer summe gleich 1/2 Prozent des Grundkapitals, welche pro Semester dem Reservefonds zuzuwenden ist, eine erste Dividende ron fünf Prozent des Aktienkapitals verteilt werden. Reieht der Gewinn dazu nicht aus, so darf die Dividende bis zu fünf Prozent erhöht werden und zwar dureh Entnahmen aus dem unter Nr. 2 genannten außerordentlichen Reservefonds und mangels eines solehen aus der statntarisehen Reserve, roransgesetzt, daß diese dadureh nicht unter die Hälfte ihres gesetzlichen Minimums sinkt. Der nach Verteilung ron fünf Prozent Diridende noch etwa rorhandene Gewimn kann zur Hälfte als zweite Dividende verteilt werden. Von der anderen Hälfte sollen zwei Zehntel dem Direktor und den auderen Bankbeamten und acht Zehntel der Reserve zugewiesen werden. Sobald diese ihr statutarisches Minimum erreieht hat, kommt dem Direktor und den Bankheamten die rolle Hälfte des Teiles des Reingewinns zu, der nach V'erteilung von fünf Prozent Dividende ïbrig bleibt, und zwar ist sie zu gleichen Teilen an len Direktor einerseits und lie ïbrigen Bankbeamten andererseits zu rerteilen.

Keine Dividende darf ohne Zustimmung des Couverneur's der Kolonie verteilt werden.2) Da die Converneure ron ihrem Yetorecht ans eigenem Antriebe fast keinen Gebranch gemacht latten, wurde ihmen in den neuen Statuten ron 1901 die Pflicht anferlegt, bei Vorliegen bestimmter, im Gesetz näher bezeichneter Statutenverstöße jede Dividendenverteilung zu verbieten, bis der Kolonialminister über den Fall eine Entscheidung getroffen hat. Stellt diese einen solehen Verstoß gegen die Statuten fest, so gilt der Verwaltungsrat von Rechts wegen als seines Amtes enthoben, und es hat unverzüglich eine Nenwahl stattzufinden; anch muß daun jerle Dividendenverteilung für die lanfende Gesehïftsperiode unterbleiben.

\footnotetext{
1) Statuten 1901 Art. 25.

2) Statuten 1901 Art. ㅇ․
} 
Das Verbot der Dividendenverteilung giht den Amorlum gen des Gesetzes eine gewisse sanktion: es bestraft abor hauptsüchlich die Aktionäre für Vergehen des Verwaltungsates. Die Alitimäre sind somit genötiøt, die (ieschältsführung der Bankdirektoren und Verwalter scharf zu ïherwachen, um sich selhst vor Sichatlen zu bewihren. Ihren Einflul anf die Bankleitung ïben sic durch die Generalversammlıng aus.

Die Gesamtheit der Aktionäre der Kónonialbank wird rortreten durch die Generalversammlung. Auf ihr haben aber nur diejenigen Alitionäre Sitz und Stimme, die mindestens zehn Alitien besitzen. Doch können Eigner ron weniger als zêhn Aktion, die aber zusammen zehn Aktien besitzen, sich durch einen unter ilmen vertreten lassen. ${ }^{1}$ ) .Jedes Mitglied der (ieneralversammlung. kann sich auf dieser nur durch einen anderen Aktionä der Bank vertreten lassen. Jeder Alitionair hat soriel Stimmen, als el je zehn Aktien besitzt. Das hierin zutage tretende plutokratische Prinzip wird dadurch gemildert, laß niemand in eigenem Namen oder als Bevollmächtigter mehr als zehn stimmen haben kamm.2)

Die Eigner ron actions d'Europe, die sich anf rer Generalversammlung vertreten lassen wollen, brauchen nicht mehr ilıre Alitien heim Zentralgeschäftsführer in Paris zu hinterlegen; es geniugt rielnehr seit $1901 \mathrm{zur}$ Verthotung anf der (ieneralversimmlung eine fünfzig Tage ror der Generalversammlung rom dem Zentralgeschäftsfülırer alusgestellte Bescheinigung über den Aktienbesitz des betreffenden Aktioniurs. $\left.{ }^{3}\right)$ Freilich dauf dieser Alitienbesitz vor Śchluß der Generalversammlung nicht übertragen werden. Da eine solche Ühertragung, wie wir schon ohen sahen, in Europa nur durch den Zentralgeschäftsführer erfolgen kiam, so ist die Bank gegen Fülschung und MiBbranch hinłänglich geschützt.

Die Leitung der Bank ist einem Velwaltungsiate anvertraut, der aus einem Direktor und vier Verwaltern besteht.*)

Der Terwaltungsiat trifft alle Verfügmogen in der inneren

1) Statuten 1901 Art. 28.

2) statuten Art. 30 .

s) Statuten 1901 Art. 29.

4) Statuten Art. 36 . 
Bankrerwaltung: er setzt den Diskontsatz und den Zinsfuf für Darlehen, die Prorisionen für Wechsel- und Kommissionsgeschäfte fest, desgleichen die Ciebüln'en für Dépits: er entscheidet, welche Wechsel und Schuldscheine zum Diskont zugelassen werden können, ohne daf er eine Zurïckweisung rom Diskont zu begründen braucht; er bestimmt die Höhe des jeweiligen Totenumlaufs imnerhalb der statutarischen Grenzen. Er wacht dariuber, daf die Bank keine anderen als die ihr durch die Statuten erlaubten (ieschäfte macht.") Der Verwaltungsiat als soleher bestimmt also die Richtlinien für den Verkehr mit der Kunrlschaft wie für den imneren Bankbetrieb. Da die vier Verwalter ron der Generalversammlung der Alitionäre gewählt werden, so hahen die Alionäre imnerhalh des Verwaltungsates entscheidenden Einfluf. Aber diesem Terwaltungsat sind manche wiehtige Befugnisse versagt. So wird der Direktor nicht ron ihm gewählt, somler'n auf Torschlag einer C̈berwachungskommision rom Präsidenten der französischen Republik ermannt.") Um ihm dem Verwaltungsiate gegeniber eine selbstindige Stellung zu geben, wurde bestimmt, daf der Kolonialminister, nicht der Verwaltungsat, dis (iehalt des Direlitors festzusetzen hat. Der Direktor hat aber auch positive Machtmittel dem Terwaltungsrate gegenüber: er ernennt und entlïbt die Bankbeamten, die dadurel ganz ron ihm abhängig sind. Der Direktor ist nominell nur ein Organ der Bank, das die Beschlüsse des Verwaltungsrats und der Generalversammlung auszuführen hat. Doch steht ihm gegen diese Beschlüsse indirekt ein V'eto zu, da jeder Beschun, der ansgeführt werrlen soll, mit der Unterschinft des Direktors rersehen sein mub und der Direktor zur Cuterschift nicht gezwmingen werden kamn. Ferner bedürfen die wichtigsten Geschüfte der Bank: die Diskontund Darlehensgeschäfte seiner Zustimmung. Der Direktor hat die Korrespondenz. Vertrïge, Quittungen, Wechselindossamente, Tratten und Anweismngen zu zeichnen. ${ }^{3}$ )

Somit besitzt der Direktor der Kolonialbanken recht um-

1) Statuten Art. 37.

2) Statuten Art. $\mathbf{1}$.

3) Statuten $1901 \mathrm{Art}$. 48.5 
fassende Befugnisse, die cr sehr zum schaden der Bank ausiaben könnte. Daher sucht man ihn durch Beteiligung am Reingewinn der Bank sowie durch die Bestimmung, laf der Direktor Eigner von mindestens zwanzig Aktien seiner Bank sein muli, ${ }^{1}$ ) nnmitelbar an Wohl und Wehe der Bank zu interessieren. Ein woiteres Gegengewicht gegen die selhstandiglieit des Direkturs ist die Bestimmung, dab der Direktor jederzeit dureh Dekret des Präsidenten der französischen Republik abgesetzt, ja in dringemden Fällen anch rom Gourernem der Kolonic ohne woiteres seines Amtes zeitweise enthohen werden kamn. ${ }^{-}$Hierdurch wird der Direktor ummittelbar abhängigron einer rorgesetzten Verwaltungsbehörde; er erhäl die sitellung eines staitsbcanten.

Dem Telwaltungsate zur seite stehen zwei Zensoren; ${ }^{3}$ ) einel ron ihnen wirl ron der Generalvelsammlnng anf zwei Jahre gewählt: er mo wie die vier Terwalter zehn Alitien zu eigen haben, die während seine Amtszeit unveräuferlich sind und die voll einhezahlt sein miissen. Der zweite Zensor ist ron Rechts wegen ein duch den franzisischen Finamzminister hemannter Finanzbeamter der Kolonie. Diestr hat allen Sitzungen des Telwaltungsiates beizuwohnen und ist daduch in stand gesetzt, die Banktïtgkeit genan zu verfolgen. Die dufoahe del beiden Zensoren ist nun, dariber zu wachen. dab die sitatuten der Bank genan befolgt werlen. sie haben den Kassen- und Wechselbestand der Bank narhzusehen und die Geschütshiicher auf ihre Richtigheit zu prüfen. Sie sollen der regelmäBig Anfang Juli zusammentretenden Generalrersummlung hechenschaft greben ïher ihre Tätighejt und eventuelle Torschläs muterheiten. ${ }^{*}$ ) Seben den Zensoren kennt das fresetz won 1901 noch hesomdere Inspektoren. Die Kolonialhanken miissen alle zwei Jahre anf ihre Kosten inspiziert werden durch Inspelitoren der Kolonie, die eigens zu diesem Zweeke ausgewählt sind, also \%eit haben, sich auf jhre Tätigkeit romzubereitun. Damit ist der Hauptein-

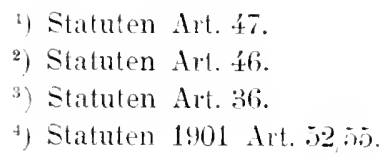


wurf. fler gegen die frïhere Anfsichtstätigkeit erhoben wurde, sie sei nicht sachrerständigen Lenten anvertraut, entkäiftet. Die Kolonialinspektoren prïfen die Banklage nach den ihnen rom Finanzminister gegehenen Instruktionen und senden ihre Berichte übor das Pröifungsergebnis dem Kolonialminister und dem Finanzministel ein. $\left.{ }^{1}\right)$

Als dritte Aufsichtshehörle ist noch die ÜberwachungsKommisson der Tolonialbanken in Paris zu nennen, die nenu Mitglieder zählt. ${ }^{2}$ ) Sio hat dem Präsidenten der französischen Republik allöhlich Bericht zu erstatton über jhre Aufsichtstätigkeit sowie ijher die allgeneine Lage der Banken. Der Bericht wird im Joumal officiel abgedruckt. Die Kommission hat nicht die Aufrabe und das Recht. in die Velwaltung und leeitung der Bank einzugreifen. Sie soll mu dem Kolonialministerium Terhessermugrorschlige moterbreiten und auf Ilängel der statuten sowie auf Gesetzwidrigkeiten in der Bankleitung aufmerksam machen. Wrenn die Üherwachungskommission trotzlem oft ihren Willen durehsetzte mul gewisse Maßnahmen der Banken exwang, so redankte sie das in erster linie ihrer sachreständigen Einsicht und ihrer im allgumeinen durchaus zutreffenden Benteilung der Terhälnisse. Natiulich was es ihr bei der weiten Entfornung ron den Lolonien nicht möglich. stets das Richtige zu treffen. Der ejnzige Torwurf fast, den man der Fommission machen kïmnte, ist der, dab ihre Warnungen und Ratschläge leider meist zu spät kommen. Die Überwachmngsommission stand chen so oft ror faits accomplis, ehe sie noch hatte einschreiten können. Der eben geriigte Mangel fïllt also der Kommission nicht zur Last. Dirse Einrichtung hat sich im fiegenteil vollauf bewïht. Wir rekapitulieren: Dic Kolonialbanken sind Privathanken: demn ihr Kapital gehört privaten Anteilseignem, die his zur Töhe ilnes Anteils für die Bankverbindliehkoiten haften, und die Aktionäre hahen durch die Genelalvesammlung und den Verwaltungsat Einflub auf den Gang der Bankgeschäfte. Doch sind ihre Rechte und Befugnise im Veroleche mit dem bej uns

1) Statuten Art. 5it.

2) Gesetz 187' Art. 15 
geltenden Aktiemrechte stark beschräint und zwar zugunsten des Staates.

Anch haben die Aktionäe keine Möghehkoit. einsoitim die Statuten abzuändern.

All dies erklärt sich aus folgendem:

a) Die Kolonialbanken sind errichtet nicht durch Rechtsgeschäft privater Griunder, sundern durch einen Akt der staatsgewalt.

b) Olganisation und Statuten der bank sind durch fosetze festgelegt und nur durch resetze abänderbar.

c) Der Direktor der Koloniabanken, der den mabgehendsten Einflub in rer Bankleitumg lat, ist ein Statsbeamter.

d) Auch die Bankkontrolle durch Zensoren, Inspektoren und C̈berwachungskommission ist in der Hauptsache cine statliche Angelegenheit.

Wenn wir noch das Notenprivileg der Kolonialbanlen in Betracht ziehen, das weiter unten zu behandeln sein wird, so können wir sagen: Die Kolonialbanken sind privilegierte Privatbanken, die unter statlichem Einflub und staatlicher Aufsicht stelien.

Es ist wohl nicht zn lengnen, dab bei den französischen Kolonialbanken an Überwachung und Beanfsichtigung des cinten zu riel geschehen ist. Immerhin ist zu bedenken, dab eine strenge Aufsicht wegen des Notenanswaberechts wohl am Platze war und sich auch dadurch noch rechtfertigte, dab der stait den Banken bei inrer Errichtung ganz hestimmte Ziele acsetzt hatte, die mit eng hegrenzten Mitteln erreicht werden sollten. Das führt uns zur Erörtermng des Geschäftskreises der Kolonialbanken.

$$
\text { 3. Kapitel. }
$$

\section{DER GESCHÄFTSKREIS DER KOLONIALBAXKEN INSBESONDERE.}

Ein Grundsatz beherrscht die Geschäftstitigkeit der Banken: sie diurfen unter keinen Unständen andere als die ihnen durch 
die rtatuten arauhten (ieschafte machen. $\left.{ }^{1}\right)$ Dor Geschäfskreis der Kolonialbanken ist also begrenzt. Wie dies bei den Sotenbauken der Fall zu sein pflegt.

Dir Banken haben sanz allwomein gespurelsen u. a. anch die Anfuabe, die in einer Tolkswirtsehaft frei rerfügharen Kapitalion an sich zu ziohen, um sie an liapitalberliuftige wieder zu verteilen. Dir resshedenen Arten dor anf die erstgenannte Aufube werichteton Tätigleit fabt man zusammen mntel dem Samen: Passirgeschäfte. Hier macht die Bank in den rerschierlonsten Formen Anlejhen heim stant oder Publiknm. Der Verteilung der so sammelten Kapitalien dienen die sogenamnten Alitireschäfte, nittelst deren die Bank ilme Kapitalien nutzbringend und werbend anlegt. Ibo Passivgesehäte sind num las Mittel, die Aktiresechäte dagegen dex Zweck der Banktätigkeit. Doch rembunt die soldune Bankreged, dab sich die Aktirgeschäfte nath den Passirgeschäften richten. Dariaher später mehr. Hier gilt es, festzustellen, welches die Aktis- nnd welches die Pasirenchäte lox Kulonialbanken sind.

Wrom wir drun Artikel 10²) der Bankstatuten, der die Ciescluifte der Binkon anfzilhlt, durchechen, so finden wir folgenule

1) Statuten 1901 Art. 9.

2) Art. 10 lautet:

Die Tiankgeschift" bestehen larm:

1. Eigene Veclisel ofler Tratten nit 2 oder mehr Unterschiften, die an ihrem Ansstellungsonte zahlhar sind, zu liskmtieren.

2. Direkte oder an order gestellte Tratten ofler Anweisungen auf Frankreich oder das Ausland zu begeben. zu diskontieren oder zu kaufen.

$\therefore$ Vorschïsse 20 geben auf handelsmätrige vder nicht handelsmäbige schuldscheine. welche garantierl sind:

a) durch Warrants oder Lagerscheine ron Waren. die hinterlent sind in äfentlichen Layerrännen oder in privaten Rämmen, deren Schlässel der Bank regehrecht eingehändict simel;

b) durch Abretung dor Ente anf dem Fulde:

c) durch Konnossemente, die an Order gestelt und regelrecht indossiert sind:

a) Aurch Abtrehms ron Rentenbritefen. Aktien der bank ader ron Worpapieren, welche die Bank von Frankreich als sicherheit für Vorschïsso zuläßl : 
Aktirgesehiafte: Das Diskontyesehäft (Art. 10.1,2) zusammen mit dem Ankauf ron Wechsehn (Art. 10, \&). ferner die Darlehensgeschäfte des Art. 10.3. lals alitive Kontokorrentgeschäft, hestehend in Auszahhungen auf Effekten, die der Bank eingehändigt sind, in der Besorgung ron Auftrïgen und Bezahlung von schecks und Anweisungen (Art 10.4): sodann das Subsirjptionsgeschifft (Art. 10,6), das gleiehsam anch ein Kauf von Effekten ist. Zweifelhaft kann die Natur des Haudels mit Edelmetallen (Art. 10.:) sein. Doch wird man den Kauf ron Eilehmetallen zu den Alitivgeschäften rechnen dürfen (und ihren Verkauf zu den Passivgeschäften), denn ein Kauf, z. B. von (roldharren, kann angesehen werden als ein Darlehen, hei dem infolge einer clausula commissoria das Pfand, hier die Goldbarren. an die Stelle der ursprünglich zurïckzuzahlenrlen Darlehensimme getreten ist.

Zu den Passirgeschäften der Kolonialbanken gehört: Das Depositengeschäft (Art. 10,5), desgleichen die Annalme der auf öffentliche Anleihen gezeichneten Betrïgen (Art. 10. z), die Rüekdiskontierung und der Verkanf ron ITechseh, ror allem aber die Ausgabe ron Noten, Anweisungen, Sulawechsehn und Tratten (Art. 10,8). In der Praxis sind Aktir- und Passirgeschäfte nicht so scharf wie hier getrennt, sondern eng mitcinander rerdinïpft,

e) durch Hinterlegung von Barren, Münzen oder Gegenständen von Gold und Silber.

4. Fiir Rechnung von Privaten oler von öffentlichen Anstalten Einund Auszahlungen auf Effekten, die der Bank eingehändigt sind. zu besorgen und alle Anweisungen und Aufträge zu bezalılen.

5. Gegen eine Verwahrungsgebüh in Empfang zu nelmen freiwillige Dépôts von Schuldtiteln, Barren, Münzen und Gegenständen von Gold und silber.

6. Alle rom Staat oder von der Kolonie eröffneten Anleihen zu zeichnen bis zur Höhe des Reservefonds.

7. Mit Emächtigung des Kolonialministers die auf öfentliche in der Kolonie oder in Frankreich eröffnete Anleihen gezeichneten Beträge entgegenzunehmen.

8. Noten. die dem Inhaber auf Sicht zahlbar sind. ferner eigene Wechsel, Tratten oder Anweisungen auszugeben. und Silber.

9. Handel zu trerben mit gemünztem oder ungemünztem Gold 
meist durch den Kontokorrentrerkehr zwischen der Bank und ihren Limslen.

Es könnte scheinen, als ob wir bei Aufzählung der Passirgeschäfte der Kolonialbank das ursprïnglichste und angenscheinlichste rergessen hätten: die Einzahlungen rer Aktionäre auf die Aktien der Bank. Das Frundkapital ist doch die erste Anleihe, wolche die Bank beim Publikum macht, freilich nicht immer die hedentendste. Trotzdem kömnen wir das Grundkapital bei Betrachtrung der Passirgeschäfte aufer acht lassen, dem es ist bei den fünf Kolonialhanken kein Betriehskapital, das seinen Gegenwert in dem Wechsel- nud Metallhestande der Bank fände. sonder'n tatsächlich ein Garantiekapital, das zur Deckung der Totenausgabe dient und in Rentenhriefen angelegt ist. Es hat somit einmal zu einem Aktirgeschäft, nämlich zum Ankauf öffentlicher Anleihen. gerlient, kommt aher für die Geschäftstätigkeit der Bank numittelbar wicht in Betracht.

\section{$\$ 5$. \\ PASSITGESCḦ̈TE DER KOLONIALBANKEN.}

Das hauptsächlichste Passirgeschäft der Kolonialbanken ist ihro Totenausgahe.

1. Wie schon öfter angedentet, sind die fünf Kolonialbanken unter Ansschluf aller anderen Kreditanstalten ermächtigt, in der Kolonie, in der sie errichtet sind, Toten anf den Inhaber in Höhe ron 500, 100, 25 und $5 \mathrm{fr}$. anszugeben. Die Yoten sind anf Sicht zuriickzahlbar am Sitze der Bank, die sie ausgegeben lat. Doch brauchen die 5 fr.- Xoten nur in Betrïigen von 25 fr. zurückgezahlt zu werden. An diese 5 fr.-Noten linüpft sich eine lange Geschichte. Das Gesetz von 1851 (Art.5) hatte ihre Ansgabe nicht gestattet, obwohl sie schon 1849 in den französischen Antillen ron den dort provisorisch eingerichteten caisses de prèts sur dépòts de denrées ansgegeben und selbst bei den Schwarzen sehr beliebt waren. Die 5 fr.-Noten drangen freilich mehr in den Verkehr ein als die Noten, welche auf größere Summen lauten, und man fürchtete, daß jene hei 
einer Panik haufenweise zur Bank zurückströmen mmd dadureh den Metallvorrat der Bank in kritischer Koit bedenklich vermindern wïrden. Aber sollte man nicht das Zutrauen zu der Bankleitung haben, dali sie an besten benrteilen wiirde, hei welcher Stückelung der Soten Halt zu machon sei? Auf den Wunsch der Banken wurten daher 1874 auch 5 fr.-Noten zugelassen. Es blieb noch die Befürchtung, dab die neuesi 5 fr.Noten die sibernen 5 fr.-Stücke ans dem Verkehre verolräingen möchten. Was damals befürchtet wurde, ist später tatsïchlich eingetreten. Doch war daran nicht die Ausgabe von 5 fr.-Noten schuld, sondern der Umstand, daf die Noten nur in ler Kolonie zirkulieren und nicht wie das Jetallgehl zu Rimessen verwendet werden komnten. Bei passiver Zahlungsbilanz wanderte das Metallgeld aus, die Noten dagegen blieben in der Kolonie zurïck.

Die Hölı des Notenumbaufs ist durch zwei Bestimmungen beschränkt. Erstens soll der Notenumlauf stets zu einem Drittel metallisch gedeckt sein. Als 1855 und später 1879 bezw. 1884 in den Zuckerkolonien Kassenschoine mit Zwangskurs ausgegehen wurden, erhielten die Banlien die Erlauhnis, diese Kassenscheine in ihren Metallbestand aufzunehmen. Eine weitere Grenze ist dem Notemumlanf dadurch gesetzt, dab der Gesamthetras der im Umlanf befindlichen Noten sowie aller sonstigen Śchulden der Bank den dreifachen Betrag ilres Grundkapitals und ihrer Reserven nicht überschreiten darf. Soweit dieser Gesamtbetrag aller Bankverbindlichkeiten über jene Grenze hinausgeht, mub ihm ein freier, d. h. nicht zur Drittelsdeckung des Notenumlaufs benötigter Metallvorrat entsprechen. ${ }^{1}$ ) Kapjital und Reserven der Kolonialbanken sind seit langer Zeit in Rentenbriefen angelegt, die einen schwankenden Kurs haben. Um num fïr die Berechnung des Maximums der Bankrerbindlichkeiten eine feste crundlage zu gewinnen, war 1863 bestimmt worden, daf die dreiprozentigen Rentenbriefe der Kolonialbanken zum Kurse von $75 \mathrm{fl}$. pro $3 \mathrm{fr}$. Rente kapitalisiert werden sollten. Das entsprach einem Kurse von $75 \mathrm{fr}$. pro $100 \mathrm{fr}$. Nominalwert, war also bei dem damaligen Rentenkurse ron $70 \mathrm{fr}$. um $5 \mathrm{fr}$. zu günstig für

1) Gesetz 1901 Art. ‘́. 
die Kolonialbanken. In den $90 \mathrm{er}$ Jahren des vergangenen Jahrhunderts war der alte Kapitalisationskurs um 25 fr. zu niedrig geworden, da der tägliche Kurs der Renten sich um den Parikurs bewegte. Deshalb wurde durch Dekret rom 9. 4. 1902- der Kapitalisationskurs für die Rentenbriefe auf $90 \mathrm{fr}$. pro $3 \mathrm{fr}$. Rente erhöht, so daß die Banken jetzt noch iminer gegen einen Kursrückgang geschützt sind.

Die Noten der Kolonialbanken sind im ganzen Unkreise der betreffenden Kolonie gesetzliches Zahlungmittel für Private wie für die öffentlichen Kassen. ${ }^{1}$ ) Sie haben also nicht nur Kassenkurs; auch der Staat kamn sie zu Zahlungen an die Bank oder an andere Privaten benutzen.

Das Gesetz spricht ron ..cour's légal", dieser wird definient mit: cours obligatoine accompagné du remboursement ì volonté. Die Einlösung der Noten auf Sicht sichert ihre Münzparität: sie ist zugleich anch die Voranssetzmng für ihre gesetzliche Zahlungskraft: in dem Augenblicke, wo die Bank ihre Zahlungen einstellte, würden die Noten der Bank aufhören, gesetzliches Zahlungsmittel zu sein. Der Staat könnte die in seinen Kassen angesammelten Noten nicht mehr zu Zahlungen an Private benutzen, und dem Cieldrerkehr wäre das wichtigste Lmbaufsmittel mit einem Schlage entzogen. Die Zahlungseinstellung einer Kolonialbank mïbte ein Stillstehen aller Geschäfte notwendig mach sich ziehen. Um ein solches Lnglïch ron der Kolonie abzuwenden, beschlob der Generalrat ron Rémion 1s94, der Bank ron Réunion, deren Liquidation zu befürchten stand, durch eine Subrention ron 1.5 Millionen fr. aus ihrer schlimmen Lage zu helfen. ${ }^{2}$ ) Der franziisische Gesetzgeber wucte durch dieses Ereignis auf eine Lücke im Kolonialbankgesetze von 15 it aufmerksam und er bestimmte 1901 im Art. 57 der Statuten, daß im Falle einer Liquidation einer Kolonialbank der Kolonialminister im Einklang mit dem Finanzminister die Bedingungen für den Umlanf und die Zurückzahlung der Banknoten prorisorisch festsetzen soll.

1) Gesetz 1901 Art. x.

2) Denizet a. a. (. S. 179 
Welch großes Interesse die Kolmie an der Einlïsmng der Xoten auf Präsentation hat. ist eben gezeigt worlen. Eine Beschränkung des Notenumlaufs auf einen tem jureiligen Metallbestand der Bank entsprechenden Betray häte die Rückzahlung der Banknoten röllig sicher gestellt. Aher die Yoten sollten nicht nur ein Ersatz der Münzen, also broßes Cmbanfmittel, sondern zugleich anch Kreditmittel sein, d. h. sie sollten der' Bank die ron ihr zu ihren Aktirgeschäften benötigten Kapitalien liefern. Darum waren die oben S. 29/30 erwähnten Bestimmungen uiber den Sotenumlauf duchaus am Platze.

Durch die Notenansaghe rerschafft lie Bank sich unverzinsliche Darlehen, die sie ihrerseits wieder gegen Zins ansleihen kann. Sun werden die Banknoten in den seltensten Fïllen durch bloßen Untausch gegen Bargetd in den Verkehr kommen (das wäre aher die notwendige Folge. wenn die Yoten röllig bar gedeckt sein müßten!. Der Hauptrorteil der Notenausgabe besteht ja aber für die Bank darin, daß sie über insen Barvorrat hinaus Noten ausgehen darf. Sie kamn und wird deshalb ihre Darlehen rorzugsweise in Noten gewähren, ihre Schulden möglichst dureh Sotenabgahe zahlen. Denn diese Noten sind ja gesetzliches Zahlungsmittel innerhalh der Kolonie. Ihre Bedentung reicht aber noch weiter. Die Soten ersparen die Kosten der Herstellung. des Transports und der Abnutzung der Geldmünzen: sie erhöhen die Elastizitït des baren creldes, indem für $100 \mathrm{fr}$.. die in den Kassen der Bank liegen. :300 fr. in Soten zirkulieren kömen. und sie sind ein einzigartiges Mittel, $u m$ den in der Kolonie rorhandenen Geldrorrat dem stark und periodisch schwankenden Geldhedarfe der Kolonie mühelos anzupassen.

2. Teben der Notenausgahe ist das Depositengeschäft das bedeutendste Passirgeschäft der Kolonialbanken. Es ist zu unterscheiden zwischen den Dépots à titre de gage. die bei anem Darlehen hingegeben werden, und zwischen den Dépoits rolontaires. Ton diesen ist hier zunächst nur die Rede.

Sach Art. 10, s der Statuten diüfen die Banken gegen eine Verwahrungsgebühr Schuldverschreibungen, Barren, Mïnzen und 
Gegenstänle ron Gold und Silber in Verwahnung nehmen. Die Vorteile des Hinterlegers: Schutz gegen Verluste durch Erdheben, dureh Diehstahl oder Feuter in eigenen Hanse waren hei der verhïltnismäbig geringen sicherheit in den französischen Kolonien recht erheblich. Leider läft sich aus den jährlichen Berichten der Überwachunghommission nicht ersehen, welcher Gełaruch ron diesen Dépots zur Verwahrung gemaeht worden ist. Die Bankkunden pflegen ilne (regenstände ron frold und Silher nicht ohne weiteres ler Bank zur Verwahrung hinzugreben; sie ziehen es ror, bei dieser Gelegenheit ein Darlehen anfzunehmen, das oft nur einen kleinen Bruchteil des in dem hinterlegten Gegenstande steckenden Werts hildet. Warden nun aber bei Hinterlegung soleher Gegenstände keine Vorschiisse verlangt und gegeben, so erhebt die Bank ummittelbar vom Werte der hinterlegten liegenstände eine Terwahrungsgebühr, deren Höhe rom V'erwaltungsart festgesetzt wird. Dieso Gehülsr repbleibt der Bank, anch wenn der Hinterleger noch ror der für die Zurickgabe les Lépots bestimmten Zeit Vorschiisse auf sein hinterlegtes (int rellangt und erhiilt. ${ }^{1}$ ) Eine brweiterung der Dépots zur bloben Verwahrung, welche die Bank ja nicht für eigene Zwecke benutzen darf, liegt in der Übernahme von Depositen zu Verwaltung, wie sie Art. 10,4 der Statuten vorsieht. ${ }^{2}$ ) Diese Depositen zur Verwaltung gehen der Bank Veranlassung zur Erhehung einer Kommissionsgebïlu oder Prorision. Darf die Bank ïher die ihr eingehändigten Ciehder oder Wertpapiere oder anteren vertretharen sachen gar noch frei rerfiigen, so liegt ein depositum irregulare ror. Diese sogenannten Depositen zur Terwendung sind das eigentliehe Depositengeschäf der Bank. Die Depositen sind ebenfalls ein Mittel für die Bank, die frei rerfüghraren Kapitalien der Kohonie an sich zn ziehen, um sie nutzbringend zu rerwenden. Hier winkte den Kolonialbanken eine grobe Aufgabe, zumal wenn sie anch Depositen, die ans Frankreich wler dem Auslande stammten, annahmen. Ein Depositenzins, der amühernd dem Diskontsatze gleichkïme, hätte die Depo-

1) Statuten 1901 Art. 21.

2) S. S. 27. 
sitengelder der Bank mächtig anwarchsen lassen, da der Diskontsatz in Paris wreentlich niedriger wall als in den Liolonion. Diese ganze Entwickelungsmöglichkeit des Depositengeschäfts war den Banken aber ron vornherein genommen, da Art. 19 ihrer Statuten ihnen die Amnahme ron zinstragenden Depositen verbot und auch jetzt noch verbietet. Man begründete dies Verbot nit der Bofürchtung, es möchten sonst die Depositen zn stark anwachsen und die Bänk dadureh reranlaßt werden, ïber das wirkliche Kredithedürfnis hinaus Darlehen zn wewihren, nu nm dio dueb die Depositen erhaltenen Kapitalien nutzhringend anzulegen. Djese Befürchtung war zum groben 'Teile berechtigt. Auf les anderen Seite hatte aber das Zinsverhot für bepositen das Mibliche, die freien Kapitalien der Kolonie den Sparkassen in die trme zu treiben, wo sie bald in Rentenbriefen angelegt wurlen. Wenn nun die Bank anch als Entgelt für die zinslose Üherlassmng ron Geldkapitalien dem Deponenten alle Aufträge und Auweisungen auf sein Kionto kostenlos besorote, so waren doch diese Vorteile wenigstens in Anfange nicht grob genug, nm eine erhehliche Ausdehnung des Depositenrolkehrs herbeizuführen. Thas war noch ron einem andern Gesichtspunkte aus bedauerlich. Enor rerknüpft mit dem Depositengeschäft ist der Giroverkehr. Die Einrichtung, daß ein Bankkunde sein Guthaben ganz ofler zum Teil durch blobes Giro auf ein anderes línto übertragen kamn, war an sich sehr geeignet, den Gedverkehr zu erleichteru, den Geldbedarf zu vermindern und dadurch ler Geldnot in den Kolonien abzuhelfen. Da aber der Depositenverkehr gering war - die Depositen erreichten selten die Höhe des Grundkapitals der Kolonialbanken -, hlieb auch der Giroverkehr unentwickelt. Melrr benutzt wurde eine andere Form der Verfügung iber ein Bankguthaben: der Scheck. Scheck-sowie Giroverkehr setzen ein Kontokorrent mit der Bank voraus. Es empfiehlt sich deshalb, an dieser Stelle die Grundziige des Kontokorrentrerkehrs der Banken darzulegen.

Das Kontokorrentgeschäft ist kein besonderes Bankgeschäft, sondern nur ein Mittel, um die verschiedensten Bankgeschïfte zu konzentrieren und darlureh zu vereinfachen. Das Kontokorrent 
besteht larin. daß die Kunden der Bank ihre laufenden Einnahmen, soweit sie diese nicht ummittelbar benötigen, hei der Bank einlegen und zwar zur freien geschäftlichen Benutzung derselben, unı sich die Zuriickziehung nach rereinbarten Fristen vorbehalten. Die Kolonialbanken besorgen dafür alle Ein- und Auszahlungen auf die hei ihr eingereichten Wertpapiere, Scheckis oder Anweisungen, also das ganze Inkassogesehäft des regulären Bankrerkehrs; sie ersparen sis dem Einheger die Mühen und Kosten der eigenen Kassenverwaltung, und sie selhst hahen den Torteil dabei, die Gelder ihrer liunden zu eigenen geschïftlichen Unternehmungen hermziehen zu kömen. Das Kontokorrent ist oft die Form für die Eröffnung eines hredits an Prirate, Gemeinden oder an ven Staat. Das hontokorrent mit dem Nationalen Diskontkontor in Paris rermittelt den Kolonialbanken den einheimischen Kredit. Der volkswirtschaftliche Tutzen des Kontokorrentrerkehrs liegt in der Steigerung der Elastizität des baren Geldes. Die in den Kolonien rorhandenen Kapitalien werden durch die Bank aufgesogen, fortdauernet in den Verkehr gebracht und im Umlauf erhalten. Da hierdurch die einzelne Nü̈nze zu hesserer Verwertung gelangt, so gen ügt schlieblich ein geringerer Geldvorrat zur heldversorgung der Kolonie. als er sonst, d. h. beim Fehlen des Kontokorrentrerkehrs benötigt würde. Noch wichtiger ist aber, dab dureh die 'Tätigkeit der Bank die Einlage eines Bankkunten mehrfache wirtschaftliche Aufgaben zu gleicher Zeit iihernimmt. ${ }^{1}$ ) Z. B. ein Importeur zahlt bei einer Kolonialbank $1000 \mathrm{fr}$. in bar ein und bestelt dafür bei der Bank Anweisungen (Rimessen) auf das Ausland. Der um $1000 \mathrm{fr}$. erhöhte Metallbestand gestattet nummehr der Bank, ihren Notenumlauf $1 \mathrm{~m} 3 \times 1000 \mathrm{fr} .=3000 \mathrm{fr}$. zu rermehren. Mit diesen. $3000 \mathrm{fr}$. Toten kann sie einem Pflanzer ein Darlehen gewïhren, der Pflanzer seine Arbeiter entlohnen und diese wiederum Einkäufe machen. Alles dies vollzieht sich innerhalb derselhen Zeit, für welche die obige Geldsumme ähergeben ist. Dieselbe Summe hat damit mehrfache wirtschaftliche Funktionen (als Garantie-

1) J. Conrad, Grundriß zum Studium der politischen Ökonomie. I. Nationalökonomie, Jena 1902, S. 149. 
mittel, als Mittel der Ḱreditgewährung, als Zahlungsmittel) zu gleicher Zeit äbernommen und leistet deshalh für die Gesamtheit das Mehrfache ron dem, was ohne Termittehng der Bank möglich wäre. Da die Zunahme des Wohlstandes eines Landes abhängt ron der Steigerung der Intensitiit seiner Geldzirkulation, so bestand die Möglichkeit, durch den Kontokorrentverkehr der Kolonialbanken die Entwickelung der Kolonien bedentend zu fördern anch ohne Erhöhung des Kapitalvorats der Kolonie.

Die im Kontokorrentrerkehr der Bank gemachten Einlagen können auf verschiedene Weise abgehoben werden. Gewöhnlich händigt die Bank ihren Kunden ein Scheckbuch ans, so daß her Kunde durch den scheck beliebige Betrïge bis zur Höhe seiner Einlage entnehmen. oder anf das Konto eines anderen Bankkunden girieren oder einen dritten hezahlen lassen kamn. oft erhält der Deponent rou der Bank nur einen Empfangsseleein (récépissé), welcher Satur und Wert des hinterlegten Ciegenstandes, Namen und Wohnung des Hinterlegers, Datum der Hinterlegung, Termin für die Rückgahe und Nummer der Hintragungsliste (letzteres zur Sicherung gegen Fälschung) angibt.1) Diese récépissés haben keine. Orderqualitït und können nicht durch Indossament ähertragen werden. Da die hinterlegten Gegenstände anch Geld sein können und da ausbedungen werden darf, daß die Geldsumme anf Verlangen jederzeit zurückzahlbar sei, so gibt es auch récépissés d'espèces payables à rue. Es entsteht nun die Frage, wie sich diese Art ron récépissés zum Scheck und zur Banknote verhiilt. Alle drei sind anf Sicht zilhbare Bankverbindlichkeiten: deshalb werden diese récépissés bei der Bestimmung des Notenmmlanfs mit eingerechnet; alle drei Papiere sind Inhaberpapiere. Allein Noten lanten nur auf Betrïge ron 500, 100, 25 und 5 fro; récépissés und Schecks auch auf andere, anch nicht runde Summen; beide wurden selu oft in Beträgen ron $2 \mathrm{fr}$., $1 \mathrm{fr}$ : und $0,50 \mathrm{fr}$, ansgestellt zur Erleichterung der Zahlungen im Kleinverkehr. Scheck nud récépissé mïssen vollkommen metallisch gedeckt sein: Noten branchen

1) Statuten 1901 Art. 21. 
es nicht zu sein. Das ist aber anch der einzige wichtige Unterschied zwischen den Noten einerseits und den Sehecks und récépissés despees parables ì rue andererseits. Zwischen Scheck und récépissó besteht kein prinzipieller Unterschied.

3 . Bei der Entgegennahmo der Zeichnumgen auf öfentliche Anleihen, die in Frankreich oder seinen Kolonien eröfnet werden, spielt die Kolonialbank die Rolle eines Kommissionär's. Sie übernimmt es anch. die durch Staat oder Kolonie ansgegebenen Sehuldverschreibungen beim Publikum unterzubringen: sie rermittelt dadurch zwischen Kapital und Arbeit nud erleichtert ganz besonders die Ausführung öffentlicher Arbeiten, die im Interesse der Kolonie unternommen werden, aber ohne Anleihe nieht durchführhal sinel.

Wir künnen die Reihe der Passirgeschaitte der Kolonialbanken nicht schlieben, ohne die zahlreichen Wechselkreditgeschäfte der Banken wenigstens kurz zu streifen. Die Benutzmng des Techselkiedits durch die Kolonialbanken wird aber am besten weiter unten im Zusimmenhange mit dem aktiren Weeliselgeschiift largelegt werden.

\section{s 6.}

\section{AKTIVGESCHÄFTE DER KOLONIALBANKEX.}

Tir wenden uns mumehr den Aktirgeschäften der Koloniabbanken zu und untersuchen, anf welche Art und Weise die Bank die angesammelten Kapitalien rerteilt, d. h. (anderen Personen) Kredit gewährt. Man unterscheidet gemeinhin zwei Arten ron Liredit: Personalkredit und Realkredit.

Der Personalkredit der Kolonialbanken zeigt die Form des Diskontgesebüfts; der Realkredit wird von ihuen in den rerschiedenen Arten des Darlehens gewälurt.

Zunächst sei das Diskontgesehäft besprochen.

1. Ein Tertpapier diskontieren heißt, es nehmen unter Abzug eines Zinses, der sich nach Höhe und Lanfzeit der im Papier verbrieften Forderung berechnet. Gegen Diskontiermng seines Effekts erbält der Diskontnehmer Bargeld. Der Diskontabzug ist 
somit für ihn zum 'Teil eine der Bank für die Beschalfung ron Bargeld gezahlte Provision. Die diskontierende Bank crwirbt durelı das Diskontgeseluät eine befristete Fordermig, das heift soviel: sie legt ihr Gell in einer kurzfristigen Forderung an. Dureh Bezahlung des Wertpapiers am Verfalltage werden die Kiapitalien der Bank wieder frei. Der Gewinn der Bank heim Diskontgeschäft rïhrt daher, daß der Diskont rom Nominalwerte der befristeten Forderung, nicht von ihren Werte zur Zeit der Diskontierung erhoben wird. Gewöhnlieh ist die Bank beim Diskontgesehäft Kreditgeberin; natürlieh kann sie aber anch ein diskontiertes oder von ihr ausgestelltes Effekt weiter diskontieren (réescompter), z. B. wenn sie Bargeld henötigt. Diese Rïickdiskontierung ist dam ein Passirgeschäft, bei dem die Bank einen Zins zahlt in Form des ron ihr zu tragenden Diskontahzugs. Da der Bank durch die Rückdiskontierumg cin Teil des hei der Diskontierung gemachten (iewinns verloren geht, so wird sie freiwillig nur dam Effekten rüekdiskontieren, wenn sie hoffen darf, ilı'e so frei werdenden Kapitalien zu höherem Zinse anlegen zu kömmen.

In folgenden betrachten wir nur den Fall der direkten Diskontierung, wobei die Bank Kreditgeberin ist. Für die Rückdiskontierung gilt ja dasselbe, was über die Diskontierung gesagt werden wird; nur sind dort die Rollen rertauseht.

Die Kolonialbanken dürfen diskontieren erstens Solawechsel sowie Tratten, die an ihrem Ausstellungsorte zahlbar sinl, zweitens Tratten und Anweismugen auf das Ausland oder Frankreieh. Diese kömnen Rekta- oder Orderpapiere sein, jene nur Orderpapiere. ${ }^{1}$ ) Merkwürdig ist, daß im Gesetze ron Wechseln anf die Kolonie, die an einem anderen Orte als ihrem Ausstellungsorte zahlbar sind, gar nicht die Rede ist. Zwar sprach das Gesetz von 1851 im Art. 12,1 ganz allgemein von „Wechsehn und anderen Orderpapieren“, worunter sowohl Platzweehsel wie Distanzweehsel auf die Kolonie, Frankreich oder das Ausland verstanden werden komnten. Aber der Wortlaut der şs 1 und 2 des Art. 10 des

1) Statuten 1901 Art. 10, 1 u. 2. 
Gesetzes ron 1901. ${ }^{1}$ ) welehr den $\$ 1$ des Art. 12 des Geretzes von 1851 ersetzt haben, schlieht die sogenannten Distanzwrehsel anf die Kolonie rom Diskont der Banken ans gemäß dem Grundsatze, daß die Bank nur die von den Statuten erlanbten, d. h. erwähnten Geschiifte treiben darf. Indes liegt hier zweifellos eine Lücke in liesetze vor, welche sich vielleicht erklïrt aus der meringen Bedeutung. welthe die Distanzwechsel auf die Kolonie solange haben und behalten mubten, als die Kolonialbanken keine Filialen oder Geschäftsstellen gegriunlet hatten (was his 1901 noch nicht geschehen war).

Die Diskontierung der auf das Ausland oder Frankreich ansgestellten Wechsel ist das Gegenstück zur Ausgahe ron Anweisungen und Tratten anf Frankicich oder das Ansland: sie wirl am besten im Zusammenhange mit den Wechselgesehaften der Banken besprochen, won denen sie einen Teil bildet.

Hier ist nur die Rede von der Diskontierung ron Platzwechseln. Sie ist durch die Statuten der Banken an rerschiedene, teils sachliche, teils persinliche Voraussetzungen geknüpft. Erstens muli der ITechsel unterschrieben sein ron mindestens zwei Personen, die notorisch zahlungsfïhig und in der Kolonie ansiissig sincl. $\left.{ }^{2}\right)$ Doch kann die zweite Unterschnift auf dem Wechsel durch hestimmte Pfänder ersetzt werden.

Zweitens darf die Verfallzeit des Wrechsels 120 Tage nicht ïbersteigen. Ind schlieblich mul der Wechsel zum Diskont eingereicht sein dureh eine zum Diskont zugelassene Person. ${ }^{3}$ )

Die Kolomialbanken verlangen also nur zwei Unterschriften auf dem Wechsel, die Bank rom Frankreich dagegen deren drei - ein wichtiger Untersehied! An sich sind ja nur zwei Unterschriften nötig. Denu das Diskontgeschäft ontspringt oder soll wenigstens entspringen einem schon vollzogenen Verkaufe, z. B. vom Waren. Beim Solawechsel stammt die erste Untersehrift vom Käufer, der das Papier ausstellt zweeks Zahlung seiner Schuld an den Verkäufer; die zweite ist diejenige des Verkäufers der

1) S. oben S. 26 .

2) Statulen Art. 11/12.

3) Statuten 1901 Art. 20. 
Wrate und exten Indosinnten des Weehsels, der durch Einreichung zum Diskont möglichst hald den diegenwert der llare in Geld, d. h. ihren Preis. zu erhalten strebt. Boi der 'Tratte zieht der Verkïufer einer Ware einen Weehsed anf den Käufer, den diesel akzeptiert. In beillen Fïllen genügen zwri Cnterschriften. Die dritte Cntersohift, die in Frankreich moist noch verlangt wird, rülnt gewöhnlied ron einem Privatbankier hes: der das von ihm indissierte Papier der Bank zum Diskont präsentiert: sie erhöht die Sicherheit des Wechsels, indem der Priratbankier die Zahlungsfähigkeit des Ausstellers und des arsten Indossanten oder des Alizeptanten prift und sieh dureh seine Unterschrift für dic Einlösmng des Wechsels haftbar macht. Der Priratbankier tut aber, genau hetrachtet, nichts anderes, als dab er dem ron ilm diskontierten Papier mit zwei Lntersehriften noch die seinige hinzufügt und las Papler dam der Bank präsentiert: er leiht zuerst ficld ans zu einem relativ hohen Diskontsatz und borgt sich lamn rom der Bank Geld zu einem niederen Satze: Der Unterschied zwisehen den beilen Diskontsätzen bildet den (iewimn des Priratbankiers. Indem man nun das Erfordernis ron drei Intersehriften besoitigt, wird die Vermittelung eines Privatbankiers zwisehen der holonialbank und dem ersten Indossanten bow, dem Akzeptanten eines Wechsels umötig, und der Bank fällt nummehr der Gerimn zu, den hislang der Privatbankier einheimste. Man kann einwenten, daß die Koloniabbanken auf diese Weise für den höheren l)isknntgewinn ein geführliches Risilio engetanscht hahen. Dem ist entgegenzuhalten, dali oft die Unterschrift des l'rivathankicrs eine sogeuannte signature de complaisance on sams valeur und damn den Kolonialbanken rerboten ist durch Art. 11 der statuten, oder dab sie umnötig ist, wem anch nur einer der zwei Wechselrerpflichteten seiner Zahhungsverpflichtung nachkommen kann, oder daß sie zu tener erkauft ist durch den geringeren Diskntgewinn, den die Yermittlung des Privathankiers für dic Bank zur Folge haben würde. Ausschlaggehend war für den liesetzgeber die Tatsache, dab es in den Kotonim keine Privathankiers gab. Das Vellangen nach trei Unterschriften war also in den 
Kolonien unerfüllbar oder es hätte, wenn es dennoch gestellt wäre, die in den Statuten rorgesehenen Diskontgeschäfte zu einem toten Buchstaben gemacht. Zu beachten ist jedoch noch eins: Die Kolonialhanken künnen Wechsel mit zwei Unterschriften diskontieren, sie brauchen es nicht zu tun. Damit war ron rornherein einer eventuellen Entwickelung und Ansbreitung des Privathankwesens in den Kolonien Rechnung getragen.

Es liegt in dem rigenen Interesse der Kolonialbanken, die ron ihren Statuten rerlangte Zahlungsähigkeit der zwei Wechselrerpflichteten sorwfältiı zu prüfen und ror allem die Konzentration ihrer Wechselforderungen auf einige wenige schuldner gemäß lem Crundsatze der Risikorerteilnng zu verhindern. Nun waren die Einwohner der franziosischen Kolonien nicht zahlreich, so dalj jede Kolonialbank an sich unschwer imstande war, sich über die Zahlungsfähigkeit ilırer Kunden zu informieren. Thr Kundenkreis war also klein - das beguinstigte eine Konzentration der Wechsel - , und andererseits hatte die eigenartige Entstehung des Kolonialhanken zur Folge gelabt, dap Verwaltungsrat und Aktionäre der Bank melur oder weniger auch Kunden der Bank waren. Wie sollte da in praxi die Bestimmung der Statuten durchgeführt werden, dab die Eigenschaft als Aktionär kein Vorzugsecht gäbe bei der Zulassung zum Diskont, zumal nur ein Mitglied des Verwaltungsats oder zwei Kontokorrentinhaber der Bank das betreffende Verlangen zu unterstiotzen brauchten?

Wirksimeren schutz gewährt den Kolonialhanken eine nene Bestimmung des Gesetzes ron 1901,1) wonach jedler Verwalter der Bank soines Ants rerlustig geht, wenn er seine Weehselverpflichtnngen der Bank gegenüher nicht erfüilt. Ferner darf kein Wechsel oder Schuldschein, den der Direktor der Bank ausgestellt hat, ron (ler Bank zum Diskont zugelassen werden. ${ }^{2}$ )

Schon das Gesagte zeigt, eine wie gefährliche Klippe das Diskontreschäft für die Bank worden kann, wenn der Direktor lokalen und persünlichen Eiuflüssen allzu leicht nachyibt.

Kurze Verfallzeiten sowie die Zahlungsfïhigkeit der Techsel-

1) Statuten 1901 Art. 50).

2) Statuten Art. 45. 
schuldner geben dem Wechselportefenille iluen Wrort. Nun rerlangt Art. 11 der Statuten in bezug auf die Verfallzeit der Wechsel nur, daß sie 120 'age nicht ibersteigt. Das ist aber ein Drittel mehr, als die längste für die Bank ron Frankreich zugelassene Frist (90 'lage) und doppelt so hoch als die durchschnittliche Verfallzeit der von der Bank ron Frankreich diskontierten Weehsel (nämlich 59-60 Tage). ') Die Verfallzeit ist bei den Kolonialbanken also sehr lang, wenn man bedenkt, daß sie diese hredite gewähren mit Geldmitteln, die ihnen auf tägliche Kïndharkeit geliehen sind. Und doch hat es sich im Lanfe der Jahre hrransgestellt, dab selbst diese lange Terfallzeit für die Verhältnisse " der Kolonien noch nicht eimmal genügt, und daß ein großor. 'Teil der Gesuche um Erneuerung der Wechseldiskontierung nach Ablauf der Terfallzeit auf diesen Umstand zmiuckzufïhren ist. Diese Erscheinung erklärt sich daraus, dab die Kolonialbanken keinen Unterschied machen, ob der Präsentierer eines $W^{r}$ echsels ein Kanfmann oder ein Pflanzer ist. (An sich ist eine solche Unterscheidung möglich, da der Terwaltungsuat die Zurückweisung vom Diskont nicht zn begriinden braucht. ${ }^{2}$ ) Und doch ist klar, daß der Pflanzer langfristigen Kredit nötig hat, während dem Kanfmann oft schon mit kurzfistigem Kredit gedient sein kann.

Der Diskont wird erhoben nach der Zahl der Tage, die der Wechsel noch läuft, ja selbst nach einem einzigen 'Tage. ${ }^{3}$ ) Für Nach-sichtwechsel wird der Diskont berechnet nach der Zahl der Tage nach Sicht; nud wemn der Weehsel auferhalb des Diskontierungsortes zahlbar ist, so rermelut sich die Zahl der Tage nach Sicht mm eine nach der Entfernung des Kahlungsorts bemessene, ron dem Verwaltungsrat festzusetzende Frist.

Der Diskontsatz wird rom Verwaltungsiat festgesetzt nach frejem Ermessen. 1874 wollte man die Kolonialbanken zwingen, nicht über den gesetzlichen Landeszinsfuß zu diskontieren. Das wäre eine Unbilligkeit gewesen, da der gesetzliche Zinsful in den verschiedenen in Betracht kommenden Kolonien sehr rer-

1) Léveillé. Parlam. Bericht 1897.

2) Statuten Art. 37.

3) Statuten 1901 Art. 18. 
schieden hoch war. Auch sagte man sich, daß das wohlverstandene Interesse die Banken selbst reramlatsen wiirde. den Diskontsatz soweit herah zu setzen, als es die sicherheit der Bank gestattet, um nur die allerhesten Papiere zum Diskont prïsentiert zu erhalten. Da Kapital und Reserven der Kolonialbanken überdies in dreiprozentigen Rentenbricfen angelegt sind. so haben die Banken es nicht nötig, in einer mißhränchlichen Erhïhung tes Diskontsatzes das Mittel zur Erziehung hoher Dividenden zu suchen.

Terninftigerweise ist die resetzliche Festlegung des Diskontsatzes hisher unterblieben.

Bei ter Finlösma der diskontierten Wechsel an Verfalltage ist die Folonialbank noch hesonders berorzugt. Während Wechelprozesce nath französischem Rechte nur damn ror die Handelscrichte gohören, wem der Wechsel ron einem Kanfmann ansgestellt ist, ${ }^{1}$ ) erklïrt Art. 12 d(u statuten ron 1901, dali Anssteller, Akzeptanten, Indossanten und Aralisten ron Wechseln, the zugunsten der Kolonialbank ansqestellt orler an sie begeben sind, hinsichtlich ilner Wechselverpflichtungen den Handelsgerichten unterworfen sind, ganz gleichgïltio, ob der Aussteller ein Kaufmam ist oder nicht. Auf diese Weise lommt die prozesierende Kolonialbank raseher und billiger zum Ziel.

Wir erwihnten wen, dab jeder Wechsel ein wirkliches Kanfgeschäft rorausetzt. Insofern ist das Diskontgeschäft kein reines I'romakreditgeschäf. sondern ein Geschäft, das durch ein anderes Handelsgeschäft herrorgerufen und garantiert wird. Ein reines (absolutes) Personallireditgeschäft wäre die Diskontierung ron effets de circulation (Kellerwechsehn), die tlen Banken aber rerboten ist. Indessen giht es noch ein Zwischenglied zwischen den Personal- und Reallireditgeschäften. Art. 12 der Kolonialiankstatuten besigt nämlich: ..Ëne ler zwei für Wechsel verlangten Unterschiften kam ersetzt werlen lureh gewisce Bürgschaften": als solehe benennt das Geretz:

1) fïr Platzwechel und nicht handelsmaifige Schuldscheine:

1) Renaml a. a. 9. S. T2 ff. 
a) die Hinterlegung ron titres mobiliers,

b) die Einhändignng eines Warrants oder Lagerscheins,

c) die Abtrotung der Frucht auf dem Felde,

d) die Hinterlegung von gemünztem und ungemünztem Edemetali,

2) für 'Tratten und Anweisungen auf das Ansland oder Frankreich:

ein Fonnossement mit spezicller Verpfändung der Ware,

3) bei Tratten genügt auch cine antizipierte Akzopterklärung des Trassaten gegoniber der Bank.

Uns geht hier nur Fall Nr. 1 an, da wir nur von Platzwechseln gegenwärtig reden.

Wird die zweite Unterschift durch eine der unter Nr.1 aufgezählten Bürgschaften ersetzt, so brauchen Wechsel und Schuldschein nicht an Order zu stehen (wie es an sich rerlangt wird rom Gesetz). ${ }^{1}$ S Sind sie nun Rektapapiere, so kann der Schuldner sich ror dem Verfalltage ron seiner Verbindlichkeit befreien durch Zahlung seiner schuld unter Abzug des Zwischenzinses. Der Wechsel wird damn riekdiskontiert, der Sehuldschein zuriickgegeben, desgleichen das (eventuclle) Pfand. Hier nimmt das Diskontgeschäft die Eormen eines Realkreulitgeschäfts an: aus einem prèt ì intérêt wird ein prot sur gage. Das Diskontgeschäft behält alleldings noch die Eigentiumlichkeit, daß der Diskontgeber einerseits aus den Bürgschaften Befriedigung suchen kann, gleichzeitig aber auch auf Grund seiner persönlichon Forderung gegen die Aussteller des Papiers rorgehen kann. Auch wenn die zweite Unterschrift durch irgend ein Pfand ersetzt wird, bleibt also das Diskontgeschäft ein Geschäft des Personalkredits; es ähnelt aber bereits den Darlehensgeschäften, d. h. den Kreditgeschäften gegen Pfandhingahe so sehr, auch decken sich die Bürgschaften für die zweite Unterschrift im allgemeinen mit den Pfändern, welche die Kolonialbanken bej ihren Darlehensgeschäften annehmen diurfen, dalj es möglich nnd ratsam erscheint, jetzt sofort zur Darstellnng der rerschiedenartigen Darlehensgeschäfte der Kolonialbanken ïherzugehen.

1) S. oben S. 87 . 
2. Sach Art. 10, 3 der Statuten darf die Kóolonialbank zunächst Torschüsse geben:

a) auf Aktien der betreffenden Kolonialbank,

b) auf Rentenbriefe oder

c) auf Werte, welche die Bank ron Frankrejeh als Sicherheit zuläit.

Die Darlehen unter a) wurden den Banken erst $187 t$ erlaubt. Das Gesetz sanktionierte aber nur einen Zustand, der schon lange roiher unter Duldung seitens der Üherwachungskrommission hestanten hatte. Die Überwachungskommission hatte gegen rliese Aktientarlehen nichts einzuwenten gehabt und nur die Höhe der von den Banken auf diese Art gewährten Darlehen beanstandet, da sie hei den Banken der Zuckerkolonien in den 60 er Jahren 1 Million fr. iiberschritten und 1864 in Martinique sogar 2 Millionen fr. = zwei Drittel des Bankkapitals betrugen. 187t wurde daher in Art. 13 der Statuten die Beleihungsgrenze für Aktien anf drei Fünftel des mittleren Werts der während der letzten sechs Monate in der Kolonie stattgehabten Übertragungen festgesetzt und zugleich bestimmt, daß der Betrag der zum Pfande gegehenen Aktien ein Sechstel des Grundkipitals der Bank nicht ïhersteigen dürfe. Beide Bestimmungen waren sehr romniten. Denn der Erwerb eigener Aktien durch die Bank, wie er leicht bei Zahnlungsunfïhigkeit des Schuldners eintrat, ist eine verdeckte Zuriickzahlung des Grundkapitals, also eine Verminderung der Haftsumme für die Bankrerbindlichkeiten, und birgt dadurch große Gefahren für die Bank und ihre Gläubiger. Anf rer anderen Seite waren sehr viele Kunden der Bank auch ihre Alitionäre: sie hatten oft kein tauglicheres Pfandobjekt als ihren Alitienbesitz: und schlieblich war, wenn die Aktien der Bank hoch im Lúrse standen, ein freihändiger Verkanf der verpfündeten Aktien für Rechnung des Schuldners mëglich, welcher die Bank gegen jeden schaden sicherstellte.

Die Kolonialbanken haben zu wiederholten Malen darum ersucht, auch Aktien anderer kolonialer Unternehmungen, z. B. der Compagnie transatlantiıne oder der Zentralzuckerraffinerien, beleihen zu dürfen. Die Üherwachmoskommission hat sich dem 
stets widersetzt mit der Begründung, dab diese Unternohmungen nicht genügend Sieherheit bïten. Das Gesetz von 1901, das im Art. 10, 3 der Statuten den Kolonialbanken gestattet, Vorsehïsse zu geben auf alle Wertpapiere, welche die Bank ron Frankreich als Sicherheit für ihre Torschüsse zulälit, dürfte den Kolonialbanken etwas mehr Freiheit in obigem sinne gebracht haben.

Ist das Risiko der Kolonialbanken boi den Aktiendarlehen nicht zu lengnen, so sind lie Torschüsse anf Rentenbriefe ziemlich gefahrlos. Dies kommt auch dadurch zum Auselrucke, daß Rentenbriefe bis zu vier Fünftel des Werts, den der letzte offiziclle in der Kolonie hekannt gewordene Kurszettel angibt, beliehen werden diurfen, Aktien und die anderen titres moliliers nur bis zu drei Fünftel ilures Kurswerts (Art. 13 der statuten).

3. Wir kommen jetzt zu dem eigenartigsten Darlehensgeschïft der Kolonialbanken : zu den prèts sur cossion de récolte pendante. Zum Verständnis sei auf den Ursprung der Kolonialbanken hingewiesen. Ihr Kapital war in Wirklichkeit dureh die koloniale Landwirtschaft geliefert worden, da die zuriiekbehaltene Entsehäidigungssumme fast nu den Pflanzern zukam, die bislang Sklaven in ihren Pflanzungen besehiiftigt hatten. Es war deshallb der Wille des Gesetzgebers, chaß dic Erriehtung der Kolonialbanken in erster Linie den Pflanzern zugute kïme; neben dem Handelskredit multe dem Agrarkredit ein weites Feld eingeräumt werden. Der Hypothelarkredit war für Handelsbanken, auch für solche ron der Eigenart der Kolonialbanken, absolut ausgesehlossen. Die Darlehen auf Waren haben zwar neben ihrem konmerziellen auch agrarischen Charakter; sie setzen aber einen zu verpfindenden Warenvorrat vorans. Wie sollte jedoch der kreditbediirftige Pflanzer die Ernte vorbereiten, wenn ilm selbst die nötigen Kapitalien fehlten und der Personalkredit in Form des Diskonts für ihn aus persönlichen oder sachlichen Griinden unerreichbar war? Es konnte sich hier nur handeln um eine Form des Realkredits, bei der das Pfand ein jedem landwirtschaftlichen Unternehmer gehörender realer Gegenstand war. Ein solehes Pfandoljekt but sieh dar in der 
Ernte auf dem Felde (récolte pendante). Das Darlehen dient zur Torbereitung der Ernte, also soll die Ernte auch das Pfandobjekt für das Darlehen sein, geradeso, wie das Haus kraft sicherungshypothek haftet für die Forderungen der Bauhandwerker. Das Prinzip ist einlenchtend und klar, die Ausfïhrung bot jedoch zahlreiche Schwierigkeiten theoretischer und pralitischer Natur. Beleihungsobjekt ist nieht die Saat, die emporkeimt, sondern die Frucht auf dem Felde in ihrem Zustande einige Monate ror der Reife. Aber der Samen und die Pflanze wird durch das Einsäen bezw. Eimpflanzen ein Teil des Bodens und wie dieser immobil. Die Frucht anf dem Felde ward von der Grundhypothek mit ergriffen und konnte nach dem code civile, da sie unbeweglich war, nicht Gegenstand eines Pfandrechts sein (das in Frankreich wie in Deutsebland nur an beweglichen sachen möglich ist). Der französische Marineminister, der 1850 in seinem diesetzentwurfe prits sur récolte pendante vorschlug, wollte also nichts Geringeres schaffen als ein Pfandrecht an einer Inmobilie und noch dazu ohne Besitziibertragung. Das mubte den Widersprueh der Juristen in der parlamentarischen hommission herrorrufen. ${ }^{1}$ ) Um ihren Widerstind zu überwinden, genügte merkwürdigerweise eine blobe Änderung der Etikette; die Sache blieb dieselbe: nur hieb es im Entwurfe des neuen Marineministers Chasseloup-Laubat statt prèts sur récolte pendante, nunmelır prèts sur cession de récolte pendante. Das war eine Unklarheit; demn der Pflanzer, nicht die Bank, ist und bleibt Eigentiimer der .abgetretenen" Ennte. Nur gilt die Bank fortan als in den Besitz der Ernte gesetzt. Auch der Wortlaut les Gesetzes: cession de récolte kamn nicht darïber hinwegtïlschen. daß die prèts sur récolte Darlehen auf Pfand, allerdings nicht anf Faustpfand, sind. Durch die Fiktion der Besitzibertragung (., la bamque est considérée comme saisie de la récolte*) waren aher der Code de commerce, der kein privilige sans dessaisissement kannte, und das Bedürfnis der Praxis rersühnt. Es blieb noch die Aufgabe,

1) Denizet a. a. 0. S. $113 \mathrm{ff}$. 
die Rechte der Bank und diejenigen der Hyputheken- und anderen Gläubiger des Bankschuldners zu regelu. Auch hier wurde ein verständiger Mittehwog gefunden.

Der Pflanzer, des hei der Bank eine Anleihs marhen will gegen Abtretung seiner Ernte auf dem Felde, gibt seine Absicht einen Monat rorher der Bank durch schriftliche Erklärung

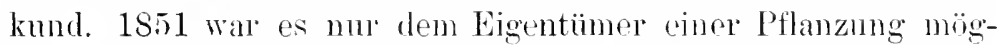
lich, seine Ennte auf dem Felde zu beleihen. Das ciesetz ron 1874 wie das ron 1901 gewïhrt dieses Recht auch dem Päichter, Halbbaner, Mieter von Grundstïcken und Plantagenunternehmer. ${ }^{1}$ ) Wenn die Bank nun einem dieser unmittelharen Besitzer, die nicht zugleich Eigentiimer der Pflanzung sind. ein Erntedarlehen gewährt, so ist es nieht ausgeschossen, lab sie bei Verfolgung ihrer Rechte in Streit gerät mit dem (irundeigentümer, der z. B. für seine Pachtzinsforderung ehenfalls an der Ernte ein gesetzliches Pfandrecht hat. Zur Termeidung eines Konflikts bestimmt das Gesetz im Art. 6, daf jeder der oben genamnten unmittelbaren Besitze der Bank die Zustimmung seines Grundherrn zur Erteilung eines Erntedarlehens an ihn nachweisen muß. Diese Zustimmung ist zusammen mit rlem Darlehensgesuch in ein Spezialbuch einzutragen, das ron dem Vorsteher der indirekten Steuern, nicht rom Hypothekenbuchbeamten, geführt wird.

AuBer dem crundeigentiimer können auch Hypothekengläubiger oder andere Glänbiger, die ein spezialpfandrecht an der Ernte haben, etwa weil sie die Kosten der Ernte rorgeschossen haben, der Bank ins Gehege kommen. Bei Verhust ihrer Rechte sind deshabb alle diese Gläubiger verpflichtet, innerhalh ron einem Monat nach Eintragung des Darlehensgesuchs gegen dessen Bewilligung Widerspruch zu erheben. l)ieser Widerspruch ist in dem Spezialbuche neben dem Darlehensgesuche zu rermerken. Wird innerhalb eines Monats kein Widerspruch erhoben oder der Widerspruch auf Verlangen durch gerichtliche Entscheidung beseitigt, so kann die Bank das

1) „tout fermier, métayer, locataire de terrains ou entrepreneur de plantations". Gesetz 1901 Art. 6. 
erbetene Erntedarlehen gewähren. Die Publizität, welche die Bank gegen die Rechte ihrer Vormämer schützt, gilt auch zum Schutze derjenigen Gläubiger, welche nach der Bank dem Pflanzer ein Darlehen erteilt haben. Deshalb mub die tatsächlich erfolgte Gewaihrung des Erntedarlehens offenkundig festgestellt werden durch Eintragung in das Spezialbuch, die das Gesetz „Zessionsakt" nennt. Erst auf Grund dieses Zessionsaktes entsteht das Pfandrecht an der Ernte.

Tenn die Bank ein Erntedarlehen erteilt hat, bedarf sie der Sicherung gegen den Darlehensschuldner selbst. Dieser kamn z. B. nach Empfang des Dardehens die Pflanzung veruachlïssigen und es unterlassen, rechtzeitig einzuernten oder die zur Ernte nötigen Vorbereitungen zu treffen. Hier darf die Bank sellst an stelle ihres schuldners die Einerntung besorgen oder sich in den Besitz der Pflanzung einweisen lassen zwecks Einerntung and Terarbeitung der Ernteerzeugnisse. Für die hierdureh resursachten Kosten erhält die Bank ein Vorzugspfandrecht an der Ernte oder ihrem Ergemnis.1)

Der schuldner der Bank kann ferner die .ahgetretene" Ernte rerschleudern oder unterschlagen. Gegen eine solche Handlungsweise, die das Gesetz, betreffend die Kolonialbanken, dem Vertrauensbruch gleichstellt, ist die Bank durch Art. 406 des corle pénal geschützt. $\left.{ }^{2}\right)$ Der beste Schutz gegen Entwendung liewt freilich darin, daß in den Zuckerkolonien die Ernteerzeugnisse fast ausschlieblich zum Export bestimmt und in die Hafenplaitze der Kolonie rersandt werden, wo sie leicht wiedergefumden und beschlagnahmt werden können. Auch ohne mala fides können Streitigkeiten zwischen Bank und Erntedarlehensschuldner entstehen äber die im Wege des Kontokorrents gewïhrten Krerlite. Das Gesetz läßt aber ausdrücklich keinen Widersprnch des Schuldners in bezng anf diese Kiredite zu. Die Verweisung der Streitigkeiten über prèts sur récolte ror die Handelsgerichte ${ }^{3}$ ) hat eine rasche und fast kostenlose

\footnotetext{
1) Gesetz 1901 Art. 8.

2) Geselz 1901 Art. 13.

3) Gesetz 1901 Art. 12.
} 
Erledigung des streits zu Fulge. Aneh das erhöht die Sirherheit der Bank.

Die Einerntung nimmt einige Monate in Anspruch. l)ie Bank kann sich nun ausbedingen, dab die Ernte, soweit sie eingebracht ist, sogleich in bestimmte Warenlager gesehafft wird. $\left.{ }^{1}\right)$ Hierdnred reswandelt sich tas Emtedarlehen in ein Warenlombardarlehen. Die Bank hat nunmehr ein geringeres Risiko und darf die dingebrachten Entcerzenguisse fortab böher - nämlich bis zu drei Viertel ihres Werts - belrihen. Werden am Verfalltage die gehorgten summen nicht zurickbezahlt. so kimn die Bank acht Tage nach erhobenem Wechselproteste (bei Wechseln, deren zweite Unterschrift dureh Ahtretung der Ernte auf dem Felde ersetzt ist) oder bei nicht handelsmäbigen schuldscheinen acht Tage nach einer einfachen Zahlungsauffordermg die Ernte oler ihr Ergebuis öfentlieh versteigern lassen, ${ }^{2}$ ) sofern die bank es nicht romicht, sich in den Besitz der Ernte einweisen zu lasien. Ans dem Yersteigerungserlöse wird zunächst die Bank hefriedigt unel zwar ror allen ihren Tormännern, die nicht gültig Widerspruch ephohen haben, und ror allen ihren Tachmännern. Nur die lilänbiger, zu deren fomsten eine Verpfïndung des Bodens noch ror dem Zessionsalite eingetragen ist, gehen der bank rol:

Oft lälit der schuldner den Verfalltag rerstrechen, whe zu zahlen, vielleicht weil die Einerntung noch nicht erfolgt war oder gar noeh nicht erfolgen komnte. Es kamn dann selbst in Interesse der Bank liegen, wegen den sehnldner njeht gleich mit den sehärfsten Mitteln rorzugehen. In Wïrdigung dieser Umstinde hat das diesetz ron 187 .t den Banken gestattet, dhe Verfallzeit der segen Abtretung der Ernte auf einen nicht handelsmäbigen schuldschein sewähton Dulohen zu verlängern. ${ }^{3}$ ) Das war umso notwendiger, als dir Erntedarlehen auf höghstens vier Monate wowährt werden sollten, ${ }^{4}$ )

1) Statuten 1901 Art. I.'.

2) Geselz 1901 Art. 10.

3) Statuten 187' Art. $1 \%$.

4) Statuten 187. Art. 11. 
eine Frist, die stch als durchaus nngenügend erwies für die Bedirinisse der Pflanzer.

Das Znckerohrl) wird in den Antillen ron Steptember. bis Fehruar je nach der Regenzeit gepflanzt und ron Jaumar bis Juni des darauffolgenden Jahres, also nach 16-18 Monatem, geerntet, sorlab fast immer zwei Ernten gleichzeitig anf dem Boden stchen. Die Erntedarlehen werden ron der Bank im Juli bewilligt, aber damn nur zum Teil ausgezalılt zwecks Ankanfs ron Dünger (der im .Juli bei Beginn der Regenperiode nötig wirl) und ron Tieren. sowie zon heparatur und Tenanschaffung der vershiedenen zum Betriebe notwentigen Utensilien. Der Rest les Darlehens wird in Monatsaten ansbezalt von August his Dezember und dient zur Bezahlung der löhne und anderes lanfenter Anstagen. Su erhält ter Pflanzer die Darlohen olne Tumittor. In Juli. wenn die asten Dandehensraten erteilt werden, sind a Zuckerwhe durchechnittlich 7-9 Donate alt. Da ihr voransichtlicher Ertrag sich damn ammïhermel schätzen lïbt, so hiotet die zukiinftige Ernte schon cin reelles l'fand dar und licine rage Zukumftshofnung. Die Bank tut noch ein ïhriges, intem sie wïhend ter ganzen Zeit bis zur Ernte die Fucht anf dem Folde und the Verwendung der monathohen Darlehensaten soitens des schuluhers äberwachen litlit und einschreitet, wenn es nötis wird.

Bein Beginn der Ernte (im Januar) sind seit (rewähung der ersten Torschïse seitens der Bank schon mehr als rier Monate rerflossen! Die Darlehen müssen daher unbedingt ernenert orler rerlingert werten. da sie erst ron Januar bis Juli mit dem Ertrage der Ernte zuröclibuahlt werlen können. Diese Verlängerung ist im Art. 14 der Bamkistatuten rorosehen. Die Erntedarlehensgeschäfte fuihren jährlich in Juni zu einem rölligen Ahschlusse, sis dali das Portefunille ler prets sur récolte in der Bilanz rom 30. Juni meist seinen niedrigsten stand anfweist. Anders liegt alie sache in Réunim. wo lie Regenzeit

1) Xur dieses kommt neten einigen kleinen Cafe- und Tanillekulluren in Rimnion mu Cinadeloupe für die Entedalehen in Betracht. 
von November bis April, nicht wie anf den Antillen ron Juli bis Oktober danert. In Rémion pf'anzt man diher das Znckerrohr ron Oktober bis Januar und erntet ron Juli his Dezember des nächstfolgenden Jahres. Die Junibilanz gibt sonach in Réunion vielleicht den höchsten Bestand an prèts sur rócolte an.

Das Zuckerrohr kommt, sobald es eingeentet ist, in Fahriken, wo es in Feinzncker verwandelt wird. Dieser - weibe - Zncker wird meist nach Frankreich rerladen: in den Kolonicn bleiht nur eine geringe Nenge braunen, d. h. anf technisch unvollkommenere Art raffinierten Zuckers. Der Erntedarlehensschuldner — oft ist er auch Besitzer einer Zuckerraffinerie - händigt der Bank je nach der Menge des nach Frankeich verdadenen weiben Zuckers Tratten auf seinen Terkaufkommiscionair in Frankieich aus, zugleich auch ein Konossement über die Larlung. In cliesem Augenblicke wird das prèt sur lécolte $z u$ einem prèt sur marchandise embarquée. Die Bank verwendet einen Teil der durch die Tratten repräsentierten Geldsumme zur' Tilgung der Darlehensschulel des Pflanzers und gibt ihm den Rest zur Bezahlung der Erntekosten und Löhne für die Schnitter: die zusammen je nach den Znekerpreisen ein Drittel bis ein Halb des Werts der Ernte ausmachen. Sodann sendet die Bank Tratte unl Konosienent ihrem Zentralagenten in Paris, der sie mit seinem visa rersieht und dem Diskontkontor, dem offiziellen Tertreter der Kolonialbanken in Paris, zustellt. Dieses läßt die Tratte von dem Terkaufskommissionär einlösen und händigt ihm dafür das Konossement ein. mittelst dessen der Kommissionär die an ihrem Bestimmungsorte angelangte Ware in Empfang nehmen kamn, um sie damn zu rerkaufen. Das Diskontkontor schreibt die auf die Tratte eingezallte Summe der betreffentlen Kolonialbank gut. Die Tratte tilgt also die schuld des Pflanzers (ganz oder nur zum Teil) und erhihht zugleich das Guthaben der Koloniabank beim Kontor. so rerknïpfen sich prèt sur réeolte mit Warenlombard- und Wechselgeschäft.

Trotz aller sicherheiten und Vorrechte der Kolonialbanken behalten die prèts sur récolte dwch einen sehr spekulativen Charakter. Denn die Ernten in den Zuckerkolonien sind nicht nur 
wie in Europa durch Dïrre, Feuchtigkeit. Hagel, Insektenplage usw. bedroht, sondem auch dureh Erdbeben und durch Orkane von einer Heftigkeit, wie man sie in Europa gar nicht kemnt. Eine Versicherung gegen diese Gefahren ist unmöglich, da Versicherungsgesellschaften in den Kolonien nicht existieren, auch nicht hestehen künnen, weil das Risiko zu groß ist. (Man denke an die Erdbebenklausel unserer europäischen Versicherungsgesclischaften.) Ferner unterliegt der Zuckerpreis von jeher großen Schwankungen, was matiirlich das Ernteergebnis in starkem Maße beeinflulit. Aus beiden Gründen muBte die Beleihungsgrenze für die Ernte auf dem Felle möglichst nindrig angesetzt werden. Da rer resctzgeber annahm, dab dic Darlchen nur auf rier Nomate erteilt würden, hielt er die Bank für himreichend gesichort, wemn er ihr gestattete, die Ernte his zn einem Drittel ihres mutnafichen Wertes zu beteihen. Dahei blicb die Tatsache unberückichtigt, daß die Erntedartehen gewöhnlich erst nach acht Momaten zurückbezahlt werden und dab sich dadurch das Risiko für die Bank betrïichtlich steigert. Um sich gegen die fast unvermedillichen Vorluste hei den Erntedarlehen zu decken, vertangten die Kolonialhanken, daß ilr Pfandrecht anf die nächstjährige Ernte ansgedchnt wïrte, für welche rlas Dartehen zum grolien Teil mit verwendet zu werlen pflegt. Diese Ansidehnng des Pfandrechts bedentet für lie Bank cine Art Tersicherung, eine Ersitzgarantie: sie wïrle die sicherheit der Bank arhöhen, ohne den Schuldner zu schäligen. Üherwachnngskommission und (ivsetzgeher rerhielten sich aber diesem W'unsche gegenüber ablehnend: sie sathen - intigerweise - in der Erstreckung des Pfandrechts auf die nächste Ernte nur eine Verlängerung der Verfallzeit der Darkhensschuld ar infinitum. Sehon der Umstand, daf dureh die Emtertarlehen die Kapitalien der Bank acht Monate festgelegt wurlen, machte lem Gesctzgeber grobe sorge, weil der Bank zu ihren Dartehen nur täglich fällige hapitatien zur Verfügmng stamlen. '/ur Beseitigung dieses Mißrerhültnisses zwischen Aktiv- und Passivgeschïft'n sehłng man schon 1 s. 1 und damn 1901 wieder die Ansgabe hesonderer bons ì moren terme, i. h. langfristiger, eventuell rerzinslicher ohligationen 
oder die Annahme rerzinslicher Depositen seitens (ler Bank vor.') Doch wurde keiner dieser Vol'sehläge 1901 Gesetz.

Die Einrichtung der prèts sur récolte war trotz der ihr anhaftenden Mängel eine erlösende Tat für die Pflanzer der Kolonie. Sie schuf an stelle des bisherigen Bodenkredits cinon rein landwirtschaftlichen Kredit und hat daduch den Kredit in den Kolonien auf eine ganz nene Grundlage gestellt. Busunders seitdem gemäl dem Gesetze ron $187 t$ anch der Pflanzer, der nicht Grundeigentïmer ist, ein Erntedarlehen anfnehmen kamn, ist der ganzen ackerbautreihenden Bevölkerung die Möglichkeit gegeben, sich Realkredit in dem gew ünschton größeren Unfange zu verschaffen.

4. In Warenlombardrenkehr heleiht die Kolonialbank sowohl Import- wie Exportwaren. Die rerpfündete Ware ist entwerler in einem Lagerraum hinterlegt oder auf ein schiff reladen, welches das Gut zum Verkanfe mach Frankreich trägt. Im ersten Falle wird die Ware vertreten durch einen Warrant oder Lagrschein, im zweiten Falle durch ein Konossement. Die Verpfindung des Importware kann also erfolgen lureh Überwahe eines Marlant oder Lagerscheines, bei Exportwaren findot sie statt dureh Übergabe des Komossements. Alle drei Papiere sind Orderpapiere, und dureh regelrechtes Indossament wird das Figentum an der im Papier bezeichneten Ware anf den Indossatar iibertragen. Warant, Lagerschein und lionossement mïssen anf die Bank indossiert sein. $\left.{ }^{2}\right)$ Gewöhntich handelt es sich hier jedoch nur um ein Terpfändungsindossament, das der Bank den juristischen Besitz der Ware verschafft: es kann aber jederzeit durch Veleinharung in ein Übertragungsindossament rerwandelt werden. Die Bank vermag anf den Schuldner in dieser Richtung einen Druck auszü̈ben, da es ihr nach Art. 15 der Statuten freisteht, mangels Zalulung des Schuldners am Verfallage die Ware acht Tage nach Protest oder Zahlungsaufforderung öfentlich versteigern zu lassen.

Der Besitz der Ware seiteus der Bank ist kein wirklicher, sondern ein fiktiver. Denn die Kolonialbanken selbst haben keine

1) Léveillé. Parlam. Bericht 1897.

2) Statuten 1901 Art. 10. 
Räume in denen die Waren hinterlegt werden können. Nach dem resetze, Art. 9. müssen die Importwaren deponiert werden in öffentlichen Magazinen, denen Zollhïuser und andere von dem Gonverneur der Kolonie bozeichete Räume gleichstehen, orler aber in privaten Lagerrämmen, deren Schlïssel der Bank eingohändigt sind. Doch muß die Einhändigung der Schliissel im Augenhlicke dos Abchlnsses des Dartehensvertrages regelrecht festrestellt sein durch Beschhio des Verwaltungsmates der Bank. Unter dieser Bedingung kann aher der Importenr die heliehene Walre and in seinen eigenen Rïumon aufbewahren.

Die öfentlichon Magazine stellon Warrants ans ïber die eingelieferten Waren, lic privaten Lageräume dagegen einen Lagerschein: Das int der wanze Unterschied zwischen Warant und Lagersedein. $\left.{ }^{1}\right)$

IVifl der Exporteur bereits reskaufte Exportwaren beleihen, so händigt er der Bank eine Tratte auf seinen Terkanfskommissionär ein. Die zweite Unterschift wird hier ersetzt entweder durch cine antizipierte Akzepterklärmng des trassaten oder durch ein Konossement unter spezidler Verpfindung der verhdenen Ware das Konossement - bekanntich der Lagerschein des secrerkehrs - wird rom Schiffskapitän ausgestellt und konstatiert die Verladung der Ware).

Tratte und Konossement heißen zusammen: traites docnmentaires.

Die hinterlesten mol rerpfündeten Waren müssen ron der Bank rersichert werten; es genügt aber, wemn sie dureh den Eigentümer hoi einer der Bank genelmen Versicherungsgesellschaft rersichert sind, und die Police der Bank ode: ihrem Tertreter in Enopa eingehändigt ist.")

Die Kommisson von 1850 war dem Warenhomhardgeschäft wenig gïnstig gesinnt. Besondere Bedenken machte sie gegen die Beloihung von Exportwaren geltend wegen der grolien schwierigkeit, die Kohnialprodukte zu verkanfen. Dieser Verkauf konnte damals nur nach dem Mutterlande (Frankrejch) und nur auf

1 Denizet a. a. O. S. $108 \mathrm{fr}$.

2) Statuten 1901 Art. 19. 
lange Frist (i long terme) erfolgen. Wenn man sich 18.51 dennoch entschlof, den kolonialbanken den Warenlombarl frei zu geben, so war in erster Linie maligebent die Erwägmng, daf gerade im Verkehr mit den Ausfuhrommissionären sich der Vtucher in der schlimmsten Form gezeigt hatte und dab nur diese Tarendarlehen jene Art des Wuchers heseitigen wïrden.

Während der" langen Zeit zwischen Gewïhrung und Zurïekzahlung des Darlehens kamn dio Ware grobe Preisschwankungon erfahren. Das reranlalite den Gesetzecher rom 1551 , die Beleihungsgrenze für Waren im Maximum anf zwei Drittel ihres durch Banksachrerstindige festestellten Werts anzusetzen. Diese Jabregel war klug und reptindig. 1570 gablo man Rómions mit der Konkmrenz des Diskontkontors motiviertem Verlangen. don rollen Wert der Ware beleihen zu dürfen, nach und lehnte diese Erlanbuis 1sit auf alle fünf Kolonialbanken aus. Das war ein Fehler, der 1901 wieder wut semacht wurde. Fortan kömen höchstens drei Viertel des Werts der Ware beliehen werilen (Art. 1:) der Statuten).

5. Zu den Waren gehriren in gewiscer Peziehnng anch die Elelmetalle. Wegen ihres besonderen Charaktors (kein Terderb durch Schwund wher Fünhnis. sqüliere Wertheständigkeit usw.) sind sie in den Bankistatuten gesondert behambelt.

Zunächst ist festzustellen, dali nur Gold- und silhersichen als Pfünder für Darlehen der Bank in Betracht kommen, doch können sie in den resschiedenten Formen reppfindet werlen, als Barren. als fremile oler aufer hins gesetzte Inimzen weler als Gegenstïnde irgendwelcher anderer Art (Schmucksachen, Silberzeug usw.). Bis. 1901 wmile bezüglieh der Boleihungsgrenze zwischen frold und Silher kein Untersehied gemacht. Infolge des starken sinkens der silberpreise hesonders seit den 90 er Jahren des rorigen Jah humlerts worde eine Differenzierung immer nütiger, und das Gesetz ron 1901 bestimmte daher, dab Gegenstände ron Gold zu ihrem rollen, mach Feingehalt und Gewicht bemessenen Werte. (iegenstïnde ron silher dagegen höchstens bis zn vier Fünftel ihres Wertes behiehen werden sollten. Das war eine halbe Yabregel, welche der Beleihung des silhers 
ihren aleatorischen Charakter nicht entzog. Jan hätte dies noch hinnehmen können. wenn der Bank wenigstens der Handel mit Silber rerboten worden wäre. Das ist aber anch 1901 trotz der ganz reränderten Verbälnisse des silbermetalls - auffallenderweise - nicht geschehen.

Die Gold- und silberdalehen kirmmen hauptsächlich den Handwerker'n und kleinen Kaufleuten zugute, aber auch allen denen, die ron ihrer Hände Arheit leben. keinen Personalkredit geniehen und nur wenige verpfüulbare Gegenstände haben, deren Besitz sie entbehren kömnen. Damit hängt zusammen, daß diese Darlehen an ihrem Verfalltage meist nicht zurückbezahlt, sondern ernenert werden. was sich darin zeigt, dah der saldo dieser Darlehen:geschiafte in der Junibilanz in der Regel größer ist als die summe aller innerhalb des abgelaufenen Geschäftsjahres gemachten Darlehen segen Hinterlegung ron Gohl- nud Silhergegenständen. Die prèts sur matieres dor ou d'argent nehmen dadurch einen gewissen Sparkassencharakter an, wobei Kapitalien der Bank auf lingere Zeit gegen bestimmten Zins festgelegt werden. Da der Crewinn aus diesen Dallehensgeschiaften recht grob war ob his 6 Prozent) und die Bank dabei infolge rorsichtiger Beleihung ohne berleutendes Risiko hlieb, so hatte die Bank diese Geschifte recht gern. obwohl sie ein fremder Element in den Geschäftsbetrieb der Bank brachten. Immerhin kamen hei dem Edelmetalmangel der meisten Kolonien nur unerhebliche summen hierbei in Frage.

Die chen besprochenen Darlehen leisteten auch den Eingeborenen gute Dienste. Für die Bank war die Annahme ron Schmuckischen. entwerteten Münzen. Silberzeng nsw. als Pfand für Darlehen das beste Mittel. um die gewöhnliche Kundschaft der Tucherer zu sich herüher zn ziehen.

\section{$\leq 7$}

DEE WECHSELOESHÄFTE DER ROLONIALBANKEX.

Trie die Koloniabanken dem Geld- und hreditrerkehr innerhalb der Kolonie dienen. so rermittehn sie anch den Zahlungs- 
verkehr der Kolonie mit dem Auskande oder Frankreich. Diese Tätigkeit der Kolonialhanken ist umso wiehtiger, als die hier' in Frage stebenden Kolonien fast ihre ganze Produktion exportieren und andererseits die Mehrzahl der täglichen Lebensund Unterhaltsmittel nicht selbst produzieren, sondern sie einführen müssen. ${ }^{1}$ )

Das internationale Zahlungsmittel ist bekamntlich der Wechsel. Durch ithn werden Fordermoen im internationalen Handelsrerkehr eingezogen, Schulden getilgt und so Bargeldsendungen erspart. Wer ins Ausland zahlen will, wird sehwerlich jemanden im Auslande finden, der sein Schuldner ist und ihm genau die Summe sehuldet, die er ins Ausland zu zahlen hat. Hier greift die Bank ein, indem sie ihren Kunden zu jedem Creldbetrage Tratten oder Anweismugen anf Frankreich oder das Ausland liefert, mittelst deren die Zahlung dorthin bewirkt werden kann. Diese Tratten und Anweisungen kann die Bank erwerben wie die Platzwechsel im Wege des Diskonts oder durch Kauf al pari oder gar gegen eine Prämie. Der häıfigste Fall ist aber der, dab die Bank selbst Tratten und Anweisumgen ausstellt. Die Anweisung unterscheidet sich ron der Tratte dadureh, daß sie nicht akzeptfähig ist: sie ist gleiehsam ein Scheck der Kolonialbank, ausgestellt auf ein Bankinstitut im Ausland oder Frankreich. Da die Banken ihren Sitz nicht in Frankreich haben, berlürfen sie für ihre Wechselgeschäfte eines Vertreters in Frankreich. Als iln Vertreter fungiert zur Zeit das Nationale Diskontkontor in Paris. Die Geschäfte, die das Kontor für die Kolonialbanken besorgt, sind zweifacher Art, ${ }^{2}$ ) entweder 1.) Einziehung von Forderungen oder 2.) Bezahlung ron Schulden der Kolonialbanken.

Ad No. 1 gehören die auf die Kolonialbanken ausgestellten oder indossierten Wechsel und Anweisungen, die in Frankreich oder im Auslande zahlbar sind. Sie werden an Order des Diskontkontors gesteilt und den Zentralagenten zugesandt, der Akzept oder Protest maugels Annahme besorgt und sie dann

1) Isaak. Parlan. Bericht 1898.

2) Renaud a. a. O. S. $110 \mathrm{ff}$. 
dem hontor einhändigt. Solten diese Wechsel am Verfalltage nicht eingelöst werden, so wird las Indossament zugunsten des Kontor's ausgestrichen und der Wechsel dem Zentralagenten zuritckegeben zwecks serichticher odor anbergerichtlicher foltendmachung der Forderung.

Zn Yo. 2 sind zu zïhlen die Thatten und Anweisungen. welehe ron den Kolonialhanken anf las Diskontkontor in Paris rezogen werden. Sie werlen heim Zentralagenten eingereicht. ron disem mit seinem visa rersehen und damn dem Kontor zur Zahlumg pü̈sentiert. Doch muf das Kontor zehn Tage ror dem Terfallage henachichtigt werden.

Schon ans dem Gesagten erhellt. dab der Zentralagent eine rein remittelnde Rolle hat: ${ }^{1}$ ) er selhst daf werler Einzahlungen ammelmen, noch dusahlungen bewirken, noch irgend welche summen, dif den liolonialbanken gehören, zmüclibehalten. Die Geschifte der Kolonialhanken kommen deshalh klan und rollstänligr zum Aushock in den Kontokorent, das jede Kolonialhank mit dem Diskontkontor unterhält. Jeder Bank ist rom Kontor ein Kredit eröfnet. dessen Maximalhöle sich bemiBt nach lem Werte der Rentenlniefe, die ron den Banken beim Kontor als Pfand hinterlegt sind. $\left.{ }^{2}\right)$ Das Kontokorrent heim Kontor enthält ant der líreditseite die Zinsen der hinterlegten Rentenbricfe, ferner die Tratten, die der Zentralagent dem Kontor zur Einzielung oder zur Diskontierung zugestellt hat. und schlieblich die Summen unl Werte, wohe direkt dirch die Koloniabank oder dum Dritte zugunsten der Rank beim Kontor eingezahlt sink. Das Debet des Kontokorrents setzt sich zusammen aus den anf das Kontor ron der Kulonialbank ansgestellten Tratteu und Anweismgen, sodamn ats den anf lie sogenamten actions d'Europe ansgezahlten Dividenden und aus sonstigen Zahlumgen, die das Kontur im Anftrage der Bank gemacht hat. Der wechselseitig zu rergitende Kontokorrentzins hetright hei einem salih zugunster des kontors ein Prozent mehr als der jeweilige

1) Tergl. Renand a. a. O. S. 112.

2) Der Kredit der Bank ron Réunion ist kraft ministerieller Verordnung auf 1,8 Milliomen fr. begrenzt. 
Diskontsatz der Bank ron Frankieich, aber nie mehr als sioben Prozent. Bei einem Sahlo zugunsten der Kolonialbank ist ihr ein Kontokorentzins zu rergüten, der ein l'rozent niedriger ist als dem jeweiligen Diskontsatze der Bank ron Frankreieh entsprechen wïrde, doch nie mehr als fünf P'rozent. AuBer dem erentuellen Kontukorrentzins erhebt das Kontor noch eine besondere Provision für jedr der ron ihr bzahlten Anweisungen. Dafïr besorgt es die Einziehung ron Furderungen der kolonialbanken umsonst. ${ }^{1}$ )

Dem Diskontkonten ist es ausdrïcklich verboten, Noten der Kolonialhanken in Zilhung zu nehmen, da ilur Notenumbanf rein lokal bleiben soll.

Alle Geschäfte zwisehen den Koloniabbanken und dem Diskontkontor miissen rermittclt werden durch den Zentralagenten. Damit wird das Ziel erreieht, las hei der Schaffung der Zentralstelle lureh Dekret rom 17. 11. 1s52 ins Auge gefaft war: Die Tiitigkeit der Kolonialbanken in bezug auf ihre Geschäfte in Enropa zu zentralisieren, mon dadurch die Ansïbung der Kontrolle. die der Überwachunskommission der Folonialbanken anvertraut ist. zu ermöglichen. Sehlieblich ist noch durch Dekret rom 9. 6. 04 bei dem Zentralagenten in Paris cin Regierungskommissar hestellt worden, der periorisch dem französischen Kolonialminister Bericht erstatten soll ïher die Geschïfte, welche die Zentralstelle im Auftrage der Kolonialhanken ansgefuilut hat.

Dep Zentralagent und der eben erwahnte Regierungskommissar werden rom folonialminister ernannt; inr Gehalt ebenso wie ihre Auslagen werden ron den Koloniabanken gemeinsam getragen und zwar im Verhältuis ihres Grundkapitals.

Die Koloniabanken. die anf das Kontor Anweisungen und Tratten ausstellen, nehmen darlurch den Krerlit des Kontors in Anspruch. Je gröher ihre Ziehnngen auf das Kontor sind, desto höher wächst ihr solde dábitem heim Kontor. Wegen des Kontokorrentzinses liegt es aber in eigenen Interesse der Koloniabanken, ihren solde dúbitem möglichst zu vermindern und

i) Renaud S. 114/115. 
ihn eventuell durch einen solde créditeur zu ersetzen. Die Banken müssen also für hinreichend Rimessen Sorge tragen. Die ganze Tätigkeit der Kolonialbanken im Wechselgescluäftsrerkehr konzentriert sich somit auf die Ausgabe ron Anweisungen oder Tratten und auf die Beschalfung von Rimessen.

Die Ausgabe ron Anweisungen und Tratten sind anf seiten der Bank cin Terkanf eines Teils des Kredits, den sie in Paris hat, ein Geschïft, las ihr Geldkapitalien in die Kassen bringt und bei dem sie eine melır oder weniger hohe Prämie erhebt. Dureh Kanf oder Diskontierung ron Tratten zu Rimessezwecken rerschafft sich umgekehrt die Bank den Kíredit des Trassanten. Der Erwerb ron Rimessen ist also für sie ein Aktivgeschäft, eine Kapitalanlage, die sich auf der Kreditseite ihres Kontos beim Kontor zeigen soll. ${ }^{1}$ )

Fïr den Importenr sind die Anweisungen auf das liontor ein Nittel, nm seinen Import, d. h. seine Schuld ans Ausland, zu bezahlen. Der Exportem erhält durch Verkauf oder Diskontierung ron Anshomwechseln an die Bank den Gegenwert seiner Trare in Geld, d. h. ihren Preis.

Es lenchtet ein. daß, wenn die Bank einen Gewimn ans ihren Trechselgeschäften erzielen will, sie ihre Anweisungen und Tratten zu einem Preise abgehen muB, der löher ist als ihr Ankaufs- oder Selbstkostenpreis. Tatsüehlich hat auch die Prämie für Anweisungen und Tratten die ron der Bank für den gleichen Betrag in Rimessen gezahlte Ankanfsprämie stets um mindestens ein Prozent uberstiegen. ${ }^{2}$ ) Diese Ankaufsprämie für Rimessen der Bank war verschieden hoch. je nachdem ein Rimessenmangel orler Rimessenüberschun bestand, d. h. je machdem der Import oder der Export überwog. In den Zuckerkolonien richtete sich das nach dem Ausfall der Zuckerernten. Anders lagen die Terhälnisse in Gurane und sénégal. In Guyane fehlte jerle landwirtschaftliche Täitigkeit und damit der Export ron Lebensmittehn. An dessen stelle dienten die Sendungen rom Rohgold, das in Guyane gefunden wurde, dazu, den Import der

1) Denizet a. a. 9. S. 137.

2) Vergl. die jährlichen Berichte der Ü. Ko. 
Kolonie zu saldieren. Die Goldsendungen gestatteten es dem Handel, Anweisungen und Tratten auf Frankreieh zn ziehen, so dab die Bank ron Gnyane neben den enrois d'or natif anch einige Handelstratten zu Rimescezweeken henutzen konnte. In Sénégal gab es keine Goldlagernngen, lie wie in Guyane zu einer Goldausfuhr bätten Anlaf geben können, und die auf Grund der dortigen Arachilenernte geschaffenen traites documentaires blieben meist in der Hand der Handelshäuser, die den Plantagenhau dort monopolisiert hatten. Der fast röllige Mangel an Handelstratten zwang die Bank ron Sombal zweeks Doekung der ron ihr ausgegebenen Anweisungen zu den 'Tratten res kolonialen Schatzamts auf Frankreich ihre Zuflucht zu nehmen. Dies hatte zur Folge, daß besonders in den ersten zwanzig Jahren seit Bestehen der Bank amision und remise bei iln annähernd gleich waren, d. h. die Bank gab nur sowiel Jratten und Anweisungen ab, als sie Schatzanweisungen erhielt. Aher dic Ansgabe ron Tratten und Anweisung stand nicht anz im Beliehen der Bank. Trem es ilır num nicht selang. diese Schatzanweisumgen in genügendem Ialie zn erhalten, so schlob ihr Konto beim Kontor mit cinem starken sulde débitenr. Dieser erhöhte wiederum den Preis der Anweismaen nnd Tratten, wolche die Koloniabank anf Frankeich ansitellte. d. h. der Wrehselkurs stieg. Hiermit sind wir zur Frage des Wechselkurses gelangt. Der Wechselkurs steht auf pari. Wenu die Wechsel anis Ansland gehandelt werden zn ihrem Nominalwerte, ansgedrïickt in dem Mïnzpari der fremden Münze. Zwischen zwei Lündern mit demselben Wïhrmgsmetall schwankt der. Wechselkurs nur wenig um das Münzpari innerlalb der beiden Coldpunkte. Der Wechselkurs in diesem Sinne, aufgrefaßt als das Verhältnis zweier Währungen zueinander, kann nur daun gröheren Schwankungen unterworfen sein, wenn die Wïhrung des einen Landes der Währung des anderen gegenüber sich entwertet oder im Werte steigt. Dieser Fall tritt ein zwischen Gold- und silberwïhrungsländern bei Entwertmong des Silhers. Dasselhe geschieht anch zwischen Papierwihrungsländern einerseits und Metallwährungsländern andererseits. 
Cnter Wechselkurs wird mun in der französischen Literatur, ${ }^{1}$ ) aher auch ron dentichen sichriftstellem, ganz allgemein der Preis rerstanden, oder²) die Prämie, die für Wechsel anf das Ansland gezahlt wird. In diesem weiteren Wortsinne werden wir hinfort den Wechselkurs rerstehen. Der Wechselkurs ist dann nicht nur durch die Landeswährung und ihr Terhäłtnis zu den fremden Währmngen, sondern ror allem noch durch die Zahlungsbilanz des Landes und in geringerem Mabe durch den Fillighoitstermin beeinfluft. Lm den letzten l'unkt forweg zu nehmen. so ist kiar, dab oin Anslandswechsel, zahlhar Bo Tage nach sicht. höher in Preise steht als ein Wechsel ron gleichem Geldbetrage der anf 90 Tage nach sicht anseestellt ist. Aber die Verfallzeit ist für den Wechselkus nur dann ron einiger Bedentung. Wenn Zahlunshilanz und Landeswährung in ihren Wirkmoen auf den Wechelkurs ansqeschaltet sind. Das war abes in den franziiveden holonien ganz selten der Fall. Zwei Male 15.5 hei der Auberkuscetzung der fremrten. hislang umdaufenden Mïnzen. und lot bei Anshruch einer Zuckerkrise. wurde w in len Antillen notwendig. Kiscenscheine mit Zwangskurs auzugeben. Da das Metallged infolge der Terendungen zu Rimessezwecken anfer Landes getroben wall. bestand der freldumlanf der holonie damals nur ans hasenscheinen des kolunialen Schatzants und ans Xoten der Bank, die gegen Kassenscheine einliobar waren and zulem nur in der holonie gesetzliche Zahlungskaft hatten. In len Antillen herrsehte tatsïehlieh für cine Zeit lang Palperwähung. Der Wechelkurs. der vorher fest war. kannte num licine direnzen mehr. obwohl Frankieich und seine Kolonien nominell dissedbe Wiahungsostem hatten. Eine gimstige Zahlungshilanz stellte damals das rileichwewicht allmählich wieder hor. Ganz schlinm wude es nur da. wo zu dem entwerteten belle oine ungüntige Zahlungsbilanz rerschärfend hinzutrat. Cnter sulchen Lmstïnden stieg der Wechselkurs in Cinadelompe anf io Prozent. ${ }^{3}$ (l. h. ein Wechel auf

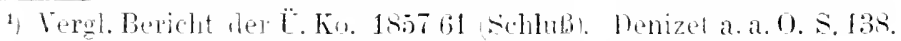

2) wenn man die französiscle kursnotiemng ins duge fabt.

i) Renaud a. a. (). . $11 \%$. 
Frankreich kostete einhalh mal mehr als soin Nominalwert betrug. Das einzige Mittel gegen einen solehen Übelstam ist rine Einschränkung des Imports, dic eine Verbesserming der Handelsund Zahlungsbilanz zur Folge hat und den Papierumlauf beseitigen hilft, indem sie wieder Metallgeld ins hand strömen lïßt.

Eine Regelung der Wechselkurse wurde 1879 durch die Bank von Réunion rersucht: der Vesuch miblang aher. Auber der Bank yōn Rémnion trieben noch andere Handelshäuse's und Banken Handel mit Wechseln anfs Ausland, so daf die Bank ron Rémion den Weehselmarkt nicht beherrschen konnte. Zndem verfügte die Bank nicht entfernt ïber die Jittel, die cine solche Regelung der auswiirtigen Wechselkurse erfordert hätte.

Der Untersuchung welt ist auch die Frage. wam die Wechselgeschäfte für dir Bank Gewim, wann Verlust hedenten.

Da den Einnahmen ans den Weehselgeschäften anch L'nkosten gegenüberstehen, so ist die Voraussetzung für einen liewinn der Kolonialbanken am Wechselgesehäft, dab es der Bank gelingt, ihre Anweisungen und Tratten mit etwa cinem Prozent Terdienst abzusetzen. Daneben ist natülich ein RimessenüberschuB das Erstrebenswerteste. Aher anch das Gegenteil, ein Überschuß der Anweismngen über die Pimessen, ist nicht not-

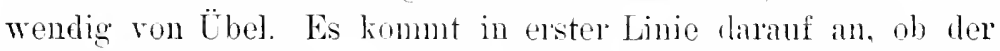
durch die Ausgabe ron Anweisungen der Kolonie gewähnte Kredit produktiver oder unproduktiver Art ist, ob er die Ausgaben vermehrt, ohne die Eimnahmen zu erhöhen. In diesem Falle können dic Wechselgeschäfte in ihrem Endergehnis ein Defizit für die Bank bedeuten, selbst wenn die Rimessen den Wert der Anweisungen decken oder gar um einges ibbersteigen. Denn ein unproduktiver Kredit vermeht nur den Import der Folonie, verschicbt die Handelsbilanz zumgunsten ihres Exports und bereitet eine Verschuldung der Kolonic ror, die schlieflich einen Rimessenmangel herbeiführt und damit das Gleichgewicht zwischen émission und remise stirit. 


\section{Dritter Abschnitt.}

\section{DIE TÄTIGKEIT DER KOLONIALBANKEN.}

Wir haben bisher die innere Struktur der Kolonialbanken und ihren Geschäftskreis gesehildert, also den Rahmen gegeben, in dem sich die Tätigkeit der Bank entfalten soll. Ihren rollen Inhalt erhalten die Bestimmungen des Kolonialbankgesetzes erst durch die Tätigkeit der Kolonialbanken selbst. Beror wir auf diese eingehen, wird es gut sein, wns noch kurz zu rergegenwärtigen, welche Anfgahen die Kolonialbanken zu erfüllen hatten.

\section{Kapitel.}

\section{s. 8 . \\ IHRE AUFGABEN.}

Zur Zeit der Gründung der Kolnnialhanken befand sich das Geldwesen der französischen Kolonien in gründlicher Unordnmng. An Metallgelı! zinkulierten französische Münzen, danehen noch koloniale scheidomiunzen, ferner fremrle Hünzen (spanische Piaster, brasilianische Milreis), an papierenen Feldzeiehen zab es Papiergold, das dir französische Juliregiemng ron 1830 ausgegeben hatte, dann die $18 t 9$ ansgegebenen Kassenscheine und in Rimion auch Soten des liquidierten Diskontkontors. Es galt nun, in den Kolonien die Geldeinheit mit Frankreich herzustellen, zugleieh aber den koloniaten cielilumlauf dem stark wechselnden (ieldhedarf der Kolonien anzupassen: Beides solte durch die Ausgabe ron Noten der Kolonialbanken meicht werden. Da die Noten gesetzliche Zahlungskraft hahen, konnten sie die cinzuziehenden (ieddwertzeichen im Umlanf ersetzen: da sie nicht wie dio Kassenscheine roll metallisch gedeckt sein müssen, hat dic Bank in der Notenansgabe ein Mittel, den Celdumlanf je nach Bedarf zn rermehren oder zu vermindern. Der rasche unt jühe Wechsel der honjunkturen stellte den Kolonialbanken die Aufgabe, die C̈bergïnge zwischen guten und 
sehlechten Erntejahren zu mildern, in guten Jahren den spartrieb anzuregen und die Gründung nener Kulturen zu fördem, in sehlechten Jahren aber dureh prorlulitive Kredite len Hilfsbediurtigen unter die Arme zu greifen, der spekulation dagegen die Kredite zu relkürzen. Die Kolonialbanken sollten auf Vermehrung des Exports sowie anf weise Beschränkming des Imports hinwirken und darlureh die Handels- und Kahhongshilanz del Kolonien regulieren. Der Erhaltung des Mïnzrorrates der Lolonien zu dienen, waren dic von den Kolonialhanken auf Fankreieh und das Ausland auszustellenden Tratten und Anweismegen hestimmt: denn sie bedeuten für den AuRenhandel der Kolonie disselhe, was die Yoten für den imneren Handelsverkehr sind: ein nenes \%ahlungsmittel, das Bargeldsendungen erspart. Dje bohen Wechselkurse waren zu beseitigen, der Leibzins zu ermäbigen $1 \mathrm{~m}$ ror allem war Stetigkeit in den Goh- und Kroditverkehr der Kolonien zu bringen. Hierin lag für die Koloniatbanken eine ihn schwierigsten Anfgaben, weil die Interesson der Bank mit denen der Kolonie in Konflikt geraten komnten. (iesetzt den fall, die Lage der Kolonie rerlange eine Heratsetzmng des Leihzinsfubes und Erweiterung der Kredite, die richerheit der Bank aber eine Erhöhung des Leihzinsfubes und Einschräinlung der Kredite. Gäbe die Kolonialhank untur solehen Lmstänten den IV ünsehen der Kolonie nach, so erfülte sie zwall nur die ihr bej ihrer Grijndung gesetzte Aufgahe: dem Handel dei Kolonie dureh Wechseldiskontierung, der Landwirtsohaft dureh Darlehen die Iittel zu gewïhren, weiter zu lehen und sich gedeihlich fort zu entwickeh. Die Bank selbst aber käme lahei in grole (iefahr. Bei der späteren Wiudienng der Tätigkeit der Kolmialbanken wird deshalb zu unterscheiden sein zwischen ihren Wirkungen auf die Kolonie und den Ergehnissen für die Aktionäre der Bank. Beides fällt durehaus nieht zusimmon.

Nun zur Taitigkeit der Kolonialbanken solbst. 


\section{Kapitel.}

\section{DIE ÄUSSERE ENTWICKELUNG DER KOLONIALBANKEX.}

Die 3 Banken der Znckerkolonien öfneten ihre Schalter 1853, die Banken von Guyane und Sénégal erst 1855. Diese verspätete Errichtung hatte in Fuyane üble Folgen. Während die Banken der Antillen und die Bank von Rémion noeh rechtzeitig genug errichtet wurden, um len Inut der fast rerzweifelten Pflanzer nen zn beleben, kam die Gründung der Bank ron Guyane eigentlieh sehon zu spät. Die cinst blïhende Landwirtsehaft Guyanes war bereits rernichtet; die in ihr besehäftigten Pflanzer hatten sich einer anderen Beschiiftigung, dem Goldsuchen, zugewandt. ${ }^{1}$ ) Erst in neuster Zeit macht sich ein Umschwung. bemerkbar. Jedenfalls führt der Bericht der Überwachungskommisrion über das Geschäftojahr $1898 / 99 \mathrm{zum}$ ersten Male die Trarenlombardartehen als selbständigen Posten auf (bislang waren sie mit den Aktiendarlehen zusammen angegeben worden). Die Warenlombardiarlehen der Bank von Guyane betrugen:

$$
\begin{aligned}
& 189899 .+. \quad .16742 \text { fr. } \\
& 1902 / 03 . .5 .5131 \ldots \\
& 190304 \text {. . . . . } 160820 \text {.. } \\
& 190+05 . .+.137300,
\end{aligned}
$$

Es ist demnach eine ganz bedentende Zunahme dieser Agrarkeditgesclaifte zu rerzeichnen.

Nach diesem Exkurse zuriick zu den ersten Entwicklungsjahren der Kolonialhanken. Da ihr Kapital durch Apports ron Rentenhriefen und nicht durch Bareinzahlungen gebildet war, fehlte ihnen gleich zu Anfing der zur Geschiftstïtigkeit benötigte Metallgeldvorrat. Sie mubten ihn sich erst verschaffen durch Verpfündung eines Teils ihrer Rentenbriefe an die Bank von Frankreich sowie an die Caisse de dépots et consignations zu l'aris, die den Kolonialbanken dafür einen mit $t^{0}, 0$ zu verzinsenden Kontokorrentkredit äoffneten. Das Bedürfnis nach franzïsischen Jïnzen wurle sehr stark, als 15.55 in den Antillen

1) Léveilli. 2. park. Bericht 1898. 
die fremden Münzen außer Ĺurs gesetzt wurden. Die darlurch hervorgerufene Geldkrise und eine gleichzeitig aushrechende Zuckerkrise veranlaßten 1855/58 die Banken rom Martinique und Sénégal, einen 'Teil ihrer Rentenbriefe zu verkafuen. Die Bank von Sénégal mußte sogar 1862 den letzten Teil ihrer Rentenbriefe im Werte ron 94461 fr. rerkanfen, hatte ladurch aber den Vorteil, ihren Yotenumlauf und damit auch ihre Diskont- und Darlehensgeschäfte um den dreifachen Betrag dre obigen Summe rermehren zu können. Bei einem Grundkapital von nur $230000 \mathrm{fr}$. war das sehr wichtig.

Die Verpfändung und Veräußerung der Rentenhriefe war nur nötig geworden, weil die Bank ron Frankreich nun die Caisse de dépots et consignations, welche anfings die V'ertreter der Kolonialbanken in Frankreich waren, nur wegen Deckung Kredit gewïhrten. $\left.{ }^{1}\right)$ Das hatte auch cine ziemliche Beschränkung des jeder Kolonialbank gew ïhrten Kredits zur Folge gehabt, weil die Rentenbriefe der Banken ja nu bis zu ${ }^{4} / 5$ ihres Werts beliehen werden durften. Ein Wandel trat hierin erst 1860 ein, als unter Vermittlung des franzïsischen Marineministersz) zwischen den Kolonialbanken und dem Diskontkontor in Paris ein Vurtrag geschlossen wurde, wonach das Kontor den Banken ron Martinique und Réunion einen Kredit ron je 4 Millionen fr., der Bank von Guadeloupe einen solchen ron o Millionen fl. und der Bank ron Guyane einen Liredit ron 400000 fr. eriffnete. ${ }^{3}$ )

\section{s 10 .}

\section{DIE KOLONIALBANKEN IN DEN ZUCKERKOLONIEX.}

Die Entwickelung der Kolonialbanken in den Zuckerkolonien ging raseh von statten. Ton den gesamten 1553 und 185 t gemachten Vorsehüssen, die anfangs fast ansschlieblich in Form ron Diskonts erfolgten (nämlich 14,5 Millionen fr. in Martinipue 9,7 Millionen fr. in Guadeloupe und 16,3 Millionen fr. in Rémom), blieb kein Wechsel oder Schuldschein am Verfalltage unein-

1) Renaud a. a. O. S. 112.

2) Der bis 1893 zugleich auch Kolonialminister war.

3) Denizet a. a. O. S. 170. 
gelöst. Anch die Wechselgeschäfte erlangten bald Bedeutung. Die Banken ron Martinigue und Guarleloupe gaben 1853 und $185 t$ für 5 bezw. 6 Millionen fir. Anweisungeu auf die Bank von Frankreich aus, die Bank von Rínnion nur für 1,4 Millimen fr:: aber sie sandte diese Anweisungen als Rimesse nach Indien zwecks Bezahlung der Einfuhr von indischen Arbeitern und indischem Rois. $\left.{ }^{1}\right)$ Dadurch wurde fortan die Ausfuhr ron Metallgeld, mit dem Réunion bislang aus Mangel an seeigneten Exportartikeh nach Indien seine iudische Einfuhr hezahlt hatte. iblerflüssig gemacht und der Geldumlanf der hoInnie sidher gestedlt.

Die Entedarlehen, ron denen der Cresetzeber 1851 im C̈berswang gesagt hatte: cest tonte ha banque colomiale entwichelten sich nur langsam, am giunstigsten noch in Guadeloupe, wo die Tandwirtschaft durch die sklavenhefreiung schwerer heimgencht war ak in don anderen beiden Zuckertolunien. ${ }^{2}$ )

Jie Kontokorrents erreichten 185859 in Martinique 32 Millionen franes und in Guadelonpe $4 t$ Millionen franes. In Rimnion blinb der Kontekorrentrerkehr vorest minimal. Die homtonorrenteinzahlungen betrugen dort bis 1 s66 jählich nicht $m e \cdot 1 \mathrm{r}$ als $200000 \mathrm{fr}$.

the aufsteigende Entwieklung der Kolonialbanken wurde

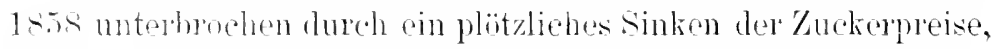
dem ein Rimrsenmangel nud eine cieldlirise in den Kolonien anf dem Fube folgten. Die Banken muliten sich Bargeld von Frankroich sendru lassen und sahen dalurch ihre Schnld an die Bank rom Frankreich beträehtlich erhëht. Wähend nun die Bank ron liémion klugerweise den Diskont erlühte und ihre Liedite einschuänkte, rermehrte die Bank ron Martinique ihre

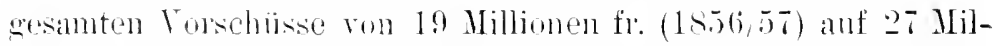
lionen fr. (1s.7, 5s). Viele Wechsel und schuldscheine blieben datauf hin am Verfallage unbezahlt; erst anf das Einschreiten der Überwachnngsommission hin nahm tie Bank die notwemlige Erhöhmng ihres Diskonts ron 6 anf 8 , ja $10^{\circ}$ o vor. Der Wechsdkurs stieg in Martinicue auf 15 bis $18 \%$, in Cinade-

1) Bericht der (U. Ko. 1853/5\%.

* Denizet a. a. 0. S. 167. 
loupe auf 15 bis $16 \%$, sank aber 1860 , als die Krise aufgenört hatte, wieder auf $20 \%$.

Der Krise von 1858 folgte eine glänzencle l'eriode ron 1859 bis 1863. Die Zuckerprorluktion in Rúunion erreichte mit is Millionen Kilogramm ihren Höhepunkt. Eine Übertreibung der Kreditgeschäfte durch die Banken von Martinirue und Guadeloupe und ein sinken der Zuckerpreise führten eine Krisenperiode ron 1863 bis 1869 ) herbei. Die Anlienstände der Bank von Guadeloupe stiegen anf 1,t Millionen fr. infolge Konkurses von 12 Handelshäusern, die seit Jahren fast ${ }^{3} 3$ aller von der Bank gewährten Vorschüsse in Anspruch genommen hatten. Die ganze Reserve der Bank, whehe schon 1 Millionen fr. erreicht hatte, wurde dureh Verluste aufgezehrt, und 2 Jahre lang konnte keine Dividende verteilt werden.

Réunion wurde um dieselbe \%eit durch anhaltende Därre, durch Blattkrankheiten und Insektenplage lieimgesucht. Die Wirkung auf die Geschäfte ter dortigen Bank blieb nicht aus: die Gesamtrorschüsse der Bank ron Réminn, die 1stil noch 26 Millionen fr. hetrugen, gingen anf y Millionen fr. im Jahre $1869 / 70$ zurück.

Die Bank vou Martinique erholte sich raseher als direjenige ron Ghadeloupe von den dureh Aubenstänte in Betrage ron mehr als $1 / 2$ Villionen fr. erlittenen Verhusten. Lhre Reserve erreichte 1868 das gesetzliche Maximum ron 1,5 Millinnen fr. und wurde in Rentenluriefen angelegt. Da die früher veräuberten, das Kapital der Bank reprïsentierenden Rentenbriefe unterdessen wieder angekauft waren, besaf die Bank ron Martinique 1873 (30. VI.) 4,5 Millionen fr. Rentenbriefe.

Nit dem Jahre 1870 begann eine ernente Aufwärtsbewogung in den Geschäftsziffern der Kolonialbanken, die sich bis $188: 3$ erstreckte. Die Gesamtzahl der produktiven Gesehäftel) der 3 Kolonialbanken zeigt 1882/83 eine Höhe, die seitdem nie wieder

\begin{tabular}{|c|c|c|c|c|}
\hline 1) Jahe $18 x$ & & Martinique & Guadeloupe & Rémnion \\
\hline Diskont-u. Darleh & isgeschäfte & 27.1 Mill. fr. & 17.8 Mill. fr. & 23.2 Mill, fr. \\
\hline Wechselgeschäfte & $. \quad . \quad$. & $33,1 \quad ., \quad$, & $38,2 \quad \ldots \quad$. & $18.9 \quad . . \quad$. \\
\hline
\end{tabular}


erreicht ist. Anch die Kontokorrentziffern ${ }^{1}$ ) des Gesehäftsjahıes 1ss? 43 bedenten einen Höhepunkt, wenn man die Bank von Réunion ausnimmt. Das war nur möglich bei sehr günstigen Konjunkturen. Der Zuckerpreis hielt sieh damals zwischen 60 bis $65 \mathrm{fr}$. pro Doppelzentner, und die Zuekerproduktion betrug in Martinique 50 Millionen Kilogramm, in Guadelonpe 50 bis 60 Millionen Kilogramm und in Réunion sogar 70 Millionen Kilugramm. ${ }^{2}$ ) Welel enormen unmittelbaren Einfluß die wechselnden Wirtsehaftskonjunkturen auf das Gesehäftsergebnis und dip Diridenden der :3 Kolonialbanken ausübten, möge nachfolgende Gegenüberstellung reranschauliehen.

Es wurten durchschnittlieh als Dividende verteilt: ron den Banken in den Jahren $\mathbf{1 8 5} \mathbf{7} \mathbf{7 0}$, hingegen $\mathbf{1 8 7 0 8 3}$

$$
\begin{aligned}
& \text { ron Martinique. . . 9.32\% \% } 15,34 \% \text {, } \\
& \text {.. cinadelnupe. . . } 7,19 \% \\
& \text { " Rémuion . . . } 8.57 \%
\end{aligned}
$$

d. h. in der 2. Periode durchschnittlich ca. $6 \%$ meln als in der ersten. Die Tabelle zeigt einen bedeutenden Untersehied zwischen dem Ergebnis einer anhaltend gïnstigen Periode (1860-1883) und demjenigen einer gleich langen, aber ron hrisen unterbrochenen Wirtsehaftsperiode (1857-1870).

lost setzte unvermittelt eine Zuckerkise ohne gleiehen ein. Der Zuekerpreis fiel infolge der Konkurenz der Zuekerrühe ron $65 \mathrm{fr}$. pro Doppelzentner auf $\left.35 \mathrm{fr} \cdot{ }^{3}\right)$ Auf Grond der in den rorigen Perioden gemachten Erfahrungen wurden ron den Banken sofort die Torsehüsse sowie the Ausgabe von Anweisungen anf Frankreich eingesehrünkt, so daß die Banken ron Martinique und Gnadeloupe dank einer guten Ernte ohne Schaden die Krise ïberwanden uni erstere von $1885 / 90: 14.5 \%, 14 \%$ und wieder $14 \%$, letztere $19 \%$, $23 \%$ und $24.5 \%$ Diridende zahlen kimnte.

Ernster lagen die Terhältnisse in Rúunion. Trotz glänzender Dividenden seit $18 i t$ hatte die dortige Banli sehwer zu leiden unter

1) Siehe Anmerkung 1 auf Seite 69.

") Denizel a. a. O. S. 174.

3) Denizet a. a. 0. S. 174. 
dem Kursfall der in Rémion umlaufenden Rupie, welcher den Wechselkurs auf Frankreich 1879 anf $25 \% / 0$ steigen lieb. Die 1879 erfolgte Auberkurssetzung der fremden in Réunion umlanfenden Geldmünzen beseitigte eine Ursache des hohen Wechselkurses: die Verschiedenheit der Währungen zwischen Frankreich und Rémion. Der Wechselkmss sauk dauaufhin auf 2-3\%. Die Herabsetzung des Wechselkurses war in diesem Malle aber nur dadurch zu erreichen gewesen, dab der Gourerneur von Réunion der Bank befahl, 'Tratten auf Frankreich ohne Einsehrïnkung zum Parikurse abzugeben; die Bank solltu dafür zu Rimessezweeken jede ron ihr verlangte Zahl von Anweisungen anf das französische Schatzant in Paris dureh das kuloniale Schatzant in Rémnion erhalten. Als nun 1884 die Zuckerkrise hereinbrach, schnelte der kïnstlich niedrig gehaltene Weehselkurs auf $7 \%$, dann auf $16 \%$ empor. Alles Metallgeld verschwand aus der Insel, auf der bald nur Kassenscheine und Banknoten umliefen. Die lange Zeit verschleierte schlechte Lage der Bank von Réunion trat jetzt zutage. Ein Inspektor, der 1855 nach Réunion gesandt wurde, $u m$ die Terhältnisse zu studieren und die Banklage zu prüfen, stellte in ciner Bilanz, welche nur reelle und statutarisehe Werte enthielt, fest, dab die ganze Reserve sowie ein 'Teil des Kapitals der Bank durch Verluste anfgezehrt sei. Die ungedeckte Schuld an das Diskontkontor in Paris betrug $5^{1 / 2}$ Millionen fr. Eine grindliche Reinigung des P'ortefenilles der Bank, das Verbot einer Dividendenverteilung für die Jahre 1885 bis 1889 und die Einschrïnkung der Geschäte, wie sie eine peinliche Beobachtung der Statuten seitens des neuen Bankdirektors mit sich brachte, besserten die Lage der Bank ron Réunion zusehends, so dah 1890 wieder eine Dividende von $9,1 \%$ verteilt werden konnte. Es blieb noch eine Schwicrigkeit zu beheben. In den Kassen des kolonialen Schatzamts hatten Noten der Bank von Réunion sich haufenweise angesammelt, da die Bank mit ihnen die ihr rom Schatzante gelieferten Anweisungen auf das französische Schatzant bezahIt hatte.1) Zusammen

1) Denizet a. a. O. S. 186. 
mit den récépissés d’espèces ïberstieg der Notenumlanf entgegen den Statuten den 3 fachen Betrag des Metallvorrats der Kasse. 1890 crfolgte nun ein ernentes, während ter 90 er Jahre anhattender Sinken des sich kaum wieder gehnbenen Zurkerpreises anf $36 \mathrm{fr}$. pro Doppelzentner. Die gewöhnliche Wirkung trat ein. Der Wechselkurs stieg rom 1\% $1 / \%$ anf $25 \%$, nnd wieder rerschwand alles Metallgeld aus der Insel. Aber das Schlimmste kam noch. Schon lange hatte die Bank von Réunion unter der Konkurrenz anderer Kreditinstitute in der Kolonie, besonders des Crédit foncier colonial und der Suciété de crúdit agricole et commercial zu leiden wehabt. Auf Drängen des (ionrernents der Kulonie rephand die bank sieh nun mit der Société de crédit agricole et commercial (s. a. c.) nnd cinigte sich mit ilur dahin, dab die Bank die ron der s.. a. c. ansgestellten Wochsel diskontieren sollte. Auf diese Weise stiegun die gesamten Torschïsse der Bank ron Rémion vom 18,1 Millionen fr. (1S88/89) auf 31 Villionen fr. (1S!2), dirunter 21.9 Millionen fr. Platzwechsel. Enter diesen Platzwechsehn gab es viele Kellerweehsel und oft ermenerte Wechsel. Die Uherwachmoskommiswion machte die Bank auf die grobe Gefahr anfmerksam - leider zu spit.

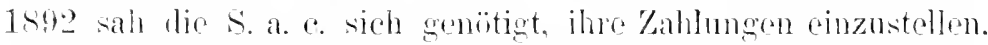
Die Bank ron Rémion wurde hierdurch so seln in Mitleidenschaft gezogen, dal die Kassenscheine eine Zeitlang oin Agio erzidten gegenüber ihren Banknotrn. ${ }^{1}$ ) Der definitive Volust der Bank an der S. a. c., der sich auf 1,5 Millionen fr. belief, wude ihr zwar durch einen zinslosen Vorschuf der Kolonie, welcher in 20 Jahresraten aus dem Gesehäftsgewinn zurïckzuzahlen ist, ersetzt. Aber der Unstand, daf neben der Reserve auch ein Drittel des Crundkapitals reploren gegangen war, daß ako nach Art. 62 der statuten die Liquidation der Bank bätte rerlangt werden können, heleuchtete die sachlage in ihrem rollen Frinst.

Die Zuckerkrise und die Bankkrise erhöhten den Wechselkuls auf $: 30 \%$. Shom die Scheidemünzen ron Nickel und

1) Denizet a. a. (). ... 179. 
Koupfer wanderten aus, trotzdem ihre Ausfulur durch Dekret rom 31 . VII. 1893 verboten und mit Gefüngnisstrafe bedroht war. Eine solche Lage muBte den Importhandel der Kolonie beunruhigen, auf den obentrein der hohe Techselkurs wie cin Einfuhrzoll wirkte: der Import nahm also ab. Der Wechselkurs sank allmählich wieder al pari, aber nicht infolge ciner günstigeren Handelsbilanz (der Export hatte ja nicht zugenommen), sondern weil von aler Kolonie weniger gekauft wurte.

Auch auf den Antillen wurde die Geldfrage in den $90 \mathrm{er}$ Jahren brennend infolge der nen ausbrechenden Zuckerkrise. Der Import überstieg in Martinique den Export um die Hälfte. Eine Feuersbrunst, die 1891 Fort-de-France auf Martinique heimsuchte, und die großen Terwïstungen, die ein Zykion in den Pflanzungen anrichtete, machten große Kiredite les Mutterlandes zum Tiederaufhau der Stadt und zur Wiederherstelhum der Pflanzungen erforterlich: sie rermehrten also den Import bei gleichzeitiger Abnahme des Exports. Unter diesen Cmstïnden stieg der Wechselkurs von $21 / 2{ }^{\circ} \%$ (1892) anf $16^{\circ} \%$ (1S97). Nicht ohne Einfluß darauf war die Konkurrenz einer englischen Liolonialbank in Martinique, welche die Bank von Martinique veranlabte, sich mit ihr die Tratten der Zuckerraffinerien ron Martinique zu teilen. ${ }^{2}$ ) Der Konkurs eines angesehenen Handelshauses in Martinique zwang 1897 die Bank, 2 Millionen fr. aus ihrem Portefenille in die Aufenstïnde zu sotzen. Das benlentete für die Bank den Verlust inrer ganzen Reserve.

In Guadeloupe bewirkte anhaltende I ürre und der niedrige Zuckerpreis eine Erhöhung des Wrehselkurses. Diesel stieg 1897 auf 28 und $30 \%$, ja stellenweise, als die Bank die Ausgahe ron Anweisungen auf Frankreich einstellte, bis auf $50 \%$. Wie schon oben \$. 62 erkiärt, war dieser enorm hohe Wechselkurs nur möglich infolge Zusammenwirkens ron passiver Zahlungsbilanz mit der Valntadifferenz zwischen ? verschiedenen Wähnngen. Guadeloupe war ja damals wie Réunion tatsächlich Papieswährungsland.

2) Denizet a. a. (). S. 183 . 
Anch die Bank ron Ginadeloupe hatte 1895 eine unrorsichtige (rewährung ron statutenwidrig hohen Erntedarlehen mit dem Terluste ihrer Reserve sowie ron ${ }^{\mathbf{1}_{3}}$ ihres Kapitals zn büßen.

$1899 \mathrm{~km}$ ror Ernenerung des Kolonialbankgesetzes waren die Banken ron Martinique und Guadelonpe ohne jede Reserve; die Bank ron Réunion begann gerade wieder nit der Neubildung ihrer Reserven. Letztere Bank hatte von 1592-97 keine Diridenden, 1 s.97 nur 201/20/, Diridende verteilt. Die Bank ron Gnadeloupe bezalnlte ron 1s95-1901 keine Dividenden, die Bank ron Martinique 1893 noch $133^{\circ}$ a, $1894: 6 \%, 1895$ und 1896 je 20 . dann $1 \triangleleft 97$ und $1 \triangleleft 9 \diamond$ keine Dividende und 1s9! wieder $5^{*}$. Diridende. Allein die Konti der Banken waren nummehr von allen schlechton Werten gesïnbert: sie enthielten nur noch reelle und statutarische Werte.

so konnte unter der Herrschaft des nenen Kolonialbankgesetzes ron 1901 eine nene Periode für die 3 Kolonialbanken beginnen, in welcher die genaue Beohachtung der Statuten das Leitmotiv ist, und in welcher mehr anf Bonität denn auf Quantitiit des Portefenilles gesehen wird. Es wurden verschiedene nene Reserven gehildet und darhurch die Stetigkeit und Sicherleit ler Creschäftergebnisse erhöht. Die Erdbebenkatastrophe in Martinique im Lai 1902 hat für den Augenblick die Bank stark mitgenommen. da rerschiedene ihrer. Wechsel rerbrannten und ein T'teil ihrer schuldnel ebenso wie der Direktor, Verwaltungsrat und die meisten Angestellten der Bank dabei ums Leben kamen. Ton danernder Sachwirkung war das Ereignis nicht. Leider läßt sich ron der Brïsseler Zuckerkonvention nicht dasselbe sagen. I las anf sie zuriickfülnende weitere sinken der Znckerpreise hat zu einer Abmahme der Geschiftsziffern der 3 Kolonialbanken geführt. die zu Bedenken Anlab gibt. Immerhin ist in Anbetracht aller Lmstände die gegen irärtige Lage der 3 Kolonialbanken befriedigend.

Fis $1: 101$ hatte keine der 3 Banken eine Zweigniederlassung gegrindet. Znerst hat dann die Bank ron Martinique eine Cieschätsstelle eröfnet mol zwal in Fort-de-France am 1. XI. 1901. Sieit 1905 ist Fort-de-France übrigens sitz der 
Bank ron Martinique und St.-Picrle in eine bloße (ieschiiftsstelle nmgewandelt. Am 13. I. 1902 griundete die Bank ron Guadeloupe eine Agentur in Basse-Terre. Die Bank von Réunion wurde schließlich durch Dekret vom 5. II. 04 ermächtigt, in St.Pierre (auf Rémion) eine Geschäftsstelle zu errichten.

Die Zeit, wo die Kolonialbanken die Cirünlung rom Nehenstellen für kostspiclig und schädlieh hielten, scheint demmach der Vergaugènheit anzugehören.

Soviel äber die äubere Entwickelung der Kolonialbanken in den Zuckerkolonien.

\section{$\$ 11$. \\ DIE BANK TON GUTANE.}

Über die Banken ron Guyane und Sénégal können wir uns wesentlich kürzer fassen.

Durch die sklavenbefreiung wurle die Landwirtschaft von Guyane tödlich getroffen. Da seitrlem Guyane werler die täglichen Lebensmittel noeh Exportwaren produzierte, sank sein Aufenlandel berlentend. Dit Einfulur der Kolonie wrode durch die Ausfuhr ron Rohgold bezahlt. Das Guldsuchen in den Flublänfen des Awa, Inoni, Carswène und Inini bildete fust die einzige Beschäftigung der Bewohner Guyanes. Die dontige Bank erwarb das Rohgold gexen Abgahe rou Bankuoten oder Anweisungen auf Frankreich und las Ausland. Die Goldverkäufer ließen dann diese Anweisungen in Europa diskontieren und arhielten dadureh das Metallgeld, das sie zur Bezahlung der Lebensmitteleinfuhr Guyaues benötigten. Oder aber die Gollverkiafer stellten selbst Tratten auf ihre Verkaufskommissionäre in Europa aus, nnd die Bank diskontierte ihmen dann diese Wechsel, deren zweite Untersehrift ersetzt war dureh ein Konossement, lautend auf eine Ladung Rohgold. Die Bank sindte das rom iln erworbene Rolngold an das Diskontkontor. Diese enrois d'or natif bildeten den Hauptbestandteil ihrer Rimessen; sie schwankten aber sehr stark ron Jahr zu Jahr und betrugen z. B. 1894/5 6,s Millionen fr., dagegen $1899 / 1900$ nur $664606 \% \mathrm{fr}$. und $1901 / 02$ wieder 6 Thillionen fr. In Jahren geringer Grold- 
ausbeute mußten Tratten des kolonialen Schatzamts der Bank helfen, ihr Kionto beim Diskontrontor zu saldieren, da es rlam mangels cines anderen Exportartikels in Guyane an Handelsrimessen fehlte.

Das Kapital der Bank ron Guyane betrug 1855 bei Beginn ihrer Geschäfte $300000 \mathrm{fr}, 1863$ wmde es auf $600000 \mathrm{fr}$. erhöht. wohei anf die nenen Aktien $250 \mathrm{fr}$. ron den Aktionären bar eingezalilt wurden und $250 \mathrm{fr}$. pro Aktic dem Reservefonds entnommen wurden. Dieser latte schon nach 7 Jahren sein gesetzliches Maximmm ron $150000 \mathrm{fr}$. erreicht, war aber jetzt neu zu bilden. Die Bank onn Guyane hatte die Kapitalvermehrung orleten. woil sie ron den damals in Guyane nen begriundeten Strafanntalten eine Belehng der kolonialen Landwirtschaft erhoffte, der es bislang nur an Arbeitskrätten getehlt hatte. Die Hoffnung der Bank erfüllte sich aber nicht. Doeh delnte die Bank in der Folgezeit ihre J)iskontgeschäfte bedentend ans Die gesamten rom ihr gewälnten Torschïsse stiegen in den ersten 10 Jahren stetig his auf ea. 1 Millonen fr. 186t/5; sie schwamkten dann zwischen 4,5 and 2,6 Millionen fr: bis sie

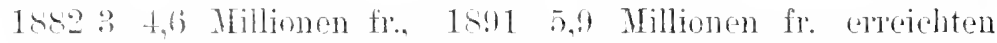

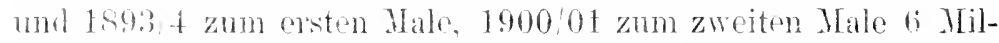
lionen fr. iberschitten. $190 t^{\prime} 5$ sanken sie wieder auf 1.7 Millionen fr.

Unter den Kroditgeschiften der Bank nahmen die Diskontgeschäfto die aste Stelle ein. Erntedarlehen hat die Bank nie gegehem, whl aber Darlehen anf Aktien und auf Importwaren. Seit 1 sos fühnt lie Bank die Warendartehen von den Aktiendarlehen getrennt auf. Erstere betrugen 1 sqsig mur 16742 fr., aber schon 1903/4 $160 \$ 20$ fr. Del Aufschwng ist unverkenmbar.

Die Kontokorrenteinzahlungen nahmen nu langsim und mit Unterbreehung zu, erreichten aher 1902/3 s,t Millionen fr. mit eincm solde dóbiteur der Bank ron 1,3 Millionen fr. Die Depositen betrugen also etwas mehr als das Doppelte des Grundkapitals ter Bank.

Der Totenmmlanf hetrug $1866 \mathrm{zum}$ ersten Male mehr als 
1 Million fr. 1904 stieg er auf 2,5 Millionen fr., das ist etwa das Vierfache des Cirmulkapitals der Bank.

Betrachtet man die ron der Bank ron Guyane seit ihrer Gründung geübten Geschäftsmethoden, so kann man nicht umhin, ihre peinlich gemane Beobaehtung der Statuten und ihre echt kaufmännische Leitnng zu rühmen. Das allein erklärt die ganz ausgezeichneten Diridenden, die den Aktionären der Bank zuteil geworden sind trotz der relativ geringen und wenig entrickelten Geschïfsziffern der Bank. Bei der Ernenerung des Kolonialbankprivilegs erkannte man aber die Notwendigkeit, die Zukunft der Bank von Guyane auf eine sichere und hreitere (irundlage zu stellen. $\left.{ }^{1}\right)$ Das war nur möglieh, wenn man endlich Hand anlegte an die landwirtsehaftliche Nutzharmachung der Kolonie; es galt ihre Wïlder zur Baumzncht, ihre Weiden zur Yiehzucht, ilne Niederungen zur Kaffee-, Kakao- und Vanillekultur zu benutzen. Was in dieser Beziehmo seit 1901 geleistet wonden ist, konnte unsererseits bislang nicht festesestellt werden. Einon erkemnbaren Einfluß hat die neubelebte wirtsehaftliche Tätigkreit in Guyane höchstens auf die Warendardehen, auf don Votenumlauf mol auf den Kontokonentrerkehr der Bank ausgeiibt. Doch kann man ans den Geschäftszifforn seit 1901 meh keine sicheren Solılüsse zichen.

Guyanes Hauptgeschift bejht nach wie ror der Gollhandel. Deshalb hat der Direktor der Bank ron (invane 1!)02 in Maroni, einem Hauptorte der Coldproluktion, einen Unterkassierer angestellt, 1 m don Zwischenhandel bei den Goldgeschäften zu beseitigen und die Goldproduzenten zu veranlassen, rlirekt mit der Bank ihre Goldrerkänfe alyusehliefen.

\section{$\$ 12$. \\ DIE BANK TON SENEGAL.}

Die Bank ron Sénégal hat sich selu langsam entwickelt. Man hat dabei zu beachten, daf St.-Louis und Dakar, die beillen Niederlassungen der Bank, bloße Handelskontore waren. Deshalb bildeten die Weehsel und Diskontgreschäfte fast die einzigen

1) Vergl. Léveillé ?. parlam. Bericht 1898. 
Geschäfte der Bank. Die einzige landwirtschaftliche Kultur Sénégals, die Arachidenkultur; befand sich in den Händen der Eingeborenen und erforderte wenig Kosten. Der Agrarkredit spielte dort keine Rolle. Von einiger Bedeutung waren noch die Darlehen anf gemünztes oder ungemünztes Gold und Silber. Dagegen gelang es der Bank mur unter grofen Schwierigkeiten, ihren Noten bei den Eingeborenen Eingang zu rerschaffen. Da diese sich die Arachiden nur mit Netallgeld, nicht mit Soten bezahlen ließen, sah sieh die Bank namentlich bei einer reichlichen Arachidenelnte gezwngen, ganz heträchtliche Geldmengen aus Frankreich kommen zu lassen. Wïhrend die Bank somit alle Lasten eines fiekl- und hreditinstitutes hatte, entging ihr der Gewimn des Weelselgeschaifts infolge dor Konkurrenz der großen Handelshäuser in Sénégal, die fast alle Handelstratten in ihrer Hand hatten. ${ }^{1}$ )

Diese Umstände hestimmten die Generalversammlung der Aktionäre am 25. I. 1901. die Lipuidation der Bank zu beschließen. Man sah ein, daß die Bank den Handelshäusern gegenüber konkmrenzfühiger gemacht werden müßte und dab sie neben einer Kapitalerhöhung, die im Lanfe der Jahre schon zweimal (1576 und 188s) stattgefunden hatte, vor allem einer Erweiterung ihres Tätigkeitsfeldes und ihres Geschäftskreises bedürfe, um nicht nur zu leben, sondern anch zu blïhen und zu gedeihen.

Die Erhschaft der Bank ron Sénégal hat 1901 die Bank ron Westafrika angetreten, ron der weiter unten noch die Rede sein wird.

\section{Kapitel.}

\section{DIE TNYERE ENTWICKLUNG DER KOLONIALBANKEX.}

Nach den Ausführungen über den äußeren Werdegang der Kolonialbanken dürfe jetzt eine Darstellung ihrer inneren Entwicklung an der Hand der einzelnen Kolonialbankgesebäfte am Platze sein.

1) Renaud a. a. 1). S. 213. 


\section{$\leqslant 13$.}

\section{DIE DISKONTGESCH ÄFTE.}

Die Diskontgeschäfte haben wir schon oben als Geschäfte des Personalkredits gekemneichmet. Das Risiko der Bank war hierbei groh, und Fehler waren schwer zu vermeilen. Allzu große Nachgiebigkeit gegenüber lokalen Einflüssen und zu geringe Prïfung der Zahlungsfähigkeit der' Unterschriften sowie der'Tendenzen, die auf Ernenerung und anf Konzentration der diskontierten Wechsel auf wenige Schuldner gerichtet waren, auf der einen Seite - ein zu hoher Diskontsatz im Terhältnis zum Leihzins für Pfanddarlehen und zur verteilten Dividende auf der anderen Seite -- waren für den Bankdirektor Scylla und Charybdis, durch die es hindurch zu stener'n galt.

Eine Zunahme der Diskontgeschäfte der Bank war oft nur die natiinliche Folge eines wirtschaftlichen Aufschwmgs dop Kolonie; sie veranlaßte dam eine erhühte Kotenansgabe oder machte gar eine Kapitalerhöhung notwendig. Wurde die Znnahme der Diskontgeschïfte herrorgerufen durch die Vornahme öfentlicher Arbeiten (z. B. ron Eisenbahnen wie in Singal) oder durch auberordentliche Ereignisse, lie das Kreditbedürfnis in ungewöhnlicher Weise steigerten (wie durch den Zyklon, der 1892 Martiniques Pflanzmngen rerwïstete), sn war an sich noch kein Grund zur Besorgnis gegehen. Denn es handelte sich ja um produktiven Kredit. Bedenklicher erwies es sich schon, wemn die Diskontgeschäfte zumahmen infolge Herabsetzung des Diskontsatzes, zumal wenn damit wie 1857 in Martinique der Austruch einer Krise zusammentraf. Geradezu verlüngnisvoll war aber für die Banken ein hoher sich jahrelang gleichbleibender' Wechselbestand, sofern er sich zusammensetzte aus ständig emenerten Wechseln, d. h. aus Krediten, wolche die Bank nach Ablanf der 120 Tage Iaximallanfzeit für Wechsel wiecler an dieselben Wechselschuldner in der alten Höhe gewäht hatte. In Martinique trat dann der Fall ein, daß gewisse Schnldner der Bank keine anderen Hilfsquellen hatten, als die ihnen beständig ernenerten Wechselkredite. Die Gefahr, die hieraus den Banken 
erwuchs, liegt anf der Hand. Da aber num mal in den Kolonien

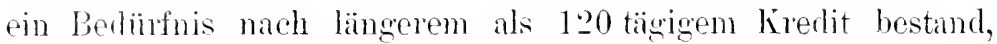
so konnte auch die Überwachungstommission der Kolonialbanken sich gegen cine Erneuerung der Wechselkredite nicht prinzipiell ablehnend rerhalten. Wohl aber - so erklärte sie - sei eine Bestimmung oder der Brauch an Platze, lab keine Erneuerung ohne Amortisation von 5-10\% der Forderung erfolgen diirfe, und daf der Schuhnes, der sich seine Schulı ernenern lasse, nicht mehr zum Liskont zugelassen werden diurfe. ${ }^{1}$ ) Ein schlechter Wechelbestand war hei den Kolonialbanken oft nur die Folge ainer Ubestreibung dor Diskontgeschifte: daturch wnute las Kapital der Bank in schlechten Papicren, d. h. in Trechseln arit geringerer. Sicherheit festgelegt und andererseits die Diskontierung guter Papiere aus Mangel an flüsigem Kapital arschwert und unmöglich zemacht. Mas schlechte Papier rertrieb das gute l'apier aus dem Wechselportefenille der Bank ähnlich wie in Doppelwährungsländern die schlechte Münze die heriere auber Landes trubt.

Auch eine Einschränkung der Diskontgeschifte durch die folonialbanken war nicht immer lobenswert: sie war eine weise Mafregel, wenn eine Uherspelulation eine Einschüunkung des Kredits als wïnschenswert arscheinen lich: sie konnte aber denso gut anch ein Fehler sem, sofern die Lage der Kolonie die weitgehendste Unterstiitzung seitens der Bank erforderte, so 1n-2. als eine Fenershrunst crurleloupe heimgesueht hatte. Ein Konflikt zwischen dem Bankinteresse und dem Interesse der Kolonie lag dann nicht anfer Bereich der Iö̈glichlieit. Eine Abnahme dos Wechelbestandes zeigte oft nur an, dalb das Wechselkomto von allen zweifehaften Fordurumgen und schlechten Papieren befreit war. Bhenso günstig war für die Bank eine Abnahme dor Diskontgetsehäfte unter gleithoitiger Znmahme ler Pfanddirtehen, weil sich auf diese Weise die Sicherheit der Bank erhöhte. Froilich ging dieser Ċberwang von den Diskontgeschäften zu den Darlehensgesehäften ïberall da nieht recht ron statten,

1) Bericht der Ü. Fo. 190:́/5. 
wo ihm langjährige Crewohnheiten und Bräuche entgegenstanden. Dies gilt besonders für Martinique, wo die Diskontgeschäfte his auf den hentigen 'Tag das hauptsïchlichste Kreditgeschäft der Bank geblieben sind und die Pfanddarlehen keine auch nur annähernd gleiche Verbreitung gefunden haben. In Martininue ist es Brauch, daß der Ausführkommissionär den vom Pflanzer ausgestellten Solawechsel indossiert und so durch seine Unterschrift die direkte Diskontierung seitens der Bank ermöglicht. $\left.{ }^{1}\right)$ Dieser Brauch hat sich trotz der Ernterlarlehen erhalten; aber es besteht kein Zweifel, daß die Möglichkeit, auf die ehen erwähnte Form des Pfanddarlehens zurïckzugreifen, Zinsfuß und Berlingungen des Diskontgesehäfts wesentlich zugunsten des diskontsuchenden Schuldners verbessert hat.

Der Diskontsatz der Kolonialbanken betrïgt $8-6 \%$, selten $10 \%$, und ist bedentend höher als der Leihzins für l'fanddarlehen; er erhöht sich, wenn der Diskontsatz in Frankreich erhöht wird.

\section{s 14 .}

\section{DIE ERTTED ARLEHEX.}

Die Erntedarlehen fanden in Martinique und Rémnion erst ganz almëhlich Eingang. In (inadelonpe ging die Entwicklung rascher ror sich, weil dort die Landwirtschaft unter der slikrenbefreiung ganz besonders gelitten hatte. Die Erntedartehen waren in Guadeloupe schon 1860 so belielst, dali die Xachfrage das Angebot der Bank, das dureh die Beloihungsgrenze der verpfändeten Ernte beschränkt und bestimmt war, überstie» und die Pflanzer gezwungen waren, sich noch ca. S-9 Millionen fr. auf dem Wege der Diskontierung zu teihen. Spaiter freilich haben die Banken ron Guadeloupe und Martinique, wohl im Interesse der Zuckerpflanzungen, ja oft fast auf Drängen des Courerneurs der Kolonie Erntedartehen in einer den Statuten widersprechenden Höhe gegeben. Diese Erntedarlehen nahmen deshabb ganz bedentend ab, als die Bank ron Martinique auf Terlangen der

1) Bericht der Ü. Ko. 185:3/5. 
Üherwachungskommission wieder nur noch $1 / 3$ des Werts der Erute belieh. Die Sicherheit der Kolonialbanken wurde noch dadureh erhöht, laß, wie z. B. 1871/3 in Guadeloupe mehr als 1/3 aller Erntedarlehen an Zuckerraffinerien erfolgten oder (1880) an Pflanzer, für deren Zahlungsfühigkeit die Zuckerraffinerien sich rerbïrgten. Trotz der großen anf diesem Wege gewährten Kredite waren die AuBenstände gering. $\left.{ }^{1}\right)$ Der Leihzins für Erntedarleben sank angesichts dieser Umstände auf 6 und $5 \%$, in Martinique sogar auf $3 \%$. Der Gewinn der Banken bei diesen Geschäften war trotzlem recht bedentend infolge besonderer Geschïftsverknüpfungen, lie im folgenden kurz erörtert werden mögen.

Tehnen wir ainen Leihzins ron $1 \% \%$ an. Bei einem Darlehen ron $10000 \mathrm{fr}$. auf eine auf :30000 fr. geschiitzte Ernte brachte clas der Bank schon $\frac{6 \times 10000}{100}=600 \mathrm{fr}$. p.a. ein. Es war num bei alen holonialbanken Branch, den ganzen Ertrag der Ernte ihrer Schuldner obne Entgelt mittelst Thatte und Konossement an sich zu nehmen und die Tratten etwa gegen 20\% Prämie zu rerkanfen. Das machte wieder $600 \mathrm{fr} .\left(\frac{2 \times 30000 \mathrm{fr} .}{100}\right)$ p. a. So ward das Geld der Bank meist mit $12 \%$ p. a. verzinst. ${ }^{2}$ ) Dieses Endergebnis anderte sich, wenn die Bank in Krisenzeiten ihre Tratten nicht mehr mit 200, Gewinn verkaufen komnte, da sie selbst den Lieferanten von Tratten eine Prämie zahlen muBte. Trotzdem zeigt das ohige Beispiel, daß der Leihzins für die Erntedarlehen eigentlich zu hoch war. Ein niederer Zinsfuß hätte dem Ertrage des Budens besser entsprochen. Immerhin ist festzustellen, daß das Risiko der Bank recht groh war. Wenn auch bei einer guten Ernte alle Darlehen pünktlich und glatt zurïckbezahlt wurden, so waren die Wirlinngen der Krisenjahre desto zerstörender. Der Pflanzer konnte hetroffen werden durch ein schlechtes Erntergebnis oder rurch ein Sinken der Zuckerpreise. Beides komnte aber auch zusammen dintreten, und dann wnrde anch die Bank ron dem

1) Vergl. Bericht der Üherwachungskommission 188081.

2) lsaak, parlam. Bericht 1898. 
Ruin des Pflanzers in Mitleidenschaft gezogen. Der l'flanzer, der in guten Jahren zwecks Vergrößerung seines Betriehes seinen Kredit bei der Bank erweitert hatte, komnte ihn hei schlechten Preisen nicht plötzlich einschränken: er mulite vielmedr versuchen, die schlechten Preise durch reichliche Ernten auszugleichen. So nahmen auch in Krisenzeiten die Eintedarlehen noch zu, und wenn dann wie 1893 der Zuckerpreis ron $50 \mathrm{fr}$. pro Doppelzentner auf $26 \mathrm{fr}$. sank, oder wie $1 \$ 90$ die Ernte $u m$ 1/: hintel der erwarteten Quantität zuriickblieb, so war ${ }^{1 / 2}{ }^{1 / 3}$, les P'fandes rerloren. Einen gewissen Schntz gegen diese Gefahren bictet den Banken der neue Art. 14, II des Gesetzes ron 1901, der den Darlehensschuldnern die Verpflichtung anferlegt. hei cinem P'reisrïckgange des Pfandes ron mehr als $20 \%$ dor Bank Deckung zu schaffen.

Die Kolonialbanken haben bei den Erntedantehen grobe Verluste erlitten, zum groben 'Teil durch eigene Schuld. So mußten 1895 ron der Bank ron Guadeloupe $3^{1}$. Millionen fr. prèts sur réeolte in die Aubenstünde gesetzt. also zu 's rerloren gegeben werden. Die schuldner dieser prits sur reolte waren in der Hauptsache zwei Zuekerraffinerien: schon seit 12 Jahren liek ihr Kontokorrent mit der Bank ainen solde débitem von 1 Million fr., ohne lab die Bank eingeschritten wäre. $\left.{ }^{1}\right)$ Diese mnkluge Kreditgewïhrung kostete die Bank damals ihre ganzen Reserven und $1 / 3$ ihres Kapitals.

Trotz alledem haben sich die Erntedartehen in den Zuckerkolonien so eingebürgert, daf ihre Beseitigung die ganze dortige Zuekerkultur in Frage stellen wiirde.

\section{$\$ 15$.}

\section{DIE WARENDARLEHEN.}

Die Warendartehen sind besonders in Rimnion ansuebildet worden. Das hing zusammen mit der Notwendigkeit, sich Bargeld oder Tratten zn verschaffen, um unverzüglich den fremden Import von Reis, Kabeljau und anderen Lebensmitteh bezahlen

\footnotetext{
1) Bericht der Ü. Ko. 18. $\$ 95$.
} 
zu können. Durch die Darlehen erhält der Exporteur die Möglichlieit, eine günstige Preishildung für seine Waren abzuwarten, ohne daf er gezwungen ist, die Waren $\mathrm{mm}$ jeden Preis zu rerkaufen und zu verschleudern. Die Bank vertritt hier also das Intcresse des kolonialen Produzenten gegenüber den fremdländischen und französischen Kauflenten.

Auch der Import der Kolonie wurde durch die Warendarlehen sehr begüntigt, besonders solange die Waren bis zu ihrem rollen Werte beliehen werden durften. Seit 1901 ist die Beleilungsgrenze für Waren auf $3 / 4$ ihres Werts herahgesetzt. Auch jetzt noch hat der Importeur den Torteil, dirl er 3/4 des Werts seines lmports realisieren kann, noch heror die Waren rerkauft sind. Eine Erleichterung dos Imports lag in Interesse der kolonialen Konsmmenten, nicht aher ein Überwiegen des Imports üher den Expost im Interesse der Kolonie. Deshalh wurden Impont- und Expontwaren bei ihrer Beleihung von den Lolonialbanken rerschieden behandelt, indem der Leilızins für jene 8.9 und $10 \%$, der Leilnzins für diese nur $6-5 \% / n$ betrug.

Die Terduste der Kolonialbanken bei den rorsichtig gewährten Tarendarlehen waren relatir gering grogenüber denjenigen, welche sie in ihren Diskont- und Erntedarlehensgeschäften erlitten.

\section{s 16 .}

DIE WECHSELGESCHÄFTE.

Für die Ausdohnung der Wechrelgeschifte der Kolonialbanken war entrcheidend das Angebot ron Rimossen. Dieses richtete sich nach der Produlition des Landes: in dron Zuckerkolonien nach der Zuckerernte, in cinyane nach der Croldaushente und in sénégal nach der Arachidenemte. Bei geringer Produktion wurden die Rimessen selten, und die Geldsendungen zu Rimessezwecken machten aine Gelleinfuln in die Kolonie seitens der Bank erforderlich. Hierhurch erhielten die Kolonialbanken oft unter großen Opforn den Cieldumlauf der Kolonie aufrecht. Aber auch ein gutes Produktionsergebnis konnte grofe Geldsendungen aus Frankreich z. B. zum Ankaufe des or natif oder 
der Arachidenernte nötim machen. Demn Rohgohl wurle in Guyane nur gegen (ioldgeld abgegeben, und die Arachidenernte von sónégal komnte nur mit gemünzten Gelde bezahlt werden, da die Eingeborenen die Noten der Bank nicht in Zahlung nahmen.

Die Produktion des Landes iabte also anf die Wechselgesehäfte der Kolonialbanken den mafgebendsten Einflub aus. Die Tratte iles Pflanzers oder Zuekerfabrikinten wurde in der Hand der Bank zur Rimesse; die Bank konnte nun auf Grund dieser Rimesse cine Anweisung auf das Diskontiontol ansstellen, z. B. zugunsten eines Kaufmanns, der eine entsprechende Summe in Frankreich oder ïberall, wo das Kontor Niederlassungen besab, zu zahlen haben konnte. Oft brauchte aber der Kunde der Bank eine Anweisung. obwohl die Bank noch keine Rimesse zur Deckung der anszugebenden Anweisung hatte. Dann stieg die Prämie für Anweismngen entsprechend mit den Kosten, welche der Bank durch den Erwerb ron Rimessen erwuchsen. Am höchsten war die l'rämie immer in der Zeit zwischen 2- Enten, also wen es gar keine Rimessen gab. Sobald die Prämie aber $t^{0 "}$ " ïberschritt, lohnte es sich, nicht mit Tratten sondern mit Bargeld zu zahlen, dal die Kosten der V'ersendung und V'ersicherung weniger als $4 \%$ ansmachten. Das Bargeld wurde dem Kassenbestand der Bank durch Präsentiermg der Banknoten entnommen und damn ausgeführt. Wenig half dagegen, dak die Kolonialbanken ilne Soten in Silber zuriickzahlten, das nicht ansgeführt wurde. Meist mubte die Bank in solchen Lagen sich Bargedd aus Frankreich kommen lassen, um die Einlösung ihrer Noten zu sichern. Das erhöhte aber die Schnll der Bank an das Kontor.

Die Kolonialbanken hatten also selbst ein Interesse an einem niedrigen Wechselkurse. 1896 hielt die Bank ron Guadeloupe den Wechselkurs auf $15 \%$ unter Schoumg des Handels und der Konsmmenten. Spekulanten kauften aber die Anweisungen der Bank zu 15\% auf, un sie höher wieder zu rerkanfen, was bei der steigenden Nachfrage leicht zu machen war. Als num die Kanfleute stürmisch Rimessen un jeden 
Preis verlangten, weil die fremdländischen oder französischen Importenre ihre Einfuhr in die Kolonie einstellen würden, wenn sie ihre Torschüsse nicht zurückbezahlt erhielten, da salı sich die Bank grnötigt, den Wechselkurs auf $30^{\circ}$ o zu erhöhen. Sie iibernahm aber zugleich die Verpflichtung an jedermann, jede verlangte Zahl von Anweisungen auf Frankreich abzugeben. Trotzdem muBte die Bank mangels aller Rimessen bald ihre Wechselgeschäfte bis zun Beginne der Ernte einstellen. Während dieser Zeit stieg der Kurs auf 48 und $49 \%$. Erst der Beginn der. Ernte brachte eine Besserung. ')

Teben den Hanlelsrimessen erwarben die Banken. besonders die Banken von Gnyane und Sénégal, zu Rimessezwecken auch Anwoisungen auf las französische Schatzant gegen eine hohe Prämie. Allmählich sammolten sich nun in den Kassen des kolonialen sehatzants eine große Zahl ron Banknoten an, mit denen die Schatzanweismugen ron der Bank bezahlt waren. Die sofortige Zurückzahhung dieser Noten durch die betreffende Bank haitte grobe Gelisendnngen ans Frankreich nötig gemacht und unter Unstinden den Ruin der betreffenden Bank herheiführen kimnen. Dessenungeachtet verlangte $1 \$ 96$ das koloniale Schatzant in Guadeloupe plützlich von der Bank von Guadeloupe die Rückzahlung ron a Millionen fr. Toten, eine Summe, ron welcher -200000 fr. auf die für die Schatzanweisungen ron ter Bank gezahlten Prämien entfielen. Das koloniale schatzamt thatte als Bankier gehandelt und an Wechselkurse zu verdienen gesncht. 2) Das wall entschieden ein Mißhauch seines Rechts, auf das franzisische Schatzamt Anweisungen auszustellen. Für die Bank hatte dies die unangenehme Folge, dab sie ron 1893 bis 1897 dem kolonialen schatzamte für t.:3 Jillionen fr. Noten (rinlisen und zu diesem Zweck 3.9 Millionen fr. Metallgeld aus Frankicich kommen lassen mubte.

In Martinique hatte die Bank $18 s 9$ gegenuiber den enormen Berlïrnissen der Kolonie nicht gezögert, ihren Kredit beim Kontor zu ïhersdneiten. Sie zahlte ihren verfügharen Metallyorrat dem

1) Isaak. Parlam. Bericht 1898.

2) Isaak, Parlam. Bericht 1898 . 
kolonialen Schatzamte ein; der Ciegenwert dieser Einzahlung wurde ihrem Konto beim Diskontkontor gut geschrieben. Auf diese Weise verschaffte sich die Bank von Martinirque $1891 / 99$ für 3,3 Millionen fr. Rimessen al pari, anf welehe das Schatzant nur 1/3 metallische Zahlung, den Rest in Noten eingrofordert hatte. Auch hier bot die Rüekzahlung der Noten grobe Schwierigkeiten.

Im Schatzante von Rénnion hatten sich Mitte der 90er Jahre Noten der dortigen Bank deshalb in so starkem Maße angesammelt, weil die Bank dem schatzamte :3 Mlilionen fr. Noten eingehändigt und dieses dafür dem Diskontkontor 3 Millionen fr. in har zugunsten der Koloniallank ausbezahlt hatte. Diese Einzahlungen sollten die Schuld der Bank gegen das Kontor vermindern; sie führten aber zu einer Übertreibung der Ziehungen (ómissions) anf das Kiontor und so zu einer ganz enormen Steigerung der Schuld an das Kontor. Am 30. VI. 1896 besab das koloniale Schatzant für 6,2 Millionen fr. Noten der Bank von Rínion, obwohl es nach ministerieller Verordnung für lü̈chstens 1,5 Millionen fr: Noten in seinen Kassen haben sollte. Man wagte damals nicht, die sofortige Rückzahlung dieser Noten zu vertangen, aus Furcht, die so wie so gefährliche Lage der Bank von hémion noch meln zn rersehlimmern. Lieber tauschte man die Noten gegen récépissis d'espèces ans und bereitete so ihre Rïekzahlung vor. Seit 1899 herrsehen wieder normale /ustïnde.

Die hohen Wechselkurse und die durch sie verankafte starke Ansammlung ron Banknoten im kolonialen Schatzamt waren Ansnahmeerscheinungen (trotzdem sie in Krisenzeiten ziemlich regełmäBig wiederkehrten), da sie mit der hrise wieder verschwanden. Aber für den Rimessenmangel in Zeiten einer wirtschaftlichen Krise war es doch sehr bezeichnend, daf die Bank von Martinique 1895 und die Bank ron Guadeloupe 1896 ihren Schuldnern aus prèts sur récolte die Verpflichtung auferlegte, alle ihre Tratten auf Frankreich zum Parikurse an die Bank abzugeben. Dagegen muften die Banken all den Lieferanten von Tratten, welche die Vermittlung und Unterstuitzung der Bank nicht brauchten, mindestens $1 / 4$ des beim Terkaufe ihrer Tratten und Anweisungen erzielten Prämiengewimns versprechen. Trotz- 
dem erhielten die Banken nicht die gewïnschten Rimessen in ausreichender Höhe.

An dieser Stelle ist anch anf die enge Beziehnng zwischen dem answärtigen Kahlumgsverkeh und dem inneren Geldumlauf der Kolonie hinzuweisen. Bei einem hohen Wechselkurse strönte das Metaligold aus der Kolonie. 'Trat damn ein reiner Papierumlanf ein, so kamnte wielerum der Wechselkurs keine Grenzen. Dem Getrlabflusse hïtte man stenern könmen durch Schaffung einer kolonialen Münze mit rein lokaler Zahlungskrait, deren Ausfuhr nicht zu befürchten stancl. Damit wäre aber die Währungseinheit zwischen Flankreich und seinen Kolonicen anfgrehoben worden. Ind man hätte die Sicherung des Geldumlanfs in der Kolonie mit einem ständig hohen IV echselkurse auf Frankreich erkanft, der schlieblich den Importenen mul damit den Konsumenten den Import häte rentenern müssen. Deshalh war der Wegr vorzmziehen, der zm Lösung der Wechselfrage heschitten wurde, nämlich neben rein lokalen IIünzen mul Gelılzeichen (monnaios divisionmaires. Toten-und Kassenscheinen), anch französisches field, das zu Rimesien rowondet werlen komnte, in der Kolonie im Umbufe zu erhalten. Man erreichte darlurch wonigstons, daf der Wechselkurs num in kisenzeiten emporschnellte, daf er aber nuter nomalen Umstanden 1-2\% nicht iiburstiog.

Das Geld, welches in kisenzeiten abflok, wurde im L'mlauf durch eine rermehrte Notenausgabe ersetzt. Und der Metallgeldmangel in der Kolonic rerlor für die Bank etwas ron seiner Gefährlichkeit darlumeh, dab es den liolonialbanken gestattet warl, ihre Noten auch in Kassenscheinen einzulösen. Diese waren in den Zuckerkolonien 1879 bezw. 1854 ausgestellt in beträgen ron 2, I und 0,50 fr., hatten \%wangskurs, und ihn roller Cregenwert in Metallgeld ruhte in den Kassen des emittierendon kolonialen schatzamts. In Guadeloupe war es auch müglich, für dic Kassenschpine 3 \% ige französische Rentenbriefe an Stelle des Metallgeldes zu hinterlegen. Die Bank ron Guadelompe hatte an 3. VI. 1905 anf liese Weise fiur 1 Milliom fu. líssenscheine erworben. 
Die Kassenscheine wurten ron $1898 / 1908$ durch jetons de nickel ersetzt.

Trotz der Kassenscheine war die Cieldrerlegenheit in den Antillen Ende der 90 el Jalne wohl infolge der Ausfuhr und des gänzlichen Terschwindens der Scheideminzen so groli, dab bei den täglichen Ühertragungen ron weniger als $1,2 \mathrm{fr}$. die Kassenscheine zerschnitten und deren 'Teilstïcke dem Verküufer' in Zahlung gegeben wurden, der tann an thend den ganzen Schein wieder zusammenstellte, indem er die cinzehnen Teilstücke auf ein Stück Palpier zusammenklehte. ${ }^{1}$ ) Einige Bedentung hatten für die Linderung der Geldnot in der Kolonie anch die récépissés d'especes, die, ähnlich wie die Kassenscheine, eine Einzahlung ron Geldmünzen, aber nicht beim krlonialen schatzante, sondern bei der Bank roraussetzten. Wichtiger waren die schecks auf die Kolonie, wie sie sich in Riunior seit 1!101 entwiclielt haben. Die im Lanfe des Ceschäftsjahres 1904/5 ron der Bank run Réunion ansgestellten scheckis hatten einen Wert ron 2.2 Dillionen fr. und ließen am :30. VI. 05 einen salelo ron 6:3 ist fr.

\section{$\$ 17$.}

\section{DER NOTENUMLAUF.}

Die Schecks anf die Kolonie und die rópissés despoces stehen den Xoten der Banlien greich als sofort fällige Verbinrllichkeiten: sie miisven deshalh nit eingerechnet werlen in den Notenumlanf bei Berechnung seines gesetzlichen Maximums. Wenn wir das tun, lahen wir festznstellen, dab der Notenumlauf der Bank von Réunion von 1890 bis $189 s$ entgegen den Statuten das Dreifache des Metallbestandes der Bank überstieg, 1895 sogar um den hohen Betrag von 1,4 Millionen fr:

Dieser hohe Notenumlauf war zum Teil die Folge der oben besprochenen Totenansammlung im kolonialen schitzant. Die anderen vier Kolonialbanken haben das gesetzliche Maximum ihres Notenumlaufs nie überschritten. Der Notenumbaf war am größten in Réunion, wo er 1898 fast 10.s Millionen fr.

1) Isaak. Parlam. Bericht 1898. 
erreichte gegen ein Maximum ron 8.1 Millionen fr. (1895) in Martinipue. S.7 Millionen fr. (1902) in Guadeloupe, 2.,5 Millionen fr. $(190 \mathrm{t})$ in Gryyane mol 1.1 Villionen fr. (1891) in Sénégal.

\section{$\$ 18$. \\ DIE DEPOSITEX.}

Yehen dem Sotenumbuf war der Kontokorrentrorkehr ein (iradnesser für den Kredit, den die Kolonialbanken genossen. Ton allen Kolonialbanken wies in der Regel die Bank ron cuadeloupe die höchsten hontoknrentziffern auf, trotzdem die Kontokorrenteinzahlungen bei dieser Bank ron 71.8 Millionen fr. 1ss:) 4 ror Ausbrnch der Zuckerkrise auf 31.6 Millionen fr. $1903 / 4$ sesmken sind, d. h. anf eine Höhe, die schon nach 4 Creschäftojihren (15.56) ron der Bank fast erreicht worden war. Die Bank ron somogal hat dem lokalen Handel erst 1867 Kontokorrente eröffnet, was riolleicht ein Berros dafuir ist, dab auch dort erst die Banknoten den Bolen für den Depositenrerkehr volbereiten mubten. Lab geracle in der kritischen Periorle 18.9-2: die kontokorrenteinzahlungen hei der Bank ron Funion relatir hoch waren (20-4 Millionen fr.) zeigt, dab das Curtranen in lie Bank nicht erschüttert war. Die Abnabme der Fontokorenteinzahlungen bei der Bank ron Martinique ${ }^{1}$ ) sind der dortigen Gelılknappheit znzuschreiben; es zeigte sieh hierbei, daf dureh die Depusiten im Ciegrensatze zu den Noten dem Verkehr Cmlanfsmittel entzogen werden, oder ander's ansgedritckt: dab bei steigendem Geldhedarfe der Notenumlauf zunimmt, die répision despèces aber abuehmen, und zwar aus dem crunde, weil Soten auch ïber den Betrag ihrer metallischen Deckung, recenpissés nur im Betrage ihres metallischen Gegenwertes in den Verkeh kommen kïnnen.

1: Sie betrwen 1882 3: 71, t Millonen fr.

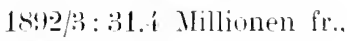
1902:3:17.2 Millionen $\mathrm{fr}$. 


\section{Kapitel.}

\section{ERGEBNISSE DER KOLONIALBANKTÄTTGKEAT.}

Wir sind hier am Schlusse unserer Erörterungen übor die Entwicklung der 5 alten Kolonialbanken und ihrer Geschäfte. Es gilt nun das Fazit zu ziehen aus ilurer Banktätigkeit. Wir fragen: "Welches waren ihre Wirkungen auf die Kolonien "* und dann: „Welches war das Ergebnis für die Alitionäro ler Bank sellst?."

\section{$\leqslant 19$.}

\section{DAS ERGEBNIS FÜR DIE KOLONIEN.}

Kapitalmangel und vorhersehender Aubenhandel, dazu eine passive Handelsbilanz, waren dic Hauptursachen des starken hireditbedürfnisses der Kolonien gewesen; sie hatten seincrzeit zur Gründung der Kolonialbanken geführt. Was ist in dieser Beziehung erreicht worden?

Die passive Handelsbilanz der Kolonien ist nicht hesritigt worden. Das hing zusammen mit der monoculture und dem absentéisme der Kolonien. Die ganze Tätigkeit der Kulonien beschränkte und beschränkt sich bis hente anf die Produktion fast nur eines Prodnktes (monoculture), und zwar eines für den Export bestimmten Produktes, sodaß Manufakturwaren und Lebensmittel nach wie vor eingeführt werlen müssen. Eine Kapitalbildung war unter solchen Unständen in der Kolonie eine Unmöglichkeit. Die Kolonialbanken haben die Umwandlung der kleinen Zuckerraffinerien in große Fabriken gefördert und tadurch die Zuckerproduktion gesteigert; ${ }^{1}$ ) sie haben durch ihre Erntedarlehen rersucht, auch Kaffee, Vanille und andere Kulturen zu unterstïtzen; aber ihr Ziel, die Verbesserung der Zahlungsbilanz, haben sie nicht erreicht. Die passive Handelsbilanz war in guten Jahren nur die Folge einer fałschen Bilanzaufstellung, da der Export der Kolonie zu seinem Preise an Verladungsorte berechnet wurde, der Verkaufspreis an Ankunftsorte aber jenen mindestens um die hosten der Versendung und Versicherung überstieg. Aber jeden Gewinn,

1) Denizet a. a. O. S. 165. 
den der Pflanzer erzielte, pflegte dieser nicht in der Kolonie anszugeben oder anzulegren; er liehte es viehmehr, nach Frankreich zu reisen und dort sein Gehl zu verschwenden (absentéisme). Im besten Falle kehrte der Reingewimn des Pflanzers nicht in Form einer Gelfkapitaleinfuhr, sondern in Form einer Wareneinfuhr in die Kolonie zuriek. Der Geldumlauf der Kolonien hatte deshalb die Tendenz stationär zu bleibon. ${ }^{1}$ )

Der absentoisme - das ist also die Sucht des Kreolen, das eben Erworbene nicht produlitiv anzulegen, sondern sofort beispiolsweise in Paris anızugeben, um damn mit leeren Händen in tie Kolonie heimzukchren - dieser absentéisme ist ron den Kolonialbanken nicht ausgerottet, ja kaum merkbar gemindert worden. Erfolg versprach hier die Einwanderung von Europäern, bei denen der spartrieh noch stark entwickelt war. Leider dachten aber die wenigsten folonisten daran, dauernd in der Kolonie zu bleiben: ilne Ersarnisse kamen also ihrem HeimatIande zugute, nicht der Krolonie, deren Naturschitzen sie ihren Wohlstand und Reichtum rerdankten (übrigens eine Erscheinung, unter der auch die von den Europäern kolonisierten südamerikanischen Republiken leiden). Es galt also den spartrieh der Einheimischen (Kreolen) anzuregen, etwa durch rerzinsliche Depositen. Die Bank ron Gnadeloupe machte 1sit in dieser Beziehung einen interessanten Versuch mit einer sparkasse für Arbeiter, indem sie jedem Deponenten von mindestens $10 \mathrm{fr}$. einen Kontokorentzins ron $4^{0 / 0}$ rersprach. Der Plan kam hedauerlicherweise nicht zur Ausfïhrung, da die Überwachungskommission den Banken die Annalme rerzinslicher Depositen als den Statuten zuwider verbieten mulite. ${ }^{2}$ )

Diesen Milierfolgen der Kolonialbanken stehen aber auch positive Leistmugen gegenüber:

Der pacte colonial ${ }^{3}$ ) hatte atch nach seiner Aufhehung im Jahre 1861 die Wirkung, dal fast der ganze Export der Kolonien nach Frankreich ging und nieht ins Ausland, ron dem aber doch

1) Isaak, Parlam. Bericht 18.s.

2) Jenizet, a. a. U. S. St.

3) S. S. 4. 
1/3-2/3 ihrer Einfulur stammten: aher dank den Kolonialbanken hat er seine verderblichen folgen rertoren, seitulem der fremde Import nicht nur clureh Bargeldsendungen sondern auch durch Anweisungen auf das Diskontkonter bezahlt werden kann.

Der Handel in llen Kolonien hatte seit Grïndung der Kolonialbanken die Möglichkrit, durch l'rä̈sentation der Banknoten sich jederzeit die nütigen (ioldmittel zu seinen answärtigen Zahlungen zu verschaffru, ansgenommen in Zciten. wo die Banknoten nur in Kassenseheinen eingelist wurden. War so der Geldrerkehr nud Zahlungsverkehr anch nicht völlig sieher gestellt, so wurten doch die Geldkrisen in den holmien dank der Vermittlertïtigkeit der Kolonialhanken wesentlich somildert. Ob mehr erreichbar war bei den beschränkten Mittehn dor Banken, ist zweifelhaft. Auf jeden Fall haben die Banlien den Kahlungsverkehr der Kolonien sehr vereinfacht mol verhilligt.

Ihr Hauptrerdienst hesteht aher darlin, dals sie dir lamswirtschaft in den Znckerkolonien sozusagen werettet hahen und dem darniederliegenden Handel wieder anfugholfen haben. Ohne die Kolonialhanken können die Kolonien nicht mehr existieren: inshesondere haben sich, wie schon ohen arwihnt, dio Erntedarlehen so eingebürgert, dal ihre beseitignng die ganzo koloniale Zuckerindustrie in Frage stellen wiirde. Cond nur dureh Opgamisation des Agrarkiedits in der Form der Erntedirlehen war es der kolonialen Landwirtschaft möglich guwesen, sich ron den Folgen der sklarenhefreinng ziemlich schnoll wieder zu erholen. Die Hypothekenschuld in Guatelompe, die 1sts nach den Gimetbüchern 94 Millionen fr. $=1 / 2 \ldots 2$ a des Wertes des Borlens betrug, war infolge der Bemihhungen der Kolonialhanken schon 1861 auf $37^{1 / 2}$ Millionen fr. gesunken. Das ist eine wanz gegewaltige Abnahme, selbst wenn die Zahl ron 94 Mlillionen fr. etwas zu hoch hegriffen sein sollte. $\left.{ }^{1}\right)$ Ferner hahen the Kolonialbanken die seit ler Sklarenbefreiung heginnende Entwertung des Bodens aufgehalten und ins ciegenteil rerkehrt, indem sie

1) Isaak, Parlam. Bericht 1898. 
den Pflanzern durch Gewährung ron Darlehen den Mut gaben, wieder hapitalien in den Grund und Boden zu stecken.

Das Kreditbediurfnis der Kolonien ist in dem ansreichendsten Mabe befriedigt worden; die Banken haben in dieser Beziehung eher zu viel als zu wenig getan. Schon 1863 und dam spaiter zu wiederholten Malen hat die Überwachungskommission die Kolonialbanken ror C̈bertreibungen in ihrer Kreditgewährung warnen miissen.

Die Herabsetzmng und Regulierung des Diskontsatzes ist ein unstreitiges Terdienst der Kolonialbanken, wie umgekehrt auch eine Lrsache ihrer Erfolge. Klar ist auch, dab der hohe Leihzins ron 1\$\%, der ror 1851 in den Kolonien gang und gäbe war und seit dem Erscheinen der Kolonialbanken auf etwa $6^{\prime \prime} \%$ im Durchselnitt gesunken ist, mit dem Verschwinden der Banken wiederkelren wiurde, besonders da, wo, wie in Guadeloupe, die Kolonialbank dis einzige Kreditinstitut der Kolonie ist.

Die Auschaltung aller Zwischenhände im Wechsel-, Lombart- und Diskontgeschät. sowie allerjüngst in Guyane beim Ankauf ron Rohgold') ist den Kolonialbanken zu verdanken. Die Banken restraten bei den Wechselgeschiften — mochten sie durch Waren- oder Entedarlehensgesehäfte herrorgerufen sein - das Interesse des kolonialen Produzenten oder Kaufmanns gegenüber den französischen oder fremdländischen Kaufleuten. $\left.{ }^{2}\right)$ Daß die Kulonien selbst die Kolonialbanken nicht entbehren zu können slauben, zeigt der mehrfach ${ }^{3}$ ) erwähnte Beschluli des Generalrats ron Rémion, der dortigen Bank mit einem Darlehen ron 1.5 Millionen fr. ans der Not zu helfen, das infolge der Rïckzahlungs- und Zinsbedingungen fast einer Subrention gleichkam. Dieser Beschlub erklärt sich nicht nur aus rer Bedeutung der Banknoten für den ciedrerkehr der Lolonie: er wird erst recht rerstindlich, wenn man erwïgt, daß die Kolonie ihre Haupteinuahmen ans den Ausfuhrzölen auf Zucker, (iold und Arachiden bezogen, und dab eine Einstellung

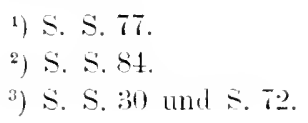


der Banktaitigkeit alle diese Produktionszweige und damit das Budget der Kolonie aufs ummittrlbarste und empfindlichste wetroffen hätte.

Die Koloniabanken haben - wie wir nach dem trexaten feststellen kömnen - trotz ihner Wingel allen billigen Erwartumgen entsprochen.

$$
\$
$$

\section{DAS ERGEBNIS FÜR BANKES UND IHRE AKTIONARE.}

Das Ergebuis für die Bank selbst wa nicht so giunstig. Freilich, wem man den Durchschnitt aller ron 165:) his 1905 gezahlten Dividenden nimmt, so haben die Entschidignngsberechtigten, welche ibber Sacht und ungefragt Alitionän von Koloniabanken geworden waren, krin Recht gebabt, sich über den Kalılungsmodus für ihre Entschädigung zu beklagen. Statt der $3 \%$, die ihmen ilue Rentonlmiefe seit $186 \%$ num cinbrachton, haben sie jährlich und durchschnittlich:

I.

$$
\text { von } 1853-1870
$$

$$
1870-1883
$$

, Guadeloupe $7.15^{\circ} . "$

, Rémnion

$5,5 \%$

1855-1870

, Guyane

$$
11.47 \%
$$

„Sénógal $15.34^{\circ} / 1$

13,2000

$14,67 \%$

III.

$$
1883-1905
$$

8.2500

(1) $.7^{\circ}, 0$

$4.62 \%$

$$
15.15 \%
$$

$14,76 \%$

$7.6930 / 0$
IV.

1.55:-1905

$10.15 \%$ $9.55^{\circ} 0$

$8,4^{\circ} / 0$

1855-1905

$16,07^{\circ} / 0$

$1855-1901$

$8.19^{\circ} 0$

Dividende erzielt. Zieht man ron den Zahlen in der letzten Rubrik (IV) etwa $4,5^{\circ}$ a ab (= drm Zinsgewinn der Banken ans den Rentenbriefen ihres Kapitals mol iluer Reserven), so rrailt sich für die 5 Kolonialbanken für die \%eit seit ihrem Bestehen

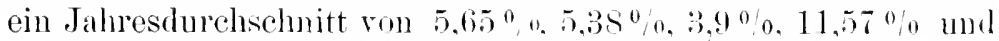
3,69\% Dividende. Das ist ein Reingewinn, aler mit Rijeksicht anf das enorme Risiko der Kolonialhanken nicht befriedigen kamu. Eine Ausnahme macht allerdings die Bank ron Guyane, bej velcher allein auch der Durchschnitsertrag der Alitie in fortdauerndem steigen begriffen ist. (s. obige Tabclle Rubrik I his IIl.) 
Wir sprachen eben ron dem großen Risiko der Kolonialbanken. Din Risikofrage wird noch am Schlusse dieser Arbeit erörtert werden. Hier sei nur bemerkt. daß das Risiko der Kolonialbanken zum Teil daher stammte, daf sie kïhnel waren in ihren Geschäften als etwa ein so altes und so fest gegründetes Institut wie die Bank ron Frankreich - eine Eigenschaft, welche die Folonialbanken mit allen lireditinstituten gemein haben, welche nene, noch unbekamnte Bahnen einschłagen müssen.

Das Kapital der Banken ron Martinique, Guadeloupe und Rémion ist jetzt wieder intakt: es war aber oft anf weniger als $2 / 3$ seines Nominatbetrages reduziert und die Reserven ganz anfgezehrt. Terhste ron äber 1 Millionen fr. in einem Jahre waren gar nicht so selten. Ruinis wirkte ror allem ler hohe Wechselkurs, indem er die schuld rer holonialbanken an das Diskontkoutor romöhte. Diese Schuld hetrug bei der Bank rom Martinique im Maximum 7.7 Mill.fr. (30. V1.1s91), gegen eine Forderung ron 1.5 Mill. fr., welche die Bank noch 1859 an das Kontor hatte.

bei der Bank ron (inadeloupe im Maximum 6.4 Mill.fr.(30. Y 1.1895): noch lss: hatte die Bank an das Kontor eine Forderung ron 6,5 Mill. fr..

hei der Bank von Réunion im Maximum s.3. Hill. fr. (30. Y1. 188:3), während ihr Konto heim Kontor 1850 mit 2.1 Mill. fr. zu ihren Gunsten schlob.

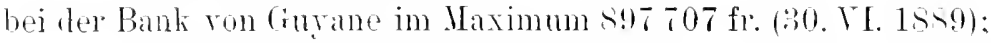
190:? hatte sich disser solde débiteur in einen solde créditenr rom $665568 \mathrm{fr}$. rerwandelt,

bei der Bank ron sénégal in Maximum 1.3 Mill. fr. (30. Y I. 1.99): schon 1901 hatte die Bank wierler einen sulde crérliteur ron $80(\mathrm{i}) 2 \mathrm{~g} ! \mathrm{fr}$.

Ian beachte hierbei den jähen VTechsel! Daf eine hohe schuld an das Diskontliontor für die Kolonialhanken infolge des $r \%$ igen Lontokorrentzinses eine grofe Last war, ist ohne weiteres klar.

Die sicherung des Gehtumlaufs in den Kolonien war den Banken nur mightieh durch standige Feldeinfuhr so lieb sich the Bank ron Guateloupe jährlich für 1,5 Millionen fr. Geld 
aus Frankreich, die Bank von Sénégal bisweilen sogar für 2 MLillionen fr.) ${ }^{1}$ ) oder aber unter Gefährdung der Einlösbarkeit ihrer Noten, also unter Gefährdung ihres Bankkredits. Die Verluste und schlechten Dividenden der Kolonialbanken waren also nicht immer von diesen selbst verschuldet durch unkaufmännische Geschäftsführung oder statutenwidrige Handlungen. Obendrein war nicht jeder Statutenver'stoß un Fehler; die Bank wurde oft durch die Macht der Verhältnisse gezwungen, anch in ihrem eigenen Interesse den Statuten zuwider zu handeln, z. B. wenn sie einem schuldner die Verfallzeit verlängerte, um seinen Konkurs zu vermeiden, oder wemn sie ilm dureh ein neues Darlehen unter die Arme griff, um ihm Gelegenheit zu geben, sich wieder empor zu arbeiten, oder wenn sie im Interesse der Kolonie mit uler Ausgabe von Anweisungen auf das Kontor fortfuhr trotz der ilur hierdurch erwachsenden Lasten und trotz der Verluste am Wechselkurse. Die Bank von Guadeloupe hat z. B. von 1898-1900 jährlich einen 'Teil ihres Gesehäftsgewinns dazu rerwandt, den Wechselkurs ron $28 \%$ anf $13 \%$ herabzudrücken, dem ein Sinken des Wechselkurses lag in ihrem eigenen Interesse. Kurzum, Risiko und Verluste der Kolonialbanken waren oft nur die natürliche, ja notwendige liehrseite der ron ilmen den Kolonien geleisteten Dienste.

Wir bestreiten nicht, daß eine bessere Bankleitung trotzdem manche schwere Verluste der Kolonialbanken rermieden hätte. Das ändert aber nichts an der Tatsache, daß die Banken, um den Kolonien zu dienen, große Opfer gebracht haben und bringen mußten.

Vielleicht hätten die fünf Kolonialbanken mit einer anderen Bankorganisation mehr Erfolge erzielen können. Eine Kolonialbank, deren Sitz in Frankreich ist, hätte in Zeiten hoher W'echselkurse den einheimischen Kredit in Anspruch nehmen kömnen und dadurch Verluste am Wechselkurse vermieden. Eine Vereinigung mehrerer Kolonialbanken, z. B. der Banken von Martinique, Guadeloupe und Guyane, zu ciner einzigen Bank hätte

1) Bericht der Ü. Ko. $1892 / 93$.

Soltau, Die französischen Kolonialbanlien. 
das Gesamtergebnis gehoben und es ermöglicht, den jähen Wechsel der Konjunkturen besser zu überwinden. Tielleicht wäre es auch ron Torteil gewesen, den Direktor der Banken nicht ron der französischen Regierung, sondern in erster Linie ron den am Wohl der Bank selbst interessierten Aktionären abhängig zu machen. Alle diese Torschlige und Änderungen sind rerwirklicht und praktisch erprobt worden ron den Kolonialbanken der zweiten Gruppe, die nummehr zu besprechen sein werden. 
ZTE EITES BUCH.

\title{
DIE BANKEN VON NEUKALE- DONIEN, INDOCHINA UND WESTAFRIKA.
}

\author{
Erster Absehnitt. \\ $\$ 21$. \\ DIE BANK VON NEUKALEDONIEN.
}

Zur zweiten Gruppe der Kolonialbanken gehören die Banken von Neukaledonien, von Iudochina und ron Westafrika.

In der im Juli 1874 gegrïndeten Bank ron Neukaledonien trat der neue Typus zum ersten Male in Erscheinung. Aber erst die ein Jahr später errichtete Bank ron Indochina hat den nenen Typus zu Ehren gebracht. Denn die Bank ron Neukaledonien nahm ein baldiges Ende.

1872 gründeten französische Kapitalisten auf der Insel Neukaledonien eine Gesellschaft zur wirtsehaftlichen Erschließung dieser französischen Kolonie und zur Erleichterung des Handels mit Australien und Europa. ${ }^{1}$ ) Diese Gesellschaft erhielt von der französischen Regierung Landkonzessionen sowie Befreiung ron der Stempelpflicht für die Noten alu porteur et à vue, die sie in der Kolonie ausgeben wïrle. Die Regierung wollte eine Kontrolle über die Gesellschaft haben und schlob deshalb 1874 mit ihr einen Tertrag, wonach die Gesellschaft das Notenrorrecht und das Recht zu Erntedarlehen unter den für die fünf alten Kolonialbanken geltenden Bedingungen erlielt. Dafür unterwarf sich die Gesellschaft bestimmten nu durch Dekret abänderlichen Statuten. In Ausführung des Art. 1 dieser Statuten teilte sich die Gesellschaft ron Nenkaledonien in eine Bank ron Nen-

1) Renaud a. a. O. S. $189 / 93$. 
kaledonien und in eine kaledonisehe Bodenkreditgesellschaft, anf welch letztere die 25000 ha Landkonzessionen der ursprünglichen Gesellschaft ron Neukaledonien übergingen. Die Bank ron Nenkaledonien behielt nur noch das Recht, bis zu dem Betrage ron 1 Million fr. Aktien der neuen Borlenkreditgesellschaft zu zeichnen. ${ }^{1}$ )

Die Bank erhielt ilur Totenprivileg auf 20 Jahre,2) ihren Sitz hatte sie in Paris, ihre Hauptniederlassung in Touméa auf Neukaledonien. Sie war eine Aktiengesellsehaft mit einem Kapital von 4 Millionen fr., auberdem gab es noch 1600 sogenannte actions de jonissance a 500 fr., die aber erst damn etwas erhalten sollten, wemn an die Alitionäre $6 \%$ des eingezahlten Kapitals verteilt und der Reserve $1 / 2 \%$ des eingezahlten Grundkapitals zugeschrieben war. Der Bank waren alle Geschäfte erlaubt, welche die fünf alten Kolonialbanken nach Gesetz ron 1874 treiben durften. Doch konnte sie nicht nur Gegenstände von Gold und silber, sondem auch solche ron Kupfer und Nickel kaufen, verkaufen, beleihen und als Dépoit annehmen. $\left.{ }^{3}\right)$ Da die Bank ilıren Sitz in Frankreich hatte, durfte sie auch dort Geschäfte machen: in Betracht kam der Handel mit Anweisungen, Schecks und Tratten auf Australien, England oder Nenkaledonien, die Diskont- und Inkassogesehäfte und die Aushündigung von hreditbriefen gegen Deckung. Es war der Bank auch erlaubt, ihr in Paris rerfügbares Kapital in erstklassigen französischen Wertpapieren oder in Wechseln auf Paris mit zwei Unterschriften und höchstens 90 Tagen Verfallzeit anzulegen. Doeh sollten ihre Geschäfte in Paris höchstens 1/4 ihres Kapitals in Anspruch nehmen.

Die V'erwaltung der Bank lag einem von den Aktionäiren gewählten Verwaltungsrat ob, der die ansgedehntesten Befugnisse hatte und sogar den Direktor (ler Bank ernannte. ${ }^{4}$ ) Der Direktor war hier im Gegensatz zu den fünf alten Kolonialbanken Beauftragter und Geschäftsführer des Verwaltungsrates. Es gab

1) Statuten 187. Art. 6.

2) Dekret 187' Art. 3.

3) Statuten Art. 20.

4) Statuten Art. 72. 
keine Zensoren und keine Überwachungskommission für die Bank, sondern nur zwei Regierungkommissare (in Paris und in Touméa).

Das Kapital der Bank war $187+$ zur Hälfte eingezahlt. Bei einem Betriebskapital von 2 Millionen fr. gab die Bank im ersten Semester 1865 (1. I. - :,0. VI.) fïr 1,4 Millionen fr. Noten aus, die in der Kolonie gut anfgenommen wurden; sie diskontierte zu 12\% und ihr Portefenille stieg ron $1088793 \mathrm{fr}$. am 30. VI.74 anf 2655752 fr. am 30. VI. 75. Ihre Wechselgeschäfte erreichten im ersten Scmester 1875 die Höhe ron 4 Millionen fr. Die Anssichten waren durchans guinstig. Allein infolge unvorsichtiger und übertriebener Vorschüsse an die Viehzuichter sah die Bank sich genötigt, am 16. Oktober 1877 ihre Zahlungen einzustellen. Am 27. Norember wurde der Konkurs über sie eröfnet und am 27. Februar 157s der Einspruch des Terwaltungsrates gegen den Konkurseröffnungsbeschluß in der Berufungsinstanz àgewiesen.

Die Hoffnung, daß die Bank bald nach Überwindung augenblicklicher Schwierigkeiten ihre Zahlungen wieder aufnehmen würde, war damit zumichte geworden.

Da die Toten der Bank ihre gesetzliche Zahlungskiraft durch die Liquidation der Bank verloren, mubte man zur Sicherung des Geldrerkehrs für 1,5 Millionen fr. Kassenscheine in Beträgen ron 5-100 fr. ausgeben und sie mit Zwangskurs rersehen.

Eine Entscheidung des Staatsrats belehrte die noch Zweifehnden, daf der Staat durch Verleihnng des Notenprivilegs keinerlei Verantwortung für die Zurückzahlung der Banknoten übernommen habe.

Der eigentliche Grund für den Mißerfolg der Bank ron Neukaledonien lag mehr anßerhalb der Bank und ihrer Tätigkeit. Neukaledonien war damals noch nicht entwickelt genug für eine Bank von der Größe der Bank ron Neukaledonien. Ihr Erbe trat später die Bank von Indochina an, welche 1888 in Nomméa eine Filiale errichtete. Die Bank ron Indochina hat den überzeugenden Nachweis erbracht, daß an dem Untergange der Bank von Neukaledonien ihre Bankorganisation nicht schuld war. 
Zweiter Abschnitt.

\title{
DIE BANK YON INDOCHINA.
}

\author{
1. Kapitel.
}

s.

\section{GRÜNDUNG DER BANK; IHR ENTWICKLUNGSGANG.}

Auch die Bank ron Indochina ist wie ihr Vorbild, die Bank von Neukaledonien, keine Schöpfung des Staates, sondern eine Privatgesellschaft. die der Staat zu einer privilegierten Bank erhob. Sie wurde dureh Dekret rom 21. Januar 1875 errichtet auf zunächst 20 Jahre mit dem Sitze in Paris und 2 Filialen in Saigon (Cochinchina) und Pondichéry (Franz. Indien), 1885 kam die Filiale Haiphong in Tonking hinzu. Durch Dekret rom 20. Februar 1888 wurle das Bankprivileg anf weitere 10 Jahre rerlïngert, rom 221. Januar 1895 ab gerechet, und der Bank rlie Verpflichtung auferlegt, zu den drei schon bestehenden eine vierte Filiale, und zwar in Nouméa, zu gründen und außerdem Filialen und Geschäftsstellen überall da im fernen Osten zu errichten, wo der Kolonialminister es verlangen würde. Gleichzeitig wurde das Kapital der Bank, das nrsprïnglich 8 Millionen fr. = 16000 Aktien à $500 \mathrm{fr}$. betrug, auf 12 Millionen fr. erhöht und die neuen Altien den alten Aktionären zum hurse ron $575 \mathrm{fr}$. pro Aktie ahgegeben. 1900 erhielt die Bank das Notenprivileg auf weitere 15 Jahre, also bis zum 221. Januar 1920 rerliehen. Ihr Kinpital wurde auf 24 Hillionen fr. erhöht und die neuen Alitien zum Kurse ron $675 \mathrm{fr}$. angeboten. Schon 1906 mußte das Kapital wiederum vermehrt werden: es stieg darlurch auf 36 Millionen fr. Die $2 \pm 000$ neuen Alitien konnten zum Kurse ron $1000 \mathrm{fr}$. pro Aktic ansgegeben werden. Die rasch aufeinander folgenden Kapitalerhöhungen waren deshalb nötig geworden, weil die Bank immer nur 1/4 des Nominalwerts der Aktien ron den Aktionären eingefordert hatte. Die Aktien blieben deshalh Namenaktien, da sie bis auf heute noch nicht vollbezahlt sind. Aber die Bank hatte durch den von ihr 
geübten modus der Kapitalerhöhung den Vorteil, ihren Reserven im ganzen 16,s Millionen fr. Agiogewinn aus dem Verkaufe der neuen Aktien zuwenden zu können.

Ein Dekret vom 24. II. 1904 ordnete die Errichtung einer Filiale auf Tahiti an. Somit besteht jetzt die Bank von Indochina aus 5 Filialen und aus den 10 wachfolgenden Geschäftsstelien: Hanoi und Tonrane in Tonking, Pnom-Pengh in Cochinchina, Shanghai, Hongkong, Canton, Hankéou in China, Bangkok und Battambang in Sian, sowie Singapore. Wen man den Sitz der Bank in Paris einrechnet, hat die Bank ron Indochina gegenwärtig 16 Niederlassungen.

Maßgebend für die Bankrerfassung ist nur das Dekret ron 1900, da es rlie Bestimmungen der früheren Dekrete aufhebt und ersetzt.

2. Kapitel.

$$
\text { s } 23 .
$$

\section{GEMEINSAMES MIT DEN ALTEN KOLONIAI,BANKEN.}

Die Bank ron Indochina hat manches gemcin mit den fünf alten Kolonialhanken: Erst eine Verordnung der öfentlichen Gewalt hat sie zu dem gemacht, was sie ist, ein privilegiertes Privatbankinstitut. Die Privelegien wurden der Bank aber nur unter der Bedingung übertragen, da? sie sich richtete nach bestimmten, durch Dekret gegebenen und nur durch Dekret veränderlichen Statuten.

Wir sehen also anch hier wie bei den alten Kolonialbanken eine Einwirkung der Staatsgewalt auf die innere Verfassung eines Privatbankinstituts. Die Abhängigkeit der Bank rom Staate zeigt sich vor allem noch in 4 Punkten: Filialen und Cieschiiftsstellen können nur durch Dekret errichtet und wierler beseitigt werden. ${ }^{1}$ ) Auch für ihre Geschäftstätigkeit gilt das oben s. 25/26 kennen gelernte einschränkende Prinzip, daß die Bank nur die ilır durch

1) Dekret 1900 Art. 4 . 
die Statuten erlaubten Geschäfte treiben darf. ") Ferner kamn keine Dividendenverteilung erfolgen ohne Zustimmung des Kolonialministers. ${ }^{2}$ ) Und schließlich übt die Überwachungskommission der Kolonialbanken anch in bezug auf die Bank von Indochina alle ihr uach dem Kolonialbankgesetz ron 1901 bezw. 1874 zustehenden Rechte und Befugnisse ans. ${ }^{3}$ )

Die Aufgabe der Bank von Indochina war wie diejenige der alten Kolonialbanken: die Vermittlung zwischen Kapital und Arbeit in der Kolonie, eine ausreichende, auch den kleinen Mann berücksichtigende Gewährung produktiven Kiedits, ferner die Sicherung des Geldumlaufs in den Kolonien sowie die Regelung und Erleichterung ihres auswärtigen Zahlungsverkehres. Wie in den Zuckerkolonien, so zeigten sich auch in Indochina zwei Schwierigkeiten, deren Lösung eine Lebensfrage für die Kolnnie wie für die Kolonialbank war, nämlich die monoculture und der Trechselkur's.

Erwïhnen wir noch, daß auch die Bank von Indochina das ausschliebliche Notenansgaherecht in ihrer Kolonie hat und alle sonstigen Rechte und Torrechte besitzt, die das Gesetz ron 1874 zugunsten der fünf alten Kolonialbanken enthält, ${ }^{\natural)}$ daß sie vor allem also anch die so charaktcristischen prèts sur récolte gewähren und Effeliten mit nur 2 Unterschriften diskontieren darf, wobei cine Unterschrift ebenfalls wie bei den fünf Kolonialbanken noch ersetzt werden kamn durch gewisse Pfänder.

Damit ist wohl die nahe Verwandtschaft der beiden Gruppen ron Kolonialbanken hinlänglich erwiesen. Es scheint riel eher der Rechtfertigung zu bediurfen, weshalb wir beide Gruppen getrennt betrachten. Wir rechtfertigen dies einerseits durch die Feststellung, daf die Bank ron Indochina eine Kolonialbank großen Stils ist, wïhrend die fünf alten Kolonialbanken, trotzdem die Kolonien sie nicht entbehren können, doch nur kleine Kíreditinstitute ron relativ geringer Bedeutung waren und geblieben

1) Statuten 1900 Art. 14.

2) Staluten Art. 36.

3) Dekret 1900 Art. 14.

4) Dekret 1875 Art. 1. 
sind. Sodamn aber ist zu beachten, dab wir hislang nur das beiden Kolonialbankgruppen Cemeinsame erwähnt haben, nieht das sie Tremnende. Das Letzte hat jetzt aber zu geselsehen.

\section{Kapitel.}

\section{BESONDERHEITEN DER BANK VON INDOCHINA.}

Die ersten Statuten der Bank ron Indoehina rom Jahre 1875 wichen sehon stark ab ron den 1874 revidierten Statuten der fünf alten Kolonialbanken. Aber diese Abweichungen erlangten erst Bedeutung durch die so ganz anders verlaufene Entwickelnng der Bank ron Indochina. Diese war Schuld daran, daß die Abweichungen sich mit jeder Statutenänderung rermehrten und daß die Kluft immer gröfer wurde.

$$
5.4 .
$$

BESONDERHEITEN IN DER BANTIEREASSUNG.

Die Bank von Indochina war zwal mit einem liapital von nominell \& Millionen fr. gegruindet. Da aber nur 1/4 daron eingezahlt wurde, war ihr tatsächliches Grundkapital $\mathrm{um}^{1 / 3}$ kleiner als dasjenige der Banken in den Znckerkolonien. Aber schon 1888 bei der ersten Kapitalerhöhung der Bank ron Indochina zeigte es sich, wie grundverschieden Lage und Entwicklungsmöglichkeiten der alten Koloniabanken und ihrer jungen Schwester waren. Dic Bank ron Indochina erzielte bei der Ausgabe ron 8000 nenen Aktien einen Agiogewinn ron 75 fr. pro Aktie, indem sie sich auf jede neue Aktie ${ }^{1 / 4}$ ihres Nominalwerts $=125 \mathrm{fr}$. $+75 \mathrm{fr}$. Kursagio $=200 \mathrm{fr}$. in bar einzahlen ließ. Man vergleiche damit die Schwiurigkeiten, unter denen sich die durch Dekret rom 15. XII. 1 s 84 genehmigte Kapitalerhöhung der Bank ron Réunion ron 3 auf 4 Millionen fr. rollzog. Lange Zeit erwartete man die Bareinzahlungen anf die 2000 neuen Aktien vergebens. Schließlich half man sich durch ein Arbitragegesehäft. Die das Kíapital der Bank repräsentierenden Rentenbriefe wurden rerkauft und der Kaufpreis in französischen Staatsobligationen angelegt. Hierdurch wurde reichlicher Gewinn 
erzielt, ${ }^{1}$ ) der zum 'Teil zu den nötigen Einzahlungen auf die nenen Aktien rerwendet wurde. ${ }^{2}$ )

Die Bank ron Indochina hat auch bei jeder weiteren Kapitalerhöhung einen steigenden Agiogewinn erzielt und sich so mühelos eine Ersatzreserve ron 16,8 Millionen fr, erworben. Auch sonst waren die Zuwendungen an die Reserven selur stark, freilich mehr anf Initiative der Bankleitung hin, als auf Crund statutarischer Bestimmungen.

Von dem Gewinn wird halbjährlich nur $1 / 2 \%$ des eingezalılten Kapitals dem ordentlichen Reservefonds zugewendet und damn eine erste Dividende von $6 \%$ an die Aktionäre verteilt. Von dem etwa rerbleibenden Restgewimn werden $80 \%$ als zweite Diridende verteilt, $10 \%$ dem Verwaltungsrate zugewendet und $10 \%$ einem besonteren ebenfalls statutarischen fonds de préroyance zugewiesen. Dieser hat schon 1s.93 die ordentliche Reserve überstiegen und war 1906 first doppelt so hoch als jene (1,7 Millionen fr. gegen 0,9 Millionen fr.).

Die Hauptsache aber sind die starken anferstatutarischen Reserven, welche die Bank gebildet hat, z. B. die Immobilienreserve $=1,5$ Millionen fr: (1906), die Reserve für neue Filialen nnd Geschäftsstellen ebenfalls 1,5 Millionen fr. (1906), die Mobilienreserve 344239 fr. (1906) und die mehrfach bereits erwälnte Ersatzreserve von 16, S Lillionen fr. (1906). Insgesamt besitzt die Bank ron Inrlochina jetzt ea. 2\& Millionen fr. Reserven.

Die Aktien der Bank, welche, solange sie nicht rollbezahlt sind, Namenaktien sind, werden ïbertragen dureh Abtretungsurkunde, deren Form der Terwaltungsrat festsetzt.

Jede Aktie gibt Anspruch auf einen entsprechenden Teil an Aktivrermögen der Bank im Falle ihrer Liquidation. Diese ist wie bei den alten Kolonialbanken geregelt: sie kann statt-

1) Isaak: Parl. Bericht 1898 .

2) 1875 mußte die Bank jedoch auf ministerielle Verfügung hin diese Staatsobligationen wieder verkaufen und dafür Rentenbriefe ankaufen. Diese Operation war mit großen Verhusten für die Bank rerbunden; sie ist wohl auch ein Grund gewesen für die 1899 vorgenommene Kapilatverminderung von 4 auf 3 Millionen fr. 
fiuden, wenn die einfache Mehrheit der anf der Generalversammlung anwesenden Aktionäre und 2/3 Mehrheit des durch sie vertretenen Kapitals dafür stimmen. Sie muß erfolgen, wenu 2/3 des Kapitals verloren sin(. $\left.{ }^{1}\right)$

Die Hauptunterschiede zwischen der Bank ron Indochina und den alten Kolonialbauken ergeben sich erst ans den Betrachtungen der inneren Bankrerfassung.

Wie schon erwïhnt, hat die Bank ron Indochina ihren Sitz in Paris. Das lag begriundet in der Art, wie hier das Kapital der Bank beschafft wurde. Es gah in Indochina keine Sklarenbefreiung und keine Entschädigungsherechtigten wie in den fünf alten Kolonien Frankreichs. Das Kapital der Bank muBte daher aufgebracht werden dureh private Zeichnungen. Diese versprachen nur dann einen vollen Erfolg, wenn es gelang, das cinleimische Kapital für die neue Bankunternehmung zu interessieren. Das war aber leichter möglich, wenn Paris sitz der Bank und Ort der Generalversammlung war, weil damn die Hochfimanz ihren Einflub und ihre Kontrolle ausiiben konnte.

Die Bank wurde dadurch, daß Paris ihr Sitz ist, unabhängig von lokalen Einfliissen. Wie wichtig und wertroll das war, ergab sich deutlich, als die Bank ihre Niederlassungen stark vermehrte. Eine Bank mit dem Sitz in Saigon hätte nie die Bedürfnisse der anderen Filialen objektiv absehiitzen und in gerechter Weise befriedigen können.

Der Sitz der Bank in Paris machte das Ant eines Zentralgeschäftsführers nach Art der alten Kolonialbanken umnötig; auch bedurfte es hier keines besonderen Bankinstituts zur Vertretung der Kolonialbank in Europa und Frankreich. Das Kapital der Bank ron Indochina war in bar eiugezahlt, nicht durch Apports von Rentenbriefen gebildet wie bei den alten Kolonialbanken. Die Bank von Indochina rerfügte also ron Anfang an über ein Betriebskapital und hatte nicht nötig, sich dieses erst von anderen Kreditinstituten zu leihen. Die alten Kolonialbanken litten stark unter dem hohen Zins, den sie für ihre Schuld an

1) Statuten 1900 Art. 71. 
das Kontor zahlen müssen. Die Bank ron Indochina kann, da sie auch in Paris Geschäfte treibt, die einheimischen Kapitalien zu viel billigerem Zins (d. h. zum Landeszinsfuße) erhalten, unter Umständen sogar umsonst, nämlich bei Annahme unverzinslicher Depositen. Als Entgelt besorgt sie den Deponenten das ganze Inkassogeschïft kostenlos.

Hochbedentsam ist num ror allem die neue Regelung der Verwaltung und Leitung der Bank.

Die Gesantleit der Aktionäre der Bank ron Indochina wird rertreten durch die Generalversammlung, auf der nur diejenigen 100 Altionäre Stimmrecht haben, welche Eigner der größten Anzahl Aktien sind. $\left.{ }^{1}\right)$ Außerdem muß seit dem 21. I. 1905 jeder stimmberechtigte Alitionär Franzose sein. 10 Aktien geben das Recht anf 1 Stimme; doch kann niemand mehr als 10 Stimmen besitzen, sowohl eigenen Xamens wic in Vertretung anderer Aktionäre.

Diese Regelung ist entschieden plutokratisch, sie paßt aber zum ganzen Banksystem. weil Einfluf und Terantwortlichkeit der Aktionäre hier gröher sind als bei den alten Kolonialbanken. Die stellung des Verwaltungsates zeigt das deutlich.

Art. 50 der Statuten sagt: Die Bank wird geleitet durch einen Terwaltungsrat, der aus mindestens \& und höchstens 15 Mitgliedern besteht. Die Verwalter werden sämtlich durch die Generalversammlung aus der Zahl der Aktionäre gewählt; der Verwaltungsrat hat hierbei ein Prösentationsrecht. Jeder Terwalter mul bei Antritt seines Amts nachweisen, daß er Eigner ron to Aktien ist, die bis zur. Höhe der eingeforderten Beträge cingezahlt sein müssen und unreränBerlich sind wïhrend der Amtsdauer ihres Eigners. Der Verwaltungsrat wählt sich aus seiner Mitte einen Torsitzenden, einen stellvertretenden Torsitzenden und einen Schriftführer. Prinzipiell hat der Terwaltungsrat alle Befuguisse in bezug auf die Bankleitung. ${ }^{2}$ ) Doch kann er sie ganz oder zum Teil iibertragen, was notwendig ist, seitdem die Bank an den verschiedeusten Orten der Erde Niederlassungen hat. Für

\footnotetext{
1) Statuten 1900 Art. 39/41.

2) Statuten 1900 Art. 5́155.
} 
die einzelnen Filialen, oft anch schon für bedentende Geschaiftsstellen werden rom Verwaltungsiate unter Zustimmmng des Kolonialministers besondere Dircktoren ernamnt. Diese Direktoren führen die Geschäfte unter Aufsicht und nach den Anweismngen des Verwaltungsrates in Paris; sie vertreten die Bank Dritten gegenüber, aber nur in Ausführumg der Verwaltungsratsbeschlüsse. Ilır Gehalt wijd rom Vorwaltungsrat festgesetzt. Für die Direktoren gilt das Verbot eines anderweitigen Ciewerbebetriebes und der Ausschlub von den Diskontgeschïften der Bank. Sie müssen beim Amtsantritt Eigner von 20 Alitien sein. Die Direktoren sind meist nicht Mitglieder des Terwaltungsrates. Sind sie es ausnahmsweise doch, so müssen sie natürlieh 40, nieht 20 Aktien zu eigen haben.

Sehr weise ist die Bestimmung, ${ }^{1}$ ) daf bei jeder Filiale ein Diskontausschnf einzusetzen ist, dessen Zusammensetzung und Befugnisse der Verwaltungswat festsetzt. Die Frage des Diskontsatzes und damit zusammenhängrand die des Weehselkurses ist gerarle im fernen Osten von eminenter Bedeutung, einerseits wegen der ausgedehnten und entwickelten Handelsbezichungen, andererseits weil dort die versehiedensten Mïnzen und Währungen neben einander in Geltung sind.

Wir wiederholen hier die bedeutsame Tatsache, daf bei der Bank ron Indochina der' Verwaltungsrat der alleinige 'Irigger' aller Rechte und Befuguisse ist, und dalj die Direktoren rom Verwaltungsrat abhängig sind im schürfsten Gegensatze zu der äbermächtigen Stellung, welehe die Direktoren bei den alten Kolonialbanken eimnehmen. ${ }^{2}$ ) Es besteht kein Zweifel, daß der Umstand, daf nieht die Regierung; sonder'n in letzten Grunde die selbst interessierten Alitionïre dureh den Verwaltungsrat die Direktiven geben, auf den Erfolg der Bank von Indochina ron unmittelbarem, allergünstigstem Einfluf gewesen ist. Eine Staatsaufsicht ward auch bei der Bank ron Indochina eingeriehtet, erwies sich aber als iiberflüssig. Sie wurde ausgeübt durch die Überwachungskommission, dureh Inspektoren, die aber hier

1) Statuten Art. 63.

2) Auch der Vorsitzende des Verwaltungsrates ist nur primus inter pares. 
nicht obligatorisch waren, und durch Regierungskommissare, welche am Sitze der Bank sowie bei jeder Filiale bestellt sind: bei den Filialen heißen sie Terwaltungszensor. ${ }^{1}$ ) Der Regierungshommissar ist zu jeder Sitzung des Verwaltungsrates zu laden und hat das Recht, den Kassen- und Wechselbestand sowie die Bankbücher nachzuprüfen. Er sendet monatlich einen Bericht über die Banklage und über seine Tätigkeit direkt an den Kolonialminister, unterbreitet ihn also nicht, wie bei den alten Kolonialbanken, der Generalversammlung.

Tach Erledigung dessen, was ïber die Bankrerfassung zu sagen war, gehen wir jetzt zur Besprechung der Geschäfte über, welche die Bank ron Indochina treiben darf.

\section{5.}

\section{BESONDERHEITEN IN BEZCG AUF DIE GESCHÄFTE DER BANK.}

Die Statuten reden ron „Finanzgesehïften, die sich knüpfen an die Länder, in denen die Bank Niederlassungen hat". Damit sind die räumlichen Grenzen der Banktätigkeit sehı weit gesteckt. Auch in der sachlichen Begrenzung les Cieschüftshreises war der (iesetzgeber der Bank ron Indochina gegenüber liberaler als gegen die alten Kolonialbanken. Wir werden noben nenen Geschäften auch schon bekannte Kolonialbankgeschäfte wiederfinden. Aber diese zeigen oft ein verändertes Bild, eine hesondere Entwickelung, die sich leicht erklärt aus dem größeren Milieu, in dem die Bank ron Indochina arbeitet.

Bei der Notenausgabe der Bank von Indochina bemerken wir zunächst den rein äuferlichen Unterschied, daf neben den bereits bei den alten Kolonialbanken kennen gelernten Yotenbetrïgen von 500, 100 und 5 fr. anch solche ron 1000 fr. gestattet sind. ${ }^{2}$ ) Die Noten ron $25 \mathrm{fr}$. sind hiel durch solehe ron $20 \mathrm{fr}$. ersetzt. Ferner erhiclt die Bank das Recht, unter Zustimmung des Kolonialministers in jedem Lande, wo sie Niederlassungen hat, Toten auch in lokinlem (ielde auszugeben, also

1) Statuten Al.t. 6:68.

2) Dekret 1900 Arl. 5. 
in Saigon in Piastern, in Pondichéry in Rupien, in Bangkok in Ticals. Doch sollten diese Noten in fremdländischer Währung nur ,in Wertbetrïgen ansgestellt werden, die der Stiickehng ron 1000, 500, 100, 20 und 5 fr. entsplïichen". Die Bank erklïrte aber 1900, dab sic sich dieser Bestimmung nicht unterwerfen könne bei der Notenansgabe in Ländern, die ein anderes als das französische Münzsıtstem hätten. Die Taels, Pianter, Rupien. Tieals usw entsprächen in keiner Weise den rom Gesetze rorgesehenen Notenstiickelungen. Sie hat daher, im Gesetze die Worte: .,in Werten, die der obigen stiickelung entsprechen“ zu streichen. Der Wunseh wurde genehmigt. Fortan darf die Bank anch Toten ron 5 Taels oder 100 Rupien orler 500 Piastern ansstellen, selbst wenn ihr in franzïsischer Währung ansgerlriickter Gegenwert der Stiickelung ron 1000, 500, 100, 20 und 5 fr. nicht entspricht. Eine zweite Eigentiumlichkeit der Bank ist, daf in den franziosischen Kolonien und Protektoraten nur die Filialen Toten ausgeben dürfen, dals aber in fremden Ländem auch bloße Geschäftsstellen zur Notenausgabe ermächtigt werden kömnen nach Zustimmung des framzïsischen Ninisters des Auswärtigen. Die Joten der Bank haben in den flanzösischen Kolonien und Protektoraten resetzliche Zahlungskiaft, 1) in fremden Länder'n sind sie natürlich ein reines Handelsgeld, das in Zahlung genonmen werden kamn, nicht mul. Das hat die Bank ron Indochina zu rersehiedenen Malen in mnangenchmer Weise erfahren. Thre Geschäftsstelle in Bangkok hatte P'iasternoten ausgegeben, die in Siam mit Vorliche in Zahlung genommen wurden. Ende 1902 galb die siamesische Regiertung anläblich des Übergangs siams ron der siberpiasterwïhrung zur Goldticalwährung Curreney notes mit gesetzlichem Lume ans. Diese Noten, die rollkommen metallisch gedeckt waren, rerminderten in kurzer Zeit den Notenumlauf der (ieschïftsitelle Banglok auf 1/3 seiner früheren Höhe. Toch nachteiliger als die Schaffung der Currener-Soten war es für die Bank, daß sian die freic Prägung ter silhernen 'Tiealstücke einstellte. Die anf Ticals ans-

i) Dekiret 1900 Art. ?. 
gestellten Toten erhielten dadurch ebenso wie ihr metallischer Gegenwert einen erhöhten Kurs gegenüber dem Piaster und den Piastermoten der Bank ron Indochina. So wurden ihre Toten in Siam bald völlig verdrïugt durch das einheimische Papiergeld. Ähnlich ging es 1904 den Noten der Geschäftsstelle Shanghai, die mehr oder weniger durch Noten der Imperial Bank of Chine und dureh japanische Banknoten im Unlaufe ersetzt wnrden, obwohl sie nur innerhalh, der europäischen Konzessionen in Shanghai zirkuliert hatten. $\left.{ }^{1}\right)$ Del' gegenwärtige Notenumlanf der Bank von Indochina beschränkt sich somit fast ganz auf die französischen Kolonien, in denen die Bank eine Niederlassung und damit das Notenmonopol hat.

Die Noten sind anf sicht zurïckzahlbar durch die Filiale oder Geschüftsstelle, welche sie ansgegeben hat und auberdem noch durch alle Filialen und Geschäftsstellen, die durch Vereinbarung zwischen Kolonialminister und Bank als solche bezeichnet werlen. Aber gegen eine solche Vereinbarung hat sich die Bank ron Indochina bisher noch stets - und zwar mit Erfolg - gesträubt. Ja Xoten einer Filiale, die auch bei einer anderen Filiale zurëiekzathlbar sind, zu Rimessen dorthin rerwendet werden künnen, so würden, eine Vereinbarung im ohigen Sinne vorausgesetzt, dalureh der die Yoten ausgebenden Filiale manche gewinnreiche Trechselgeschäfte entgehen. Demn die Filialen und Geschäftstellen rerkehren lebhaft miteinander, und es ist ein nicht geringer Vorteil des grofen Tetzes ron Niederlassungen der Bank, daß die eine Tiederlassung der anderen nötigenfalls mit Rimessen aushelfen kann oder gar mit Bargehl, wobei zwar nicht die Transporthosten, wohl aber die Provision an den hommissionär erspart wird.

Die metallische Drittelsdeckung der Toten muß natiirich für jede emittierende Filiale oder Geschäftsstelle besonders rerlangt und erfüllt werden. Hierbei ist aber der Metallbestand der von der emittierenden Filiale oder Geschäftsstelle abhän-

1) Vergl. Bericht des Verwallungsrates der Bank ron Indochina über das Jahr $1902 \mathrm{im}$ Economiste français 1903, 1. sem. p. 806. 
gigen Geschäftsstelle mit einzurechnen in den M[etallvorrat der Emissionsstelle.

Abhängig sind im obigen Sinne die Cieschäftsstellen PnomPengh und Battambang ron der Filiale Saimon, Canton von Hongkong, Hanoi und Tourane ron der Filiale Haiphong und bis 1903 auch Hankéon ron shanghai.

Wie bei den alten Kolonialbanken genügt nicht nur die metallische Drittelsdeckung des Notenumlaufs. Das Gesetz rerlangt auch, daß der Notenumlauf und die Kontokorrent- und anderen Schulden der Bank zusammen nic den dreifachen Betrag von Kapital und Reserven ïbersteigen. Der Geschäftsgehrauch - nicht eine statutarische Bestimmung, wie bei den alten Kolonialbanken - erlauht es der Bank ron Indochina, bei del Berechnung des gesetzlichen Maximums ihrer Schulden neben Kapital und Reserven anch den zur Drittelsdeckung der Noten nicht benötigten Metallrorrat zu beriicksichtigen. Wenn man das tut, ergibt sich für den 31. X11. 1904:

eine Bankschuld ron 104162013 fi., wogegen das gesetzliche Maximum:

113910070 fr. betrug. Die Schuld der Bank hielt sich in diesem Falle - wie ïhrigens immer - innerhalb ihrer gesetzlichen Grenze.

Neben der Notenausqabe beansprucht das Depositengeschäft der Bank ron Indochina besondere Aufmerksamkeit. Die Bank kamn nämlich im Gegensatze zu den alten Kolonialbanken auch verzinsliche Depositen annehmen : ${ }^{1}$ ) doch darf die Summe der zinstragenden Depositen das eingezahlte Grundkapital nicht übersteigen und der für die Depositen gewährte Zins höchstens halb so hoch sein, als der Diskontsatz der Bank, nie aber höher als $5 \%$. Eine Ausnahme hierron ist nur gestattet, wenn die Depositen aus der Reservekasse der Kolonie stammen.

Alle diese Bestimmungen haben bislang keine praktische Bedeutung erlangt. Denn die Bank ron Indochina hat von ihrem Rechte, die empfangenen Depositen zu verzinsen, keinen Ge-

1) Statuten 1900, Art. 15 . 
114 II. DIE BANKEX VON NEUKALEDONIEN, INDOCHINA UND WESTAFRITA.

brauch gemacht. Sie hatte es auch nicht nötig, weil sie auch olne Zinsvergütung soriel Depositengelder erhielt, als sie brauchen konnte.

Die Bank ron Indochina empfängt nicht nur Depositen; sie leiht anch solche im Kontokorrentrerkehr ans in Gestalt ron Volschüssen, aber höchstens auf 6 Monate. Dann haben wir es aber mit einem Aktirgeschïft der Bank zu tun.

Unter den Altirgeschäften der Bank ron Indochina nehmen die Diskontgeschaifte die erste Stelle ein. Die Bank kann Solawechsel und Tratten mit zwei Unterschriften, die an ihrem Ausstellungsorte zahlbar sind, diskontieren, wenn ihre Terfallzeit 120 Tage nicht iibersteigt; ferner durf sie Tratten, Anweisungen orler Scheckis, the direkt orler an Order stehen und gezogen sind auf die Kolonie, das Mutterland oder das Ausland, ausstellen, abgehen, kanfen oder diskontieren. ${ }^{1}$ ) Wohlgemerkt: im Gegensatze zu den fünf alten Kolonialbanken sind hier auch Distanzwechsel auf die Kolonie, nicht hlof Platzwechsel auf die Kolonie statthaft.

Die Terfallzeit der 'Tratten und Anweisungen darf, wenn sie bestimmt ist, 120 Tage nicht überschreiten: ist sie unbestimmt, so hat man zu unterscheiden: Nachsichtwechsel, die einem lokalen Geschäfte ihre Entstehung danken, dürfen nicht mehr als 90 'Tage Laufzeit haben, alle anderen dagegen bis zu 180 Tagen nach Sicht. Das sind rolle 6 Monate Lanfzeit, also die Hälfte mehr, als dic Maximallanfzeit der Wechsel bei den alten Tolonialhanken beträgt.

Der Ersatz der zweiten Unterschift auf dem Wechsel durch eine reale sicherheit ist hier ähnlich wie bei rlen alten Kolonialbanken geregelt. Nen ist, daß bei der Bank von Indochina die zweite Unterschrift auch noch ersetzt werden kann:

a) auf Platzwechseln und nicht handelsmäßigen Obligationen durch regelrechte Abtretung ron Forderungen gegen Stadtrerwaltungen, die gesetzlich zur Ausgabe ron Obligationeu ermächtigt sind, oder ron Schiffshypotheken, die an französischen Schiffen

1) Statuten Art. 15, 1, 2 u, 3 
oder an solchen, die wenigstens dem franzïsischen Gesetz unterworfen sind, bestehen. ${ }^{1}$ )

b) bei Tratten nut Anweisungen durch die der Bank gemachte Mitteilung von cinem dem Trassanten durch den Trassaten eröffneten Kredit. $\left.{ }^{1}\right)$ Der Geschäftsrorgang, der sich dabei abspielt, heißt: Kanf gegen bestïtigten Bankliredit. Der 'Trassat übersendet hier als kolonialer Importeur (Käufer) der Bank einen Kreditbrief, durch den er liese ermächtigt, bis zu einer bestimmten Höhe Wechsel, die von einem auslïndischen Lieferanten auf ihn gezogen sisd, zu honorieren gegen Einhändigung des honossoments über die gekaufte Ware. In der antizipierten Akzeptserklärung, die ebenfalls die zweite Unterschrift einer 'lratte ersetzen kann, sehen wir die im Exportverkehr der Kolonie iibliche Form des Akzeptkredites. Hier weist der Küufer einer kolonialen Ware den kolonialen Lieferanten an, anf eine bestimmte Bank zu ziehen. Diese akzeptiert damn die Tratte gegen Einhändigung des Konossements über die verkanfte Ware.

Der Kanf gegen bestätigten Bankkredit ist ühlich beim kolonialen Import, der sog. Akzeptkredit dagegen beim kolonialen Export. Beide Formen der Krediteröffnung kommen in ihren Wirkungen einander gleich; darmm war es verkehrt, den alten líolonialbanken nur die eine Form (den Akzeptkredit) zu gestatten; der Bank ron Indochina stehen, wie gesagt, beide Wege offen.

Die Bank kann schlieblich auch handelsmälige oder nicht handelsmäßige Schuddscheine diskontieren, die durch bestimmte Pfänder gedeckt sind. Es sind das Realkreditgeschïfte; rerschiedene solcher Darlchensgeschäfte lernten wir bereits bei den alten Kolonialbanken kemnen. Doch sind hier in zweifacher Beziehung erhebliche Abweichungen festzustellen. Zunächst ist hier die Zahl der Pfänder vermehrt. Als Ifand für ein Darlehen sind nicht nur zngelassen titres moliliers, anf welche die Bank ron Fraukreich Darlehen gibt, sondern anch solehe Sehuldbriefe, die ausgegeben oder garantiert sind durch die Regierungen und Stadtverwaltungen der Lünder, in denen die Bank Filialen oder Creschäftsstellen hat; desgleichen in Französisch Indien eng1) Statuten Art. 16. 
lische oder indische Rentenbriefe. Neben Gegenständen von Gold und Silber können auch solche von Kupfer sowie Edelsteine als Pfand dienen, wie die Bank ja auch solche Gegenstände kaufen, rerkaufen und als Dépòt volontaire annehmen darf. $\left.{ }^{1}\right)$ Hingegen ist der Bank ron Indochina die Beleihung ihrer Aktien verboten.

Eine zweite Eigentümlichkeit der Darlehensgeschäfte der Bank ron Indochina besteht darin, daß die wichtigsten, schon bei deu alten Kolonialbanken kemnen gelernten Darlehensarten eine verïnderte Gestalt oder eine besondere Entwicklung aufweisen. Bei den Waren lombardgeschäften der alten Kolonialbanken mußte die Ware hinterlegt werden in öfentlichen Magazinen oder in privaten Lagerräumen, deren Schlüssel der Bank ausgehändigt waren. Für die Bank ron Indochina besteht noch eine dritte Möglichkeit. Sie kann die ihr verpfändeten Waren auch in Räumen hinterlegen lassen, die (ler Bank selbst gehören. ${ }^{1}$ ) In diesem Falle hat die Bank den tatsächlichen, nicht blob fiktiren Besitz der Waren. Andererseits darf die Bank ron Indochina sogar, wenn es die lokaten Gewohnheiten zulassen und die Bank sich dabei für hinreichend gesichert hält, Darlehen auf Waren gewähren, welche in der Hand des Dạlehensschuldners bleiben. ${ }^{1}$ ) Damn hätte die Bank nicht eimmal fiktiven Besitz, sondern der Schuldner bliebe Besitzer.

In analoger Weise darf die Bank in Ansnahmefïllen und wenn der Ortsgebrauch es gestattet, das Konossement ïber eine Ware dem Trassaten aushändigen, bevor dieser den dem Konossement entsprechenden Wechsel gezahlt hat. ${ }^{1)}$ Die Bank hat hierbei keine andere Sicherheit als die rein persönliche Garantie des Trassaten. Gelingt es diesem nicht. der Bank vor Verfall des Wechsels durch den Verkanf der Ware oder sonstwie Deckung zu verschaffen, so steht die Bank einer fälligen Wechselforderung ohne Deckung gegenüber. Sie hat die Tratte des überseeischen Lieferanten für den Trassaten (kolonialen Importeur) akzeptiert und muf sie nun einlösen, auch wenn der Trassat sie im Stich läßt. Dieser - in seiner Grundform schon oben

1) Statuten Art. 15. 4. 
besprochene -- Akzeptkredit zeigt den aleatorischen Charakter des ïberseeischen Bankgeschäfts.

Die Überlassung der Ware oder des Konossements an den Schuldner in der eben besprochenen Weise ist der Bank ron Indochina erst seit 1900 und zwar auf ihr eigenes Terlangen gestattet, um sie in den stand zu setzen, mit den fremden Bankinstituten elfolgreich konkurricren zu kïmnen.

Wiè schon oben S. $10 t$ bemerkt wurde, gewährt die Bank ron Indochina auch die Erntedarlehen, welche für die Banken der Zuckerkolonien so bedeutungsvoll waren. Bei der Bank von Indochina finden wir nu cine Besonderheit, die mit der französischen Verwaltung Indochinas zusammenhängt. Die Erntedarlehen können nämlich nicht nur Einzelpersonen unter den uns bekannten Bedingungen erteilt werden, sondern auch Agrargenossenschaften, welche juristische Persönlichkeit besitzen, zugute kommen. Erfolgen diese Darlehen unter Mitwirkung oder Garantie der Lokalverwaltung, so sind besondere, ron der benannten Verwaltung mit der Bank rereinbarte Bestimmungen zu erfüllen. Num sind die Kommmen in Annam und Tonking juristische Personen; sie bilden eine Genossenschaft, die geleitet wird durch eine Art Junizipalrat, aber keiner Regierungsaufsicht unterstelit. Die Bank ron Indochina kann also einem ganzen Dorfe ein Erntedarlehen geben, für welches die dem Dorfe gehörigen Reisfelder haften. Die Kommunen liömnen das Darlehen auch aufnehmen zugunsten einzehner Gemeindeangehörigen. Das Darlehensgesuch ist durch Termittlung der Verwaltungsbehörde an die Bank zu richten: es muß enthalten: Namen und Wohnort des Entleihers, Lage und Größe seiner Ländereien, Art der Kultur und den Grundstücks-Eigentumserwerbsqund, die rerlangte Darlehenssumme und den Zweck, zu dem sie verwendet werden soll; die Verpflichtung, das Darlehen mit Zins in 6 MLonateu oder - bei Verlüngerung des Darlehens - in 1 Jahr zuriickzuzahlen. Das Gesuch wird geprüft und, falls es genehmigt wird, stellt die Terwaltungsbehörde eine Zahlungsanweisung auf die Stenerkasse der Kolonie aus, die rem Darlehenssucher in Gegenwart des Dorfschulzen und zweier Dorfnotabeln ausbezahlt wird. 
Sohald der Bank eine Ausfertigung des Darlehensvertrages zugestellt ist, sendet sie einen der Darlehenssumme entsprechenden Scheck an die Terwaltungsbehörde. Dieser Scheck, der ausgestellt wird zugunsten der Terwaltungsbehörde, tilgt die Forderung, die der Terwaltung gegen die Bank aus der Bezahlung einer Anweisung anf die Stenerkasse entstanden war. $\left.{ }^{1}\right)$

Die prèts sur récolte werden in der Regel auf 6 Monate bewilligt, da die mannigfachen Formalitïten, die zu erfüllen sind, und die weiten Entfernungen rer Schuldner ron den Kassen der Bank eine längere Terfallzeit nötig machen. Im Falle einer schlechten Ernte, z. B. infolge einer Überschwemmung, ist nach Zustimmung der obersten Verwaltungsbehörde eine Enenerung der Darlehen anf weitere $i$ Jonate zuläsig anf Grund eines einfachen schriftlichen Gesuchs des Dorfschulzen an die Verwaltungsbehörde, das rom Schuldner und zwei Dorfnotabehn zu unterschreihen ist. Zwei Wochen ror Fälligkeit der Darlehensschuld hat die Bank durch Vermittlung der Verwaltungsbehörde den Kommunen eine Tabello der zurïckuzahlenden summe zu übersenden: diese Tabelle soll die Schuldner an die Fïlligkeit ihrer schuht erinnern. Im Einklang mit dem in Französisch Indochina geltenden Prinzipe, rab die Terwaltung dort keine Individuen. sondern nur Kommunen kemnt, sind es die Dorfnotabeln, welche die Schuld eintreiben und die erhaltenen summen den staatlichen Kassen zư̈uckzahlen. Die Kommunen müssen innerhalb eines délai de rigncur ron 30 Tagen rom Terfalltage ab für die röllige Zurückzahlung der Darlehensumme Sorge tragen. Gemïß dem Carantieprinzip wird die Bank unverzïglich für jeden dabei etwa erlittenen Ausfall durch ein mandat budgitaire der Verwaltungsbehörde entschäligt. Sollte der Schuldner zur Verfallzeit nicht zahlen, so können die Totabeln nach einem neuen déai de rigueur ron 14 'Tagen anf einfache Anordnmg der Verwaltungsbehörde ermächtigt werden, die Ernte des Schuldners, ja sogar seinen Grund und Boden rerkanfen zu lassen, wenn die Ernte nicht ausreicht zur Rückzahlung der Schuld. $\left.{ }^{2}\right)$

1) Vergl Renaur a. a. 0. S. $179 \mathrm{ff}$.

2) Renaud a. a. O. S. 183. 
Die Erntedarlehen an die Kommunen sind erst 1sss aufgekommen und in den Bankstatuten beriicksichtigt. Bis dahin unterhielt die Bank fast keine Beziehungen mit den Eingeborenen. Man erkannte aber damals, daß es der Bank nur durch Vermittlung der Regierung möglich sein würde, sich mit der Bevölkerung in engere Beziehungen zu setzen und ihr Mißtranen zu ïberwinden.

Der Leihzins für die Entedarlehen war anfangs sehr hoch $(12-15 \%)$. Wemn trotzden die Nachfrage nach ihnen fortgesetzt stieg, so war damit der Beweis erbracht, daf diese Einrichtung des Realkredits in Indochina einem großen Bedürfnis entgegenkam. So rerhielt es sich tatsächlich anch. Die Eingeborenen in Indochina besafen kamm Kapitalien. Der Wucher verzehrte den größten Teil ihrer Einkiunfte. Da sie kamm soviel ernteten, als ihr Lebensunterhalt erforderte, komnten sie auch garnicht ans Sparen denken. In schlechten Jahren muliten sie sogar zu einem Darlehen ihre Zuflucht nehmen. Etwas besser stand es mit denjenigen. die auf ihrem Boden Nebenprodukte (Gemüse, Seide, Baumwolle) banen konnten: aber ihnen fehlte es oft wieder an Kapital orler an Arbeitskräten. Ein Kreditbedürfnis war somit in guten wie in schlechten Jahren unleugbar vorhanden. Aber was komnte der Schuldner der Bank als reale Sicherheit bieten: sein Haus ist eine wertlose Strohhuitte, sein Mobiliar besteht ans einigen Brettern, 2-3 Stiihlen ans Bambus und einigen plumpen Gefäßen ron der allernotwendigsten Art. $\left.{ }^{1}\right)$ Unter solchen Umständen lot nur die Ente auf dem Felde ein wirkliches Beleihungsohjekt. Dazu kam. daß der Handel im Lande in der Hand ron Chinesen lag, die den Eingeborenen für ein Darlehen :3-4\% Zinsen pro Monat, das sind $36-48 \%$ p. a. abverlangten. Der Wucher ward rerboten, aber notgedrungen ein Zins ron $36 \%$ gesetzlich gestattet! Trotzdem blieb der Wucher weit verbreitet, weil die Eingeborenen nur wertlose Pfandobjekte besaßen und weil Geld nur ron wenig begiiterten Leuten, meist Chinesen, ansgeliehen wnrde, die nur dann ron ihrem Kapital leben komnten, wem es ihnen hohen Zins einbrachte.

1) Renand a. a. 0. S. 179. 
Ans dem Gesagten geht hervor, welche Torteile die Bank ron Indochina durch die Erntedarlehen den Eingeborenen brachte. Der Nutzen für das Land stieg, als 1896 die Bank den Leihzinsfus auf 10 und $\mathrm{S} \%$ ermäßigte. Dies war ihr nur möglich, weil die Kolonie damals der Bank gegenïber sich für die Rückzahlumg der Entedarlehen verbürgte (Garantieprinzip) und so das Risiko der Bank beseitigte. Immerhin beträgt die durchschnittliche Höhe des Leihzinses für Erntedarlehen an Kommunen $8 \%$, der Leihzinsfun ist also wesentlich höher, als bei den alten Kolonialbanken. Das erkliirt sich darans, daf die Bank ron Indochina eine Gebühr ron $20 \%=1_{14}$ des erhobenen Zinses an die Lokalcerwaltung als Entgelt für ihre Mühen, Kosten und ihre Bürgschaft zahlen mub.

Gegenstand der Beleihung bei den Erntedarlehen ist in Indochina der Reis. Es ist bemerkenswert, daf der Reis in Cochinchina zweimal im Jahre geerntet wird, jede Ernte also im ganzen (i Monate in Anspruch nimnt, eine Frist, die der ron den Statuten für die Gewïhrung ron Erntedarlehen rorgesehenen Terfallzeit genau entspricht. Bei der Bank ron Indochina ist also die Terfallzeit für Erntedartehen dem praktischen Bedürfnis angepalit. Das Gleiche lïlit sich ron den alten Kolonialbanken nicht hehaupten. Die Folge war dort eine genaue Beobachtung der Statuten, hier fast chronische Zuwiderhandlungen gegen die Statuten. Welches System den Torzug rerdient, ist ohne weiteres klar.

Auch die Bank ron Indochina darf die Ernte auf dem Felde nur bis zu ${ }^{1 / 3}$ ihres mutmaflichen Wertes beleihen. Überlaupt ist the Beleihungsgrenze für die rersehiedenen Pfandobjekte bei ihr ganz ähnlich wie bei den alten Kolonialbanken geregelt. Für Edelsteine ist sie auf ${ }^{1 / 3}$ ihres Werts festgesetzt. Bislang haben wir die Notenausgabe der Bank ron Indochina, ihr Depositengeschäft, ihre Diskontgeschäfte und ihre rersehiedenen Darlehensgeschäfte betrachtet - lauter Bankgeschäfte, welehe anch den alten Kolonialbanken erlaubt sind. Es gilt jetzt die Geschäfte namhaft zu machen, welche die Bank ron Indochina nicht mit den alten Kolonialbanken teilt; es sind 
das: die Geschäfte in Paris, die Ausstellung ron Kreditbriefen und die Beteiligung an der Gründung wirtschaftlicher Unternehmungen. sowie an der Emission von Statsanleihen ${ }^{1}$ ).

Als Geschäfte, welehe die Bank von Indochina in Paris betreibt, sind zn nennen: das ganze Inkassogesehäft des regulären Bankrerkehrs, die Annahme von Zeichnmgen anf öfentliche Anleihen, die in den Kolonien oder in Mutterlaude eröffnet sind, die Ausstellung von Wechseln und Anweisungen beispielsweise auf Indochina, China, Indien, Australien, sowie die Diskontierung ron Tratten und Anweisungen mit zwei Unterschriften oder ron solchen, deren zweite Unterschrift durch ein Konossement ersetzt ist, und sehließlich ler Kauf oder Terkanf von Gold, silber und liupfer.

Welche enorme Bedeutung die Geschäftstätigkeit in Paris für die Bank hat, zeigt sich ror allem in ihren Wechselgeschäften. Der Kontokorrentrerkelur in Paris rerschafft der Bank unverzinsliche Depositengelder, die sie ebenso wie das in der Metropole angekaufte Eılelmetall je nach Bodanf an ilne Filialen versenden oder zur Tilgung der durch die tirages rerursachten Schuld an das Mutterland verwenden kimn.

In gleich günstiger Lage befinden sich die alten Kobonialbanken nicht, da jede Creldsendung, die sie sich ans Frankieich kommen lassen, ihre schuld an das kontor erhöht.

Die Möglichkeit, in Paris Wechsel auf den fermen Osten auszustellen, erleichtert der Bank ron Indochina die Kimsversicherung d. h. die Tersicherung gegen das Fallen oder Steigen der Wechselkurse, dadurch daß sie für jedes im fer'nen Osten abgeschlossene Geschäft ein entsprechendes Gegengeschüft in Paris rornehmen läbt.

Die Bank darf femer - aber nicht nur in Paris - gegen vorherige Deckung Kredithriefe ausstellen. Kreditbriefe stehen ihrem Wesen nach in naher Verwandtschaft mit den Anweisungen; sie sind eine Ermächtigung an eine Bank, einem Kunden einer anderen Bank Geldbeträge bis zu einer bestimmten Ilöhe auszu-

1) Statuten, Art. 15 
zahlen. Die Kreditbriefe haben grofe Bedeutung für alle, welche nach dem fernen Osten reisen und denen ein Krerlitbrief es erspart, viel Geld bei sich zu tragen. Bei den alten Kolonialbanken haben die Kiredithriefe keinen Sinn, da ilır räumliches Tätigkeitsfeld zu klein ist.

Die Bank ron Indochina nimmt auch Teil an der Emission von Staatsanleihen in allen Ländern, in denen sie Niederlassungen hat. Doch darf der Gesamthetrag ihrer dabei engagierten Kapitalien nie höher sein als $1 / 4$ ihres eingezahlten Grundkapitals, es sei denn, daß der Kolonialminister - bei Anleihen, die ron einer fremden Regierung ausgegeben werden, auch noch der französische Minister des Auswärtigen - seine Ermächtigung dazu gilıt.

Hochbedeutsam ist, daß die Bank ron Indochina sich seit 1900 sogar heteiligen darf an der ciruindung ron Finanz-, Industrie- und Handelsunternehmungen, sofern ihr fiegenstand in Ländern liegt, in denen die Bank Niederlassungen hat. Die Beteiligmg ler Bank soll nie ${ }^{1 / 3}$ ihrer Reserven übersteigen. Ton der Teilnahme der Bank ron Indoehina an Agrarunternehmungen ist in den Statuten keine Retle. Doch kamn die Bank natiolich auch Agrarbanken und Agramgenossenschaften, falls solche gegründet werden, unterstützen, z. B. durch Gewährung ron Vorsehüssen im Wege des Kontokorrentrerkehrs.

Diese fir̈̈ndungs- und Finanzicrungsgeschäfte der Bank stempeln sie zu einer bank groben Stils.

\section{$\$ 26$.}

BESONDERHEITEN IN DER GESCHÄFTSEÜHRUNG DER BANK.

Eine gewisse Großzügigkeit zeigt anch die Leitung der Bank wie üherhaupt ihre ganze Entwicklung.

Wir machten sehon oben auf die grofen Reservehaltmingen der Bank aufmerksam, welche sie gegen alle Erentualitäten sicher stellen. Die Bank hat ferner überall, wo sie sich nielerlieb, eigene Grundstiicke erworben - ein Zeichen, daß sie der Zukunft rertrant. Sie stellt Reserven ein für die Verluste, die durch Kurs- 
schwankungen entstehen kïnnen: sie üht den weisen firumdsatz, alle AuBenstïnde restlus und ohne Abzug sofort ins Verlustlionto zu setzen, obwohl keine Statutenbestimmung sic dazu rerpllichtet. Daher sind demn auch die ron ihr veröfentlichten Bilanzen durchaus zuverlässig. Nur ein Mangel haftet ihnen an. Die meisten Geschäfte der Bank werden nicht in framzösischer Währung, sondern je nach dem Erfüllmgssorte in Rupien- odler Piasteroder Ticalwährung gemacht und dementsprechend bei der betreffenden Bankstelle gebucht. Für die Bilanzen mul Berichte an den Verwaltungsat in Paris muf aber sine Umrechmung in die Frankenwälung erfolgen. Infolge der wechselnden Kurse wird dadurch der Vergleich der Bilanzen verschiedener Jahre und Gesehäftsperioden sehr erschwert. So zeigten inshesondere die Bilanzen der $90 \mathrm{er}$ Jahre eine Abnahme der Geschäftsziffern an, während in Wirklichkeit die Geschïte der Bank zugenommen hatten. Die Erscheinung erkïrte sich aus dem damaligen sinken des Wechselkurses im fernen Osten.

Die Torsicht, die wir der Bankleitung nachriihmten, tritt auch noch in folgendem zutage. Die Bank hat betrïchtliche Kapitalsummen jederzeit in Rupien- oder Piaster- oder Taelswährung angelegt; sei es, daß sie Forderungen erworben hat, die auf Rupien, Piaster oder Taels lanten, sei es, daß sie ihren Schuldnern die Erfüllung ihrer Terbindlichkeiten in jenen Geldarten gestattet. Ein Sinken des Kurses dieser Geldmünzen mub die Bank notwendig in sturke Mitleidenschaft ziehen, besonders wenn die Entwertung des Geldes einen solchen Umfang annimmt wie beim Piaster, ler ron 5.50 fr. (1875) anf 2.23 fr. (1897) fiel. Als Schutzmittel hiergegen dient die sogenannte Kursrersicherung, die darin besteht, daß man sich entweder direkt bei einer Gesellschaft gegen Verluste am Wechselkurse versichert oder daß man ein entsprechendes Cregengeschüft abschließt, d. h. wemn die Bank eine Forderung von 1000 Piastern, zahlbar am 1. 1. 190 .. erwirbt, muß sie sich nach einem Gläubiger umsehen, dem sie zum gleichen Fälligkeitstermin eine gleich hohe Summe schuldet. Das geht natiirlich nieht so einfach. Um nun ihren Geschäftsgang ror anormalen Störungen zu bewahren, stellt 
die Bank ihre in fremden Währungen angelegten Kapitalien regehmäßig zu dem niedrigsten Kurse in Rechnung, den die betreffenden Geldminzen im letzten Semester gehabt haben.

Anch die Bank ron Indoehina hat unter den schwankenden Wechselkursen stark gelitten, sie ist aber in der Wecliselkursfrage erfolgreicher gewesen als die alten Kolonialbanken.

Als die Bauk ron Indochina 1875 ihre elste Filiale in Saigon erriehtete, bestand der Geldumlauf Cochinchinas nur aus mexikanischen Piastern, die $27,073 \mathrm{gr}$ wogen und ea. 5,50 fr. wert waren. 1883 entstand in China eine große Nachfrage nach Silber. Die mexikanischen Piaster wurden darauf ron den chinesischen Kaufleuten in Indochina haufenweise nach China ausgefühnt. Der Bank ron Indochina wurden ihre Noten so häufig und zahlreich pröisentiert, daß ihr Metallvorrat unter das statutarische Minimum sank. Dieser Zustand dauerte mit Unterbrechung bis 18s5; trotzdem die Bank unter großen Opfern beträchtliche Mengen von Piastern (1884 allein für 1S Mill. fr.) in Hongkong, Singapore, St. Franeisco, London und Paris ankaufen und nach Indochina einführen ließ. Zur Bekämpfung der Geldkrise trug ferner die Prägung französischer Piaster bei, die von den Eingeborenen sehr gern genommen wurden. 1890 gab die Bank anch Noten ron 1 Piaster aus (bislang waren nur Noten ron 100 Piastern zur Ausgabe gelangt). Trotzdem blieb die Piasterfrage schwierig. Sie wurde noch komplizierter dureh folgenden Umstand. Seit Jahren latte Mexilo zur Saldierung scines Einfuhrübersehusses jühlich bedentende Hengen ron Piastern zu Rimessezwecken ins Ausland rersenden miissen: das erklärte den großen Piasternmlauf im fernen Osten. Nun hatte im Laufe der Jahre Mexikos Einfuhr sich allmählich vermindert, seine Ausfuhr sich gleichzeitig rermehrt; das hatte zur Folge, daß die Piasterausfuhr Mexikos geringer, d. h. daß der Piaster im fernen Osten seltener wurde. Es erwuchs der Bank damit die Notwendigkeit, für den teilweisen Ersatz der Piaster im Geldumlauf der Kolonie Sorge zu tragen. In Finverstindnis mit der französischen Regierung ließ sie 1895, wie sie es schon 1885 getan, französische Handelspiaster für den Gebrauch in Indochina 
in Paris prägen. Diese Naßregel versprach auch diesmal Erfolg, da die Asiaten jerle Münze nur als einen Motallbarren betrachten, dessen Prägung seinen Feingehalt und sein Gewicht beglaubigt. Leider beging man den Fehler, den französischen Piaster zu schwer auszuprïgen. Von den im fernen Osten umlaufenden Münzen hatte der mexikanische Piaster cin Gewicht ron 27,073 gr, der japanische Yen wie der amerikanische Dollar ein solches von 26,756 gr.- Bei einem Gewichte von 27,215 gr wog der französische Piaster fast $1 \%$ mehr als der Yen, Dollar oder der mexikanische Piaster. Die Folge war, dâ die französischen Piaster kurz nachdem sie in Indochina eingefülnt waren, wieder auswanderten und nu² gegen cin Aufgeld wieder zurïckkehrten, was in ungünstiger Weise anf Diskontsatz und Wechselkurs einwirkte. Die Erhöhung des Diskontsatzes und der Techselprämie gegen Übernahme der Verpflichtung seitens iler Bank, dem Handel jederzeit die nötigen Rimessen nach China zu liefern, waren nur Palliatirmittel gegen den Geldabfluf. Hilfe brachte erst das Dekret rom S. Juli 1895, welches das Cewicht der französischen Piaster auf $27 \mathrm{gr}$ herabsetzte. Der geringe Gewichtsunterschied zwisehen dem nenen französischen Piaster und den auderen Silbermünzen des fernen Ostens ist jetzt nicht mehr imstande, eine Auswanderung der französischen Piaster nach China zu veranlassen. ${ }^{1}$ ) Der innere Geldumlanf Indochinas ist damit sichergestellt und der Bank die Sorge für die Erhaltung eines hinreichenden Metallbestandes genommen. Aler die Schwankungen des Wechselkurses blieben. Ein erster Schritt zu ihrer Beseitigung geschah dadurch, daß die Einfuhr mexikanischer Piaster nach Indochina verboten wurde. Gleichzeitig wurden große Mengen französischer Piaster nach Indochina eingeführt; ihnen gelang es, die mexikanischen Piaster fast ganz aus dem Geldumlauf Indochinas zu verdrängen. Hierdureh ging dem Handel ein Mittel zu Rimessen nach China verloren. Aher man nüherte sich zugleich dem Ziel, den Kurs des französischen Piasters lediglich vom Silberpreise und von der Zahlungsbilanz Indochinas ab-

1) Vergl. Denizet a. a. O. S. 198/9. 
luängig zu machen. Dem mexikanischen Piaster wurde 1905 die gesetzliche Zahlungskiaft in Indochina entzogen. Aber das letzte Ziel aller dieser Maßregeln: die Stabilisierung des französischen Piasterkurses konute bislang noch nicht erreicht werden; es fehlte eben der Bank ron Indochina an der nötigen Goldreserve, mit deren Hilfe sie instande geresen wäre, den Piasterkurs auf der für seine Stabilisierung adoptierten Höhe zu halten. $\left.{ }^{1}\right)$ Indochina hat also auch in Zukunft mit einem Schwanken der Techselkurse zu rechnen. Daß dies für die Bank ron Indochina bislang keine rerderblichen Folgen hatte. liegt daran, daß die Bank regelmïßig einen TherschuB der Rimessen ïber rie ron der Bank ausgestellten Tratten und Anweisungen verzeichnen komnte, der 1899 und 1902 sogar 47.5 bezw. 46.8 Iillionen fr. betrug. Dieses ginnstige Ergebnis ist dem Cmstande zu danken, dab die Melurzahl der französischen Kolonien, in denen die Bank Niederlassungen hat, eine alitive Handelshilanz haben. Sollten trotzdem bei einer Filiale oler Cieschäftsitelle der Bank die émissions die rémises ständig oder nur vorïbergehend infolge schlechter Ernten übertreffen. so wird der Mehrbetrag der émissions ansgeglichen durch den RimesienüberschuB, den andere Bankstellen regehnäßig oder infolge einer guten Konjunlitur anfzureisen haben.

Dieser Rimessenüherschuß ist für die Bank ron Indochina hochbedeutsam, da die Wechselgeschäfte immer 50--60\% der sogenannten poduktiven Geschäfte der Bank ausmachten, wie machfolgende Tabelle beweist:

\begin{tabular}{|c|c|c|c|c|c|}
\hline $\begin{array}{l}\text { Pank yon } \\
\text { Indochina }\end{array}$ & Wechselet & eschiifte & $\begin{array}{l}\text { Gesants } \\
\text { der prorl } \\
\text { Bankges }\end{array}$ & $\begin{array}{l}\text { mme } \\
\text { ktiven } \\
\text { häfte }\end{array}$ & $\begin{array}{l}\text { Wechselgeschäfte im } \\
\text { Verhältnis zu den pro- } \\
\text { duktiven Geschäften }\end{array}$ \\
\hline 1875 & 12.21 & Mill. fr. & 29,97 & Mill. fr. & $50,94^{0} \%$ \\
\hline 1855 & 112.20 &. & 145.23 &. & $63.49 \%$ \\
\hline 1895 & 127.47 & .. & 2.205 & .. & $57.63^{\circ} / 0$ \\
\hline 1904 & 407.64 & .. & $78(2.2)$ & .. & $51, \pi 20 / 0$ \\
\hline 521904 & 406.5 .78 & .. & $7 \cdot 206.39$ & ., & $56.26 \%$ \\
\hline
\end{tabular}

Ein ähnliches Verhältnis nehmen die Diskontgeschäifte der

1) Vergl. Jahresberichle des Verwaltungsrates der Bank ron Indochina $1898-19025$ in dem Economiste français. 
Bank ron Indochina zu ihren Gesantrorschüssen (= Diskont+ Darlehensgesehäften) ein. Es betrugen:

\begin{tabular}{|c|c|c|c|}
\hline Jahr & Diskontgeschäfte & Gicsaml rorschüsse & $\begin{array}{l}\text { Diskontgeschiffte } \\
\text { in } \% \text { der } \\
\text { fiesamt vorschiisse }\end{array}$ \\
\hline $188 t$ & $13,0-$ Mill. fr. & 34,8s Mill. fi'. & $: \quad 37,50 \%$ \\
\hline 1894 & $40,19 \quad . \quad$. & so,is , . & $49,760 \%$ \\
\hline 1904 & 170.24 & $380,5 \mathrm{~s}$ & $44,73 \%$ \\
\hline $1882 / 190 t$ & 1582.84 & 3160,61 & $50,01 \%_{0}$ \\
\hline
\end{tabular}

Im Durehschnitt wurde die Hïlfte aller Torschïsse der Bank im Wege des Diskontgeschïfts erteilt: 1892 sogall fast $2 / 3$. Bei den Diskontgeschäften der Bank handelt es sich nur um Diskontierung ron Platzwechseln, deren Höhe direkt abhängig ist ron den Konjunkturen, in Cochinchina z. B. ron der Reisernte. Ist diese sehr gut, so ist die Reisausfuhr grof und damit anch die Zahl der diskontierten Platzweehsel. Eine sehlechte Ernte macht dagegen eine Reiseinfuhr nötig, die wieder'um eine lebhafte Bewegung im Diskontrerkehr herror'uft. Sur eine mittelmäßige Ernte, welehe keinen bedeutenden Reishandel zu veranlassen imstande ist, läbt auch die Diskontgeschäfte ahflanen.

Zu interessanten Ergebnissen führt eine Betrachtung der einzelnen Darlehensgeschäfte der Bauk von Indochina in ihrem Terhälnis zur Summe aller von der Bank gewährten Darlehen.

Während die Erntedarlelien hei den alten Kolonialbanken einen beträchtlichen Teil der von ihnen gewähten Darlehen ansmachten. hielten sie sich bei der Bank ron Indochina stets in bescheidenen Grenzen und seheinen kaum jemals 2 Millionen fr. erreicht zu haben. Doch ist die durchsehnittliche Höhe der Erntedarlehen bemerkenswert. Die Bankstelle in Hanoi z. B. gewährte 1898 für 150000 Piaster prèts sur récolte, die sich auf ea. 1000 Darlehensempfünger verteilten; das macht im Durchsehnitt 150 Piaster $=$ ci. $400 \mathrm{fl}^{2}$. pro Kopf. ${ }^{1)}$ Das Beispiel zeigt, daß auch die kleinen Reisbanern bei der Bank Hilfe und Berücksichtigung fanden.

In Gegensatz zu den Erntedarlehen spielten die Waren-

1) Economiste français 1899, 2. sem. p. 193. 
lombardgeschäfte bei der Bank von Indochina eine große Rolle. Sie betrugen:

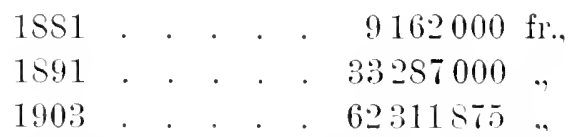

während unter den alten Kolonialhanken die Bank ron Rémion schon mit 16.9 Millionen fr. (1S79s0) den Rekord gesehlagen hatte. Auch die Darlehen auf Cregenstände rou Gold, Silber, Kinfer und auf Edelsteine zeigten ïberraschend hohe Ziffern, z. B. 189513.6 Millionen fr'., 1899 7 Millionen fr. Die normale Höhe war $12-1$ Million fr. Die Filiale Pondichéry war hauptsäichlich an diesen Darlehensgeschïften beteiligt. Herrorgehoben zu werden rerdient die Tatsache, daß bei der Bank von Indochina der Sahlo dieser Darlehen an Schlusse des Cieschäftsjahres stets bednutend niedriger war als der Betrag der im verflossenen Geschäftsjahre gewährten Darlehen - ein Beweis, daß der sparkassencharakter, den diese Darkhen bei den alten Kolonialbanken angenommen haben, nicht notwendig mit ihnen rerbunden ist.

Nicht nur die Aktirgeschäfte der Bank, auch der Kíedit, den sie genießt, sind ein Maßstab für ihre Prosperität. Wie steht es in dieser Beziehung mit der Bank ron Indochina?

Ihr Notenumlauf zeigt eine fast ständige Aufwärtsbewegung. $\left.{ }^{1}\right)$ Er betrug:

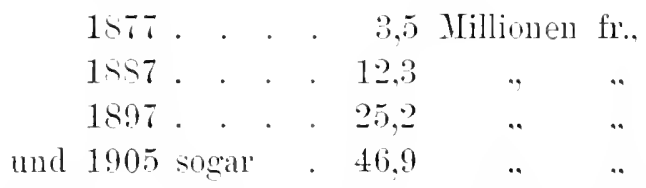

das ist fast $S$ mal soriel als das eingezahlte Kapital der Bank (6 Millionen fr.) damals betrug. Dieser hohe Notenumlauf ist um so bemerkenswerter, als die in Siam und China in Unlauf gesetzten Toten in der letztrergangenen Zeit der Konkurrenz

1) Der scheinbare Rückgang 1895 und 1896 erklärt sich durch den niedrigen Piasterkurs, der den Notenumlauf in der Bilanz geringer erscheinen ließ, als er in Wirklichkeit war. 
habber eingezogen werden muBten, wie das bereits oben $\$ .112$ gesagt worden ist.

Der Metallbestand der Bank zeigte 1905 (31. XII) die erfrenliche Höhe ron 26,6 Millionen fr., 1904 sogall eine Höhe ron 3:,7 Millionen fr. Die metallisehe Drittelsdeckung der Noten ist von der Bank stets eingehalten worden, wenn wir die Krisenzeit 1883-1887 ausnchmen. Fiir die damals vorgekommenen Unregelmäßigkeiten kann aber die bank nicht vesantwortlich gemacht werden, woranf oben S. 124 bereits hingewiesen ist.

Auch der Kontokorrentverkehr der Bank rom Indochina zeugt von ihrer glänzenden Entwicklung. Es betrugen:

Jahr. Kontokorrenteinzahlıngen. Solde débiteur der Bank.

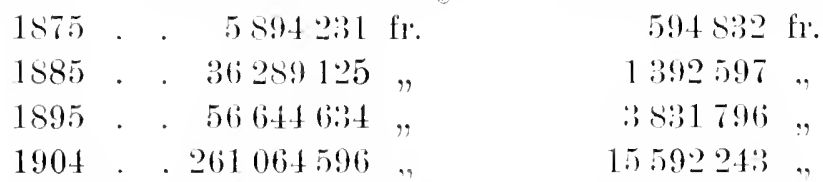

Außerdem unterhält die Bank ein hesonderes Kontokorrent mit rem kolonialen Schatzant in Indochina. Dureh Artikel 11 des Dekrets rom 16. Y. 1900 ist nämlich die Bank von Indochina rerpflichtet, anf Verlangen des französischen holonialministers in allen Kolonien und Protektoraten, in denen sich Bankistellen von ihr befinden, das Amt eines Schatzmeister's zu übernehmen. Diese 'Tïtigkeit bedingt einen Kontokonentrerkehr wer Bank mit dem kolonialen Schatzamt. 1905 schlob dieses Kontokor'ent mit einem Saldo ron $2: 3,1$ Millionen fr. zugunsten des kolonialen Schatzants. Aber auch ein Salto zugunsten del Bank ist denkbar. Die Bank hat nämlich 1899 mit tem französischen Finanzminister cinen Vertrag geschlossen, wonach sie dem Schatzamt in Indochina monatlich eine Summe von höchstens 500000 Piastem zur Verfügung stellen soll gegen gleichzeitige Deckung der Bank in Paris. Zweek dieses Vertrags ist, den regelmäßigen Dienst des kolonialen Schatzamts sicher zu stellen, bis das ron Finanzministerium experlierte field in Inclochina eingetroffen ist. ${ }^{1}$ )

1) Economiste français 1900, 1er sem. p. 706 . 
Wir kennen jetzt die Bank ron Indochina sowohl ihrer Bankverfassmg, wie der' ron ihr' entwickelten 'T'itigkeit nach.

Welches war num der Erfolg ihrer Tritigkejt, was hat die Bank in den 30 Jahren ihres Bestehens erreicht?

4. Kapitel.

DTE ERFOLGE DER BANK.

$$
\text { s. } 27 .
$$

\section{DIE DEN ROLONIEN ERUIESENEN DIENSTE.}

Die Bank fand bei ihrer Grïndung zwei grofe Schwierigkeiten vor: zunächst die monoculture, d. h. die Reiskultur war in Indochina fast die einzige Produltion molloinge Quelle des Gerleihens des Landes. Zudem machte der Wechselkurs der Bank viel zu schaffen. Ein Vergleich mit den oben geschilderten Verhältnissen in den französischen Zuckenkolonien drüugt sich da ron selbst auf. Der dortige absentérisme tehlte zwar in Indochina, hatte hier aher ein wiirdiges regenstïck in der angeborenen Fantheit der Eingeborenen, speziell der Ammaniten.

Es kimn nun festgestellt werden, dap dank der Unterstiitzung der Bank die monocnlture in Indechina tatsächlich beseitigt worden ist. Eine Menge neuer Kulturen (Pfeffer-, Kaffee-, Tee-, Kautschuk-, Seide- und Maiskulturen) sind teils direkt durch die Mitwirkung der Bank ins Leben gerufen, teils, wie z. B. die Kohlenproduktion, indirekt dureh Teinnahme am Bau von Eisenbahnen grefürdert worden. Als in Pondichery des blühende Arachidenhandel zurückging, suchte und fand die dortige Filiale Ersatz in dem Baumwollenhandel mit Madagaskar und Indochina. In Nouméa hat die Bank neben der Fleischkomservenindustrie auch die verschiedenen Minenindustrien (Kupfer-, Nickel-, Kobaltund Chromminen) unterstützt und wesentlich zu ihrer jetzigen Bliite beigetragen.

Ehenso erfolgreich war die Bank in der Lösmng der Wechselkursfrage, wenngleich das Endziel, die Stabilisierung des Weeh- 
selkurses, noch nicht erreicht ist. Durch Einfühnung der französischen Piaster ist der innere Geldumlauf der Kolonie gesichert worlen, ohne daf es cinen Augenblick nötig gewesen wäre, Kassenscheine mit \%wangsums ansugeben wie in den /uckerkolonien.

Freilich kam der bank hieriei die aktive Handelsbilanz Indochinas sehr zul stitten.

Del Leihzinstuf der Bank von Intochina war in ganzen etwas höher als derjenige der alten Kolonialbanken. Fine Esklärung hierfür ist für die Erntedarlehen oben schon gegeben. Das dort S. 120 Gesagte gibt uns vielleicht einen Fingerzoig auch fiir dis anderen Geschïfte der Bank.

Die Geschäfte mit den chinesischen Kunden der Bank erfolgen stets unter Termittlung eines Compratore, einer Art bestallter Makler, der die (iesehäftsbedingungen festsetzt und zugleich das Zähten und Wiegen der Piaster und anderen silbermiinzen vornimmt. ${ }^{1}$ ) Die Termittung tos Compradore nub natürlich den Darlehenszins erhöhen, ohne daf dachuch die sicherheit der Bank vermelnt wird. Haben doch gerade diese Compradores hisweilen eine Henge Wrechsel gefïlscht und dadurch der Bank ziemliche Verluste beigebracht. ${ }^{2}$ )

Die Bank ron Indochina hat oft in demselben Geschäftszweige rerschiedene Zinssätze in Anwendung gebracht. Zieht man üherall nur die niedrigsten ron der Bank gewïhten Zinssitze in Betracht - diese werden wohl nen Europäern und sonstigen sicheren Kunden zugebilligt sein -, so hat die Bank ron Indochina keineswegs tenreren Kredit gegeben, als rie alten Kílonialbanken. Zweifellos steht aber fest, daß der Bank ron Indochina eine starke Herabsetzung les Leihzinses wie überhaupt eine Erleichterung und Verbilligung des Kredits zu danken ist. Der Kredit ist auberordentlich erweitert und auch dem kleinen Manne zugänglich gemacht worden; er ist nicht nur Privatpersonen, sondern anch öfenthichen Körperschaften zugute gekommen. so hat die Bank der Kolonie Neukaledonien im

1) Vergleiche das auf S. 125 Gesagte.

2) Economiste français 1898, 1er sem. p. 905 . 
Wege des Fontokorrents 1894 einen mit $5 \%$ zu rerzinsenden Vorschub von $575000 \mathrm{fr}$. gegeben, um die Kolonie in Stand zu sctzen, die durch Einfuhr asiatiseher Arbeiter verursachten Kosten zu bezahlen. Im selben Jahre machten die Protektorate Annam und Tonking bei der Bank eine Anleihe ron 750000 Piastern = ca. 2 Nillionen fr: zrecks Baus einer Eisenbahn. ${ }^{1)}$

\section{$\$ 28$. \\ LEISTUNGEN AN DEN FRANZÖSISCHEN STAAT.}

Anch der französische Staat hat sich der Dienste der Bank von Indochina zu erfrenen gehabt. Wir erinnern nur daran, das die Bank für die französische Regierung das Amt eines Schatzmeisters in Indochina äbernommen hat. Ferner wurde die Bank beauftragt, den Teil der chinesisehen Ḱriegsentschälligung ron 1900, der Frankreich zukommt, in Empfang zu nehmen..2) Diese Aufgabe stellt die Bank ron Indochina in den Dienst der französischen Politik. Sie ist ja überhaupt keine ganz selbstïndige Kolonialbank mehr, seittem ihr dureh Dekret vom 16. V. $1900^{3}$ ) die Terpflichtung auferlegt ist, auf Verlangen der französischen Regierung in allen französischen Kóonien und Protektoraten des Indisehen und Stillen Ozeans, desgleichen in Siam. Japan und China, sowie in allen nichtfranzösisehen Häfen des Indischen und Stillen Ozeans Filialen oder Gesehäftsstellen zu erriehten. Diese Bestimmung macht die Bank in der Hand der französischen Regierung zu einem politischen Instrument: die Bank wird ein ITittel zur Vermehrung und Terbreitung des französischen Einflusses im fernen Osten. Die französisehe Regierung hat ron ihren Rechten häufigen Gebrauch gemacht und der Bank dalurch große Opfer zugemutet. Gar manche Bankstelle, so z. B. die Filiale Tahiti und die Geschäftsstelle Battambang, sind nur auf Drängen der Regierung und unter starkem Widerstreben der Bankleitung eingerichtet worden, weil die Bank selbst ron

*) Bouchié de Belle a. a. O.

2) Economiste français 1902 , 2e sem. p. 75 .

3) Art. 2/3. 
diesen Nengründungen keine Vorteile, wohl aber, wenigstens für die ersten Jahre, ziemliche Verluste zu erwarten hatte. Und wenn nun anch manche dieser Neugründungen, die nicht einem wirtschaftlichen Bediüfnis, sondern politischen Erwägungen ihre Entstehung rerdankten, später besser angegangen sind und günstigere Ergebnisse geliefert haben, als die Bank hei rorsichtiger Berechnung angenommen hatte, so fehlt es doch andererseits nicht an Beispielen, daß die Bank mit ihren geringen Erwartungen Recht behielt. Als 1877 in Pondiehéry eine Filiale gegründet wurde, rertrat die Bank die Ansicht, daß diese Bankstelle dem lokalen Handel nur geringe Torteile lieten und ihre eigenen Ausligen und Kosten kaum decken wïrde. ${ }^{1}$ ) In der Tat ist diese Filiale stets ein Schmerzenskind der Bank von Indochina gewesen. Anfangs läfit sich bei ihr ein ziemlicher Aufschwong beobachten infolge des starken Arachidenhandels. Dieser veranlaßte die Bankstelle sogar eigene Lagerrïume herzustellen zur Anfnahme der ihr verpfändeten Arachiden. Ziemlich plötzlich erfolgt dann Mitte der $90 \mathrm{er}$ Jahre cine anhaltende Geschäftsabnahme; die Lageräume standen lange Zeit leer. Der Grund hierfür lag einerseits in der Abnahme des Arachidenernteergebnisses, andererseits in der Konkurrenz des henachbarten britischen Cuddalore, das durch bessere Eisenbahnverbindung mit dem Innern Torderindiens Pondichéry gegenüber entschieden im Vorteil war. Seit 1900 ist wiederum ein starkes Steigen aller Geschäfte der Filiale Pondichéry festzustellen. Es bleibt indes abzuwarten, ob diese Besserung der Lage von Daner ist. Jedenfalls hat auch die Stabilisierung des Rupienkurses, die 1898 der indischen Regierung gelang, die dortigen Verhältnisse giunstig beeinflußt. Das Hauptübel, an dem die Filiale Pondichéry krankt, ist ihre geringe räumliche Ausdehnung und dadurch auch ihre beschränkte Entwicklungsfähigkeit. Wäre die Filiale in Ponrlichéry eine selbständige Bank, ilıe Ergebnisse würden kaum glänzender sein als diejenigen der Banken ron Martinique, Guadeloupe und Réunion.

1) Economiste français 1878,2 e sem. p. 29. 
134 11. DHE BANKEX YON NEUKALEDONHEX, IXDOCHIXA UND WESTAFRIKA.

$\$ 29$.

DAS ERGEBNIS FÜR DIE BANK SELBST'

Trotz aller Schwierigkeiten hat die Bank von Indochina gute Resultate erzielt. Dies verdankt sie zum T'eil den Filialen Saigon und Haiphong, vor allem aber den Bankstellen in China, die sich äußerst rasch and gïnstig entwickelt haben.

Auch die Filiale Nouméa anf Neukaledonien bewies, was dort bei geschickter Gesehüftsführung zu erreichen war. Wenn die letzten 1904 veröffentlichten Geschäftsziffern einen gewissen Rüekgang dartun, so hängt das mit dem Verfall der dortigen Fleischkonservenindustrie zusammen, wolcher mansbleiblich wurde, seitdem der französisehe Kriegsminister verordnet hat, daf kein Konscrvenfleisch aus Neukaledonien mehr für die Terproviantierung der französischen Armee verwendet werden dïrfe. Auch der Arheitermangel in Neukaledonien war ein Grund für den Räckgam der dortigen Landwirtschaft. Die anfhïhlende Minenindustrie ist jetzt fast das einzige Lebenselement der Lolonie und wird sehon aus diesen Grunde ron der Bank von Indochina kräftig unterstiitzt. ${ }^{1}$ )

'T'rotz der zahlleichen Filialen und Geschäftsstellen der Bank von Indochina ist doch die Einheitlichkeit in der Bankleitung stets gewalnt worden. Die gegenseitige Unterstiitzung der Bankstellen mutereinander ist dank dieser Zentralisation überall rasch und wirksam durchgeführt worden.

so worden lokale Krisen leichter überwunden, und das (iesantgesehäftsergebnis der Bank gewann an Stetigkeit. Die Bank ron Indochina verteilte 1866 eine Dividende von $5 \%$ 1876 eine solche ron $8 \%, 1880$ gar $10 \%$. Seit 188 s sehwankte die Dividende mit zwei Ausnahmen zwiselsen 16 und $17,6 \%$, stieg damn auf $20 \%$ (1896) und $30 \%$ (190:3) und betrug 1905 $36 \%$.

In den 30 Jahren ron $1576-1905$ haben die Aktien der Bank ron Indochina einen Durehsehnittsertrag von $17,73 \%$ eingebracht und zwar:

1) Berichte des Verwallungsrates a. a. 0. 1899, 1900, 1903/05. 


$$
\begin{aligned}
& 1876 / 55 . \quad . \quad 10.060 \% \text {, } \\
& 188095 . \quad \text {. . 18.30\% } \\
& 18961905 \text {. . 24,8\% }
\end{aligned}
$$

Vergleicht man hiermit die Tabelle auf Seite 95, so erkemnt man, daß die alten Kolonialbanken weit zuriuckgeblieben siml, und elab nur die Bank ron Gurane mit ihren 16,07\% Durchschnittsdividende den hohen Ertrag der Aktien der Bank von Indochina-ungefïh erreicht.

$17,73 \% / 0$ sind wirklich ein gutes Äpuivalent für tas grobe Risiko einer kolonialen Bank. Zn danken ist dies Ergebnis neben versehiedenen oben beribhten wirtschaftlichen Umständen vor allem der vorsichtigen und zugleieh energischen Bankleitumg, welche alle Mittel und Kapitalien der Bank zur vollen Verwendung und Ausnutzung gebracht hat.

Zieht man noch die Terdienste in Betracht, welche die Bank sich um die Entwickelung des französischen Kolonialbesitzes im fermen Osten erworben lat, so kommt man zu dem Schlusse, daß die Bank die hohen Erwartungen, die man an die Gründung dieses kolonialen Bankunternehmens knüufte, vollauf erfüllt und nebenbei noch ihren Aktionären glänzende Ciewime verschafft hat.

\section{Dritter Abschnitt.}

\section{DIE BANK TON WESTAFRIKA.}

Die Erfolge der Bank von Indochina sind angenscheinliche; es wird deshalb ron Interesse sein, das Schicksal der Bank ron Westafrika kennen zu lernen, da sie ahnlich organisiert ist, wie die Bank von Indoclina.

Eine Generalrersammlung der Bank ron Sénégal rom 25. II. 1901 luatte besehlossen, daf im Interesse der Entwickelmng des Handels an der westafrikanischen Kïste die Bank von sénégal liquidieren und sich fusionieren sollte mit einer neu zu gründenden Bank, die nach dem Vorbilde der Bank ron Induchina organisiert wäre. $\left.{ }^{1}\right)$ Toch in selben Jahre warl eine nene Bank unter dem Namen Bank von Westafrika ins Leben gerufen.

\footnotetext{
1) Journal officiel rom 26. VII. 1902.
} 


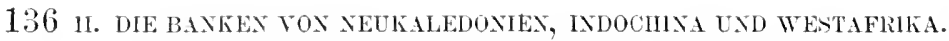

1. Kapitel.

$\$ 30$.

GRÜNDUNG DER BANK.

Durch Dekret rom 29. VI. 1901 wurde nun eine Bank ron Westafrika gegrïndet, die sofort, d. h. rom 1. VIl.01 ab, die Geschäfte der liquidierten Bank ron Sénégal ïbernahm.

Die neue Bank ist eine Noten-, Diskont- und Darlehensbank und hat den Zweck, alle ihr durch die Statuten erlaubten Geschäfte in den französischen Besitzungen wie in den fremden Ländern der westafrikanischen Küiste zu treiben. Die Dauer der Bank ist auf 20 Jahre festgesetzt: loch kann im Lanfe des Jahres 1911 ein Dekret der Bank das Notemprivileg zum 1.I.1912 entziehen. $\left.{ }^{1}\right)$

Das Kapital der Bank war ursprünglich auf 1,5 Millionen fr. festgesetzt und zerfiel in 3000 Aktion ì 500 fr. $\left.{ }^{2}\right)$ Die Einzalılungen auf 1800 dieser Aktien erfolgten durel Apports der Aktiva der liquidierten Bank ron Sénégal, welche auf $900000 \mathrm{fr}$. gewertet wurden; die Einzahlnngen auf die übrigen 1200 Aktien waren in har zu bewirken, doch wurden zuerst nur 125 fr. pro Aktie eingefordert. 1904 erhöhte ein Dekret das Bankkapital nominell auf $5895000 \mathrm{fr}$. $=11790$ Aktien ì $500 \mathrm{fr}$., ron denen 70 Aktien roll eingelöst nud 11 i20 Aktien nur zu 1/4 eingelöst wurden. In Wirklichkeit fand somit keine Kapitalerhöhung statt.

Das Cipundkapital der Bank kann auch fernerhin erhöht werden dureh Generalversammlungsbeschlub nach Genehmigung des Kolonialministers. Bei allen Kapitalerhöhungen, die in Form ron apports en espèces elfolgen, haben die alten Aktien ein Torbezugsreeht auf die neuen Alitien.

Die Aktien sind bis zu ihrer völligen Einlösung Yamenaktien, nach ihrer Einlösung kümen sie anch Inhaberaktien sein.

\footnotetext{
1) Dekret 1901, Art. 1, 2.

2) Statuten 1901, Art. 4/5.
} 
Die Bank von Westafrika untersteht dem régime de dierets, indem nur dureh Dekret ihre Verfassmng und Statuten geändert sowie Bankstellen nen errichtet oder beseitigt werden kömen. ${ }^{1}$ )

2. Kapitel.

$\$ 31$.

VEREASSUNG UND (

Die Bank von Westafrika hat, wie schon erwähnt, das Notenprivileg in allen französischen Kolonien und Protektoraten Westafrikas. Stiickelung und Zahlungskraft der Noten sowie dic Höhe des Notenumlaufs sind ähnlich wie bei der Bank ron Indochina geregelt; doch gibt die Bank ron Westafrika Noten von $50 \mathrm{fr}$. aus statt solcher von $20 \mathrm{fr}$., dameben auch noch 25 fr.-Noten; ferner besitzt sie nicht das Recht, Noten in fremder Währung auszugeben.

Wie die meisten Kolonialbanken, darf die Bank von Westafrika Erntedarlehen unter den uns bekannten Bedingungen gewähren. Wir können überhaupt hier auf das über die Bank von Indochina Gesagte rerweisen und uns begnügen, die Punkte hervorzulıben, in denen beide Banken voneinander abweichen.

Die Verfallzeit der Wechsel und Anweisungen, welche die Bank ron Westafrika kauft, begibt oder diskontiert, darf höchstens 180 Tage betragen ${ }^{3}$ ) - bei der Bank ron Indochina zumeist nur 120 'Tage. ${ }^{\text {) }}$

Bezïglich der Warenlombardgeschäfte und der Vorschüsse auf Konossemente ist zu bemerken, daß die der Bank von Indochina eingeräumten, auf S. 116 erwähnten Erleichterungen nicht auch für die Bank ron Westafrika gelten. Dagegen darf die Bank ron Westafrika ihre eigenen Aktien beleihen bis zu $3 / 5$ ihres nach den Notierungen der letzten 6 Monate festgestellten mittleren Wertes. Sie kann auch in Paris Geschäfte machen, darf teilnehmen an französischen und fremden staatsanleihen und
1) Dekret 1901 Art. 5.
2) Dekret 1901, Art. 3, 4, 6.
3) Statuten Art. 16.
4) Vgl. oben S. 114. 
sich beteiligen an der Gründung ron finanziellen, industriellen und kommerziellen ITnternehmungen mit lokalem Gegenstande — aber höchstens bis zur Hälfte ihrer Reserven. ${ }^{1}$ )

Aufer ihrem Sitz in Paris besitzt die Bank 3 Filialen: st. Louis (Sénegal), Conacry (Guinée) und Porto Noro (Dahomé) und 3 Geschäftsstellen: Dacar, Rufisque und Monporia, ron denen die beiden ersten in Súnégal getegen und ron der Filiale St. Lonis abhängig sind. Im ganzen zählt die Bank 7 Niederlassungen. Sie kam ron der französisehen Regierung gezwungen werden, nene Bankstellen zu errichten , in den Ländern, anf die sich ihre (ieschäfte beziehen", d. h. in Testafrika. Sie hat auf Verlangen für den französischen staat das Ant eines Schatzmeisters zu äbernehmen in den französisch-westafrikanischen Besitzungen, in denen sie Filialen unterhält. $\left.{ }^{2}\right)$

Die Leitmng der Bank liegt wie hei der Bank ron Indochina einem Verwaltungsiat ob. Er besteht aus 5-8 Mitgliedern, die sämtlich Franzosen und Eigner ron mindestens to Aktien sein mïsen. Sie werden auf 5 Jahre ron der Generalversammlung gewählt.

Auch bei der Bank ron Westafrika hat der Verwaltungsrat prinzipiell alle Rechte und Befugnisse, ${ }^{3}$ ) und die Direktoren sind seine Untergebenen.

Die Vertretumg der Aktionäre auf der Generalversammlung ist wie bei den alten Kolonialbanken geregelt. Die Generalversammlung besteht ans allen Aktionären, die seit 6 Monaten mindestens 10 Aktien besitzen. Doch kïnnen Eigner ron weniger als 10 Aktien, die znsammen 10 Aktien besitzen, sich durch einen von ihmen vertreten lassen. ${ }^{*}$ )

Die Stantsaufsiclst wird ausgeüht durch ren Regierungskommisar, respektive Verwaltungszensor, den fakultativen Inspektor und die allen Koloniabanken gemeinsane Überwachnngskommission.

1) Statuten Art. 16.

2) Dekret 1901 Arl. 13.

3) Stiluten Art. $1-62$.

4) Vergl. Art. 36/i6. 
:3. Kilpitel.

$\$ 32$.

DIE ENTWICKLENG: DER BANK.

Die Bank ron Westafrika besteht erst seit 6 Jahren. Doch läßt sich schon einiges über ihre Tätigkeit sagen. Auch diese nach dem Trpus der Bank ron Indochina geschaffene Kolonialbank zeichnet sich hurch eine rorsichtige Bankleitung aus. Dies kommt besonder's darin zum Ausdruck, dab regelmäßig ein Teil des Reingewinns, der als Dividende rerteilt werden könnte, zur Verstairung der Reserve rerwendet wird. Nach fünf Jahren beträgt diese $311^{2} 09 \mathrm{fr}$. Die Bank will lieber bescheidene aber stetige, als hohe aber sehwankende Dividenden zahlen. In den ersten vier Jahren kamen: $5 \%, 5 \%, 6 \%$ und $6 \%$ zur Ansschüttung.

Die Diskont- und Darlehensgeschäfte der Bank bewegen sich noch in mäßigen Grenzen; sie betrugen zusammen ca. 2 Millionen fr.. woran die Diskontgeschäfte den größten Anteil haben. Bemerkenswert ist die Entwickhng der Warenlombardgeschäfte, welche bei der Bank ron Sénégal eine ganz untergeordnete Rolle gespielt hatten. Dagegen hat die Bank noch keine Erntedarlehen gewährt. Ferner zeigen die Kontokorrentziffern eine starke und steigende Anfwärtsbewegung. Während die Kontokorrenteinzahlungen der Bank ron Sénégal im Maximum 3 Millionen fr. betrugen, stiegen sie bei der Bank ron Westafrika von 6,7 Millionen $(1901 / 2)$ auf $26, \pm$ Millionen $\mathrm{fr}$. (1904/5) und ließen einen solde créditeur zugunsten der Bankkunden ron 2269657 fr. Das ist ein gutes Zeichen für den Kredit der Bank.

Auch der Notenumlauf, der fast 7 Mill. fr. (30. VI. 1906) erreicht, weist eine starke Zunahme auf. Dabei besitzt die Bank einen starken Metallbestand in Höhe ron 3433 rot fr. (30. VI. 06).

Die Wechselgeschäfte haben seit Gründung rler Bank einen bedentenden Aufschwung genommen: sie betrugen 1904/5 19,2 Millionen fr. und ergaben einen kleinen Überschub der émissions über die remises. 
140 II. DIE BANKEX YON NELKALEDONIEA, INDOCHINA UND WESTAFRIKA.

'lrotzdem die Bank ihren Sitz in Paris hat und dort keinen Vertreter benötigt, unterhält sie doch Beziehungen mit dem Nationalen Diskontkontor in Paris. Das Geschäftsjahr $1905 / 06$ schloß mit einem solde créditeur ron $1528401 \mathrm{fr}$. zugunsten der Bank von Westafrika.

Wenn wir diesen Angaben noch hinzufügen, daß die Bank von Westafrika den kolonialen Kredit noch etwas verbilligt hat gegenüber der Bank ron Śnégal, so wird klar, daß damit in sechs Jahren alles geschehen ist, was billigerweise erwartet werden konnte. Die Bank hat gute Zukunftsaussichten. 


\title{
DRI'TIES BUCH.
}

\section{DIE BANK VON ALGERIEN.}

\author{
1. Kapitel.
}

$\leq 33$.

\section{ERRICHTUNG UND VERFASSUNG DER BANK.}

Wir haben jetzt noch eine Kolonialbank zu betrachten, welcher manche Schriftsteller die Eigenschaft als Kolonialbank abgesprochen haben, nämlich die Bank von Algerien. Algerien sei eine bloße Fortsetzung des Mutterlandes Frankreich und habe sich in bezug auf seine wirtschaftlichen Verhältnisse dem Mutterlande schon so sehr angepaßt, daß auch die Bank ron Algerien in ihrer inneren Struktur sich nicht mehr sonderlich von der Bank von Frankreich unterscheide. $\left.{ }^{1}\right)$ Trotzilem rechnen wir die Bank ron Algerien noch zu den Kolonialbanken gemäß der auf Seite 2 gegebenen Definition, da sie einerseits in einer Kolonie errichtet ist und dort arbeitet, und andererseits in der Kolonie das Notenprivileg besitzt.

Ende der $40 \mathrm{er}$ Jahre machte sich in Algerien das Bedürfnis nach einer Bank geltend. Die zu gründende Bank sollte sowohl die Vorzüge der Bank ron Frankreich, wie diejenigen der nationalen Kiontore, die 1848 während der schwersten Krisenzeiten geschaffen waren und Algerien ausgezeichnete Dienste geleistet hatten, in sich vereinigen. Man entschlob sich aber schließlich, nicht eine Filiale der Bank ron Frankreich, sondern eine selbständige Bank mit dem sitze in Algier zu gründen. Das gescha' durch Gesetz rom 4. VIII. 1851. Ein Gesetz vom

1) Denizet, a. a. 0. S. 27. 
19. VIII. 185:3 regelte das Verhälnis der Bank und ihrer Filiaten, von denen bis 1900 fünf entstanden sind. 1900 wurde der Sitz der Bank von Algerien ron Algier nach Paris verlegt und Algier sank zu einer bloben Filiale herab. 1904 wrde in Tunis eine (7.) Filiale der Bank errichtet. Dies geschah in Ausübung eines der Bank ron Algerien 1900 verliehenen Rechts nicht nur in Algerien, sondern auch in den anderen französischen Kolonien und Protektoraten (Nord) Afrikas, Niederlassungen gründen und Noten answeben zu dürfen. Anch die französische Regierung kann bis zum 31. XIl. 1905 die Gründung ron vier nenen Filialen seitens der Bark ron Algerien vertangen.

Die bank ron Algerien ist mit Hilfe des Stales errichtet worden, inden dieser ron dem Anfangskapital der Bank (3 Millionen fr.) 1 Hillion fr: rorsehol und sich nur deren Verzinsung (zu 3\%) und Rückzahlung nach drei Jahren ausbedang. Das Kiplatal dor Bank wurde 1861 auf 10 Millionen fr. erhöht und betrïigt seit 1880 ?0 Millionen fr.

Vas Batnkprivileg wurde ursprïnglich ntr anf 20 Jahre crteilt, dam aber immer wieter verlingert, zuletzt im Jahre 1900 bis zum 31. XII. 1920.

Das Hauptrorrecht der Bank ron Algerien ist das alleinige Reeht zur Ausgabe von Noten in Beträgen von 1000, 500, 100, 50 unct seit 1872 anch ron 20 und 5 fr. 1850 wurden die 5 fr.-Noten wieder beseitigt. Die Noten hatten anfangs weder Zwangatius noch Kassenkur's. Während der lírse ron 1870 , ron der anch Algerien in Mitleidenschaft gezogen wurde, erhielten sie ebenso wje die Noten der Bank ron Frankreich Zwangskurs, d. h. die Noten wurden gesetzliches Zahlungsmittel, und die Bank ward ron ihrer Einlösungspflicht entbunden. Der Zwangskurs der Noten wurde erst durch Gesetz rom 4. IV. 1880 beseitigt. Dieses (iesetz legte den Noten aler Bank ron Agerien gesetzliche Zahlungskraft bei, d. l. die Toten sind gesetzliches Zahlungsmittel, aber nur solange dio Bank ihre Einlösungspflicht erfüllt. ${ }^{1}$ ) Bei dieser Regelung ist es seitlem geblieben.

\footnotetext{
1) $\mathrm{Vgl}$. oben S. 30 .
} 
Der Votenumlauf war zuerst dureh zwei Bestimmungen begrenzt worden. Erstens sollte der Notenumbuf zusimmen mit den sonstigen sehulden der Bank nie das dreifache des Metallbestandes der Bank ïbersteigen diurfen, und zweitens sollte der Überschuß der Passiva der Bank äber ihren Netallvorrat nie gröBer sein als der dreifache Betrag des eingrezhlten bankkapitals. $\left.{ }^{1}\right)$

Diese letzte Bestimmmng, welche sich als mzweckmäbig erwies, wrude 1\$s0 anfgehohen. 1900 wurle die manze Frage im Art. 2 des Gesetzes in folgender Weise neu geregelt: die Notenausgabe der Bank hat sich in solchen bienzen zu halten, dafi die Bank mittelst ilures Metallrorrats und der sofort fälligen Papiere ihres Portefenilles jeclerzeit imstande ist, ihre Zahlungsverpflichtungen unverzüglich zu erfüllen. Doch darf der Notenumlauf nie 150 Jillionen fr. übersteigen.

Das zweite Privileg, das wir bej den Kolonialbanken kennen lernten: die unter besonderer Verounstigung füj die Bank crfolgenden Emtedardehen, ist der Bank ron Algerien ron Anfing an versagt geblieben. Es wäre verkehrt, in diesen prèts sur récolte ein Kriterium für die Koloniabanken sehen zu wollen. Denn dann gehörten die Banken ron Guyane, Sénégal murl Westafrika nicht zu den Kolonialbanken. Tiel wesentlicher ist die Verfassung und die (ieschäftsmethoden der Bank, und diese zeigen eine unverkembare Terwandtschaft mit den übrigen Kolonialbanken. Auch die Bank ron Algejirn darf nur die Geschäfte treiben, die ihr durch die Statuten erlaubt sind. ${ }^{2}$ ) In der Hauptsache handelt es sich um Diskontierung ron Wrechsehn, un Darlehen gegen Hinterlegung ron Waren, öffentlichen Schuldbriefen und gewissen anderen Wertpapieren oder von gemïnztem und ungemünztem Gold und silber, sowie un die Ausgabe ron Wechsehn, Anweisungen, Schecks und Soten. Auch das Kontokorrentund Inkassogeschäft des regulären Bankbetriehs wäre hier zu nennen. Die W echsel brauchen nur zwei Unterschriften zu tragen, ron denen die eine noch durch bestimmte Pfänder ersetzt werden kann. Inre Terfallzeit muß bestimmt sein (damit sind alle sicht-
1) Gesetz t. VIII. 18.s1. Art. 6.
2) Statuten 1900, Art. 10. 
und Nach-Sichtwechsel ausgeschlossen) und darf 100 Tage nicht iiberstejgen - lanter Abweichungen ron den Regeln der Bank ron Frankreich. Die Bank ron Algerien darf für gewöhnlich keine verzinsliche Depositen amnehmen - das erimert umgekehrt an die alten Kolonialbanken. 1/3 des Reingewimnes der Bank ist halbjährlich der Reserve zuzuschreiben, bis diese $1 / 3$ des eingezahlten Kapitals erreicht. Diese starke Reservebildung war ja auch für die ïbrigen Kolonialbanken charakteristisch. Im Gegensatz zu den Banken ron Indochina und ron Westafrika wurde es der Bank ron Algerien, als sie ihren sitz nach Paris verlegte, nicht erlauht. dort Diskont-, Darlehens- und Kontokorrentgeschäfte zu machen. $\left.{ }^{1}\right)$ Die Bank von Algerien sollte eben eine reine Koloniabank bleiben, d. h. nur in der Kolonie arbeiten.

Über die Terfassung der Bank sei noch kurz folgendes festgestellt: Die Bankleitung liegt einem Verwaltungsrate ob, hestehend aus 1 Direktor, 1 Unterdirektor, 9 Verwaltern und ; Zensoren. Die Verwalter und Zensoren werden dureh die Ciencralversimmlung der Aktionäre gewählt: der Direlitor dureh den Prïisidenten der franzïsischen Republik ant Vorschlag des Finanzministers, der Cnterdirektor dureh den Finanzminister selbst ermannt. Da der Direktor die iibrigen Bankbeanten ernennt und entläBt. hat er dem Verwaltungsrat gegenüber eine ähnlich unabhängige Stellung wie die Direktoren der alten Kolonialbanken.

Bemerkenswert ist noch, dab nehen dem oben erwähnten Verwaltungsuate in Paris auch bei jeder Filiale ein besonderer Verwaltungsrat geschaffen ist, der ans 1 Direktor, 6-9 Verwaltern und :3 Zensoren besteht. Er erhïlt seine Weisungen ron dem Terwaltungsrate in Paris, handelt aber sonst frei und unter eigener Verantwortung. Anch der Direktor einer Filiale wird durch den Finanzminister aber auf Vorsehlag des Direktors der Bank ron Algerien ernannt.

Auf der Generalversammlung hat jeder Aktionär Stimmrecht, der seit vier Monaten mindestens 10 Aktien zu eigen hat. Ein Vergleich der Bank ron Algerien mit der Bank ron 1) Art. 12 der Statulen ron 1900. 
Frankreich würde ergeben, daß theoretisch der Unterschicd zwischen beiden micht mehr allzu groß ist. Praktisch ist el trotzdem rorhanden. Er hat sich trotz einer mehr als 50jührigen Bankentwicklung noch nicht rerwischt. Anch 1900 mußte der seit 1880 ständig ernenerte Antrag auf Fusion der Bank ron Algerien mit der Bank ron Frankreich noch abgelehnt werten auf Grund der großen wirtschaftlichen Terschiedenheit zwischen Frankreich und Algerien. Diese Tatsache gibt uns ein Recht. zwischen beiden Banken einen deutlichen strich zu ziehen. Die folgende Darstellung der Entwicklung der Bank von Algerien wird Aufschluf darüber geben, ob die Bank mehr von der Bank ron Frankreich oder von den Kolonialbanken an sich hat.

2. Kapitel.

$\$: 3.4$.

\section{DIE ENTWICKLUNG DER BANK YON ALGERIEN.}

Die erste Tat der Bank war, daf sie den in den 40 er Jahren des rorigen Jahrhunderts in Algerien stark verbreiteten Umlauf spanischer Piaster durch ihre Noten ersetzte und dadurch die französische Wührung einführen half. Trotz finanzieller Zusammenbrüche infolge des Araberanfstandes, trotz Cholera, Erdbeben, Dürre nnd Hungersnot nahm die Bank eine günstige Entwicklung; sie dankte dies ihrer guten Leitung, welche ror allem auf kurze Terfallzeit der Wechsel ihres Portefenilles und auf Verteilung des Risikos bedacht war. Von 1881 ab machte die Bank, der öffentliehen Meinung nachgebend, Geschäfte. die sich eher für einen Crédit foncier als für eine Notenbank eigneten. Die glänzenden Ergebnisse in den ersten Jahren dieser nenen Geschäftsperiode täuschte hinweg ïber die Übertreibungen, die sich die Bank in ihrer Kreditgewährung zuschulden kommen ließ. Die Agrarkreditgeschäfte der Bank führten zu anhaltender Immobilisierung des Bankkapitals durch irreguläre Diskontgeschäfte. $\left.^{1}\right)$ Die Folge war, daß die Diskontgeschäfte bis 1895

1) Es wurden Grundstücke als Pfand gegeben und bei Zahlungsunfähigkeit des Schuldners notgedrungen von der Bank zu Eigentum erworben.

Soltau, Die französischen Kolonialbanken. 
stationär blieben zwischen 400 und 460 Millionen fr. Bei Ernenerung des Bankprivilegs 1897 hatte die Bank einen Grundbesitz in Werte von 10 Millionen fr., einen immobilisierten Wechselbestand ron 9,4 Millionen fr. und anßerdem noch Außenstände ron 8,4 Millionen fr. Um die Emenerung ihres Notenprivilegs zu erhalten, mußte die Bank ilıren Grundbesitz, der bislang glänzende Èträge geliefert hatte, für \& Millionen fr., d. h. unter Verlust ron 2 Millionen fr. an eine neugebildete Société domaniale algérienne abtreten und ilne ganzen Außenstände nebst den immobilisierten Wechseln ihres Portefenilles ins Verlustkonto setzen. Diese Maßnahmen zehrten die ganze Reserve der Bank auf, die noch 1898 (31. X.) ca. 18 Millionen fr. betragen hatte. Aber Wechselportefeuille und Bilanz wurden frei ron statutenwidrigen Werten. Eine vorsichtige, aber geschickte Bankleitung hat es in den darauf folgenden 6 Jahren zuwege gebracht, daß durch Zuwendung eines Teils des eigentJich als Dividende zu verteilenden Gewinns der Reservefonds an 31. X. 1906 bereits wieder 13 Millionen fr. überstieg. 1904/5 wurden von der Bank für $7 \$ 1464747 \mathrm{fr}$. Wechsel diskontiert gegen 477400000 fr. im Durchschnitt der letzten 10 Jahre. ${ }^{1}$ ) Diese Diskontgeschäfte waren das Hauptgeschäft der Bank, neben dem die eigentlichen Darlehensgeschäfte geringe Bedeutung hatten. Der Notenumlauf betrug 1906 (31. X.) 126271480 fr. bei einem Metallbestande ron $50873357 \mathrm{fr} .1904 / 5$ erzielte die Bank mit einem Kapital von 20 Millionen fr. einen Reingewinn von 2,9 Millionen fr.

Auch der Bank ron Algerien fiel wie den anderen Kolonialbanken die bedentsame Aufgabe zu, die Wechselkurse zu regulieren. Das war nicht leicht, weil Algerien meist eine passive Handelsbilanz aufwies. Sein Budget schloß in der Regel mit einem Ausgabenüberschub ron 50-60 Millionen fr., der durch Anweisungen auf das französische Schatzamt in Paris gedeckt wurde. Bei dem Rimessenmangel kam es dem Handel in Algerien sehr zu statten, daß er von dem kolonialen Schatz-

1) Vergl. Berichte des Verwaltungsrates der B. v. A. im Economiste français. 
ant in Algier Anweisungen auf Paris erhalten konnte. Ihren Gegenwert zahlte el dafür bei der Bank ron Algerien, welche die Kassengeschäfte des kolonialen Schatzamts führte, in bar ein. Die rom Handel für die Rimessen bei der Bank eingezahlten Summen tilgten das oben erwähnte Defizit der Kolonie, indem sie das Gutlaben der Kolonie bei der Bank rerstärkten. Auf Grund dieses Bankguthabens hätte der französische Stat die Bank rerpflichten können, dem Handel jederzeit und unentgeltlich Rimessen auf Frankreich zu lieferm. Man begnïgte sich aber 1900 mit der halben Maßregel, die Bank zu bestimmen, in Algier, Oran, Bine und Philipperille ihre Noten bis zum Betrage ron 1000 fr. jeder Person, die ihre Abreise nach Frankreich nachweist, auf Terlangen gegen Noten der Bank ron Frankreich zun Parikurse einzutauschen. ${ }^{1}$ ) Da del französische Finanzminister schon 1899 angeordnet hat, daß die Anweisungen auf das Schatzamt in Parris olne Prämie oder höchstens unter Abzug einer proportionellen stempelgebiilur abgegeben werden sollen, so beträgt, so lange die Bank solche Anweisungen abgibt, der Maximalwechselkurs für Rimessen auf Frankreich, die gewöhnlich 6 Tage nach Ausstellung fällig sind, 3\% $3 \%$ das ist der Betrag der Stempelgebühr.

Manche hatten gehofft, den Wechselkurs zwischen Frankreich und Algerien ganz beseitigen zu können durch Frrichtung einer Filiale der Bank ron Frankreich in Algier. Aber die Erfahrung hat gelehrt, daß die Eingeborenen in Algerien dic Noten der Bank ron Algerien nur deshalb in Zahlung nehmen, weil sie gewisse arabische Zeichen und Merkmale tragen, die es den Eingeborenen ermöglichen, den Wert der Noten zu erkennen. Die Noten der Bank ron Frankreich wurden, wemn überhaupt, nur gegen ein Disagio genommen. Wenn die Bank ron Frankreich nun für ihre eine zeitlang projektierte Filiale in Algier besondere Noten mit arabischen Zeichen ausgegeben hätte, so würden diese ohne weiteres ein Agio gegenüber ihren nur für den Gebrauch im Mutterlande bestimmten Noten erzielt haben. ${ }^{2}$ )

1) Parlamentarischer Bericht von Moigne a. a. O.

2) Brice, Parlam. Bericht 1879, a. a. 0 . 
Eine Filiale in Algier würde die Bank ron Frankseich zwingen, zu gewissen Zeiten Geld ron Frankreich nach Algerien zu senden, zu anderen Zeiten es wieder nach Frankreich zurückzuschicken, um es nicht unproduktiv in Algerien liegen zu lassen. Die Kosten der Bargeldsendungen lü̈tten eine Ergänzungsprovision oder eine Erhöhung des Diskontsatzes zur Folge, und der Wechselkurs zwischen Frankreich und Algerien wäre in anderer Form doch da. Also eine Umwandlung der Bank ron Algerien in eine Filiale der Bank von Frankreich hätte nicht den erwarteten Erfolg gehabt. Gegen eine Fusion der beiden Banken sprach auch noch, daf es der Bank ron Frankreich im Interesse der Einlüsbarkeit ihrer Noten auch 1900 noch nicht möglich war, dem Handel in Algerien dieselben Erleichtermngen und Vergünstigungen zu gewähren, wie die Bank ron Algerien, die z. B. nur 2 Unterschriften auf den Wechseln rerlangt, 100 Tage Wrechsellaufzeit gestattet und daneben ein weit rerzweigtes Netz ron Filialen unl Hilfskassen hat. Insbesondere würde die ron der Bank ron Frankiceich rerlangte 3 . Unterschrift dem Handel in Algerien große Schwierigkeit machen und jedenfalls den Diskontsatz erhöhen. Und damit wäre ein Torteil der vorgeschlagenen Fusion, den Handel in Algerien an dem niedrigen Diskont der Bank von Frankreich teilnehmen zu lassen, illusorisch gemacht. Es rerdient übrigens hervorgehoben zu werden, daß die Bank ron Algerien seit 1902 zu $4 \%$ diskontiert, also zu eimem mäßigen und wenig lästigen Satze. Aus allen diesen Cründen sah man 1900 daron ab, die beiden in Frage stehenden Banken zu rereinigen. Man hat aber das Notenprivileg beider Banken ïbereinstimmend nur bis zum 31. Dezember 1920 verlängert. Falls der französische Staat dann eine Fusion für nötig hält, hat er ein Machtmittel in der Hand, um seinen Willen den Banken aufzuzwingen. Denn ohne Notenprivileg sind beide Banken nicht existenzfähig.

1851 bei ihrer Gründung erhielt die Bank ron Algerien einen Staatsrorseluuf ron 1 Million fr., der aber schon nach 3 Jahren zurtickgezahlt wurde. 1871 hat umgekehrt die Bank dem französischen State ein Darlehen ron 12 Milionen fr. gewährt. Seit 1900 sind ihn dem Staate gegenüber neue, ziemlich 
bedeutende Leistungen anferlegt. Dazu nehört erstens eine jährliche Abgabe an den Stat ron $200000 \mathrm{fr}$, die ron 19306 ab auf $250000 \mathrm{fr}$. und ron 1913 ab anf $300000 \mathrm{fr}$. steigt; sodann ein einmaliges zinsluses Dimlehen ron :3 Millionen fr. für die Daner des Privilegs der Bank. Dartehen und jährliche Abgabe sollen zur Grändung einer Agrarbank in Algerien dienen und die Entwickelung (ler Bank von Algerien zu einer reinen Handelsbank in die Wege leiten.")

Neben diesen Leistungen an den Stat muß die Bank noch rerschiedene fest benamute Gesehüfte des framzösisehen Schatzamts in Algerien unentgeltlich besorgen. ${ }^{2}$ ) In dieser Aufgahe berührt sie sich mit der Bank ron Indochina. Auch sonst komnten wir bislang anf manches hinweisen, was sie mit allen Kolonialbanken gemeinsam hat. Aber im Ganzen fällt die Bank von Algerien doch etwas aus dem Rahmen einer Kolonialbank heraus; sie bildet schon eine Übergangsstufe zwischen den Kolonialbanken und den Banken des Mutterlandes (Kontinentalbanken). Dieser Umstand rechtfertigt es wohl zur Genïge, daß wir die Bank von Algerien, wie eingangs dieser Arbeit rersprochen, von allen Kolonialbanken zuletzt und nicht zuerst behandelt haben.

1) Gesetz rom 5. VII. 1900 Art. 5/6.

$\left.{ }^{2}\right)$ Gesetz rom 5. VII. 1900 Art. 7-9. 
IIERTES BUCH.

\title{
VERGLEICH DER KOLONIALBANKEN MIT ANDEREN BANKEN SOWIE DER KOLONIAL- BANKEN UNTEREINANDER.
}

\author{
1. Kapitel.
}

\section{IHR VERGLEICH MIT ANDEREX BANKEN.}

Die Reihe der französisehen Kolonialbanken ist mit der Bank von Algerien gesehlosien. Es gilt nummehr auf rirund des vorgebrachten Materials, das Wesen der Kolonialbanken im Gegensatze zu unseren Kontinentalbanken zu erfassen und darzustellen.

Dabei werden noch einmal alle Eigentïmlichkeiten und Sonderheiten kurz festzustellen sein, denen wir bei Besprechung der ! Kolonialbanken begegnet sind, auch wenn sie nicht allen 9 Kolonialbanken gemeinsam sein sollten.

$$
\$ 35 .
$$

I. Alle Kolonialhanken hahen das Notenprivileg, das sie nicht entbehren können, wenn sie erfolgreich wirken sollen.

Dies unterscheidet sie bereits ron den vielen Banken, die nicht privilegierte Notenhanken sind.

11. Allen Kolonialbanken ist nur ein fest umgrenzter Kreis ron Geschäften gestattet. Einer solchen Beschränkmng unterliegen unsere Notenbanken anch. Wichtig ist aher die Feststellung, daß diese Begrenzung bei den Kolonialbanken liein gesetzgeberiseher Willkiurakt ist, sondern noch mehr als bei den anderen Notenbanken mit Notwendigkeit aus dem Charakter und Zweck der Kolonialbanken entspringt. Das große Risiko, das den Koloniabanken infolge der besonderen Verhältnisse ans fast jedem wichtigeren Geschäft erwïchst oder loch erwachsen kann, 
macht es dem Giesetzgeber zur P'flicht, den Kolonialbanken alle im eigentlichen Simne spekulativen Geschäfte, z. B. die Beleihmng von Land, Hänsern, Schiffen oder den Handel mit Schiffen oder Waren ${ }^{1)}$ zu verbieten.

Daß der Geschäftskreis der Kolonialbanken beschränkt wurde, ist festgestellt, lesgleichen weshalb dies geschalı. Noch bedeutsamer ist es zu crgriuden, in welcher Weise die Kolonialbanktätigkeit eingeengt wurde und auf welche Geschiifte die Folonialhanken sich notgedrungen konzentrieren mußten. Zugleich mit den ihnen eigentïmlichen Geschäften sind auch noch die besonderen Geschäftsmethoden, die sich bei den Kolonialbanken entwickelt haben, kur zu streifen.

$$
\$ 36 .
$$

\section{DIE DEN KOLONIALBANKEN EIGENTÜULICHEN GESCHÄFTE UND GESCHÄFTSMETHODEX.}

III. Bei keiner der zahlreichen französischen Banken des Mutterlandes finden sich die prèts sur recolte. Sie sind eine bemerkenswerte Schöpfung und Einrichtung les Kolonialkredits, die der französische Gesetzgeber bislang rergeblich in Mutterlande einzuführen versucht hat. Wenngleich die Russische Reichsbank ähnliche Darlehen gewährt, indem sie eingeernteten Weizen bis zu $75 \%$ seines Verkanfswertes und noch nicht eingeernteten Weizen und Stroh bis zu $40 \%$ seines Werts beleilht, so scheint doch der Mißerfolg aller auf Einführung der Erntedarlehen in Frankreich gerichteten Bestrehungen zu zeigen, daß für diese Form des landwirtschaftlichen Kredits in kultivierten Ländern das Bedürfnis fehlt. Damit wirre aher der Beweis erbracht, daß die prêts sur récolte eine spezifisch koloniale Kreditform und somit ein naturale, wenn anch kein essentiale der Kolonialbanken sind.

Teben den Erntedarlehen ist die Diskontierung rou Wechseln mit nur 2 Unterschriften für die Kolonialbanken

1) Nur der Handel mit Gold, Silber, Kupfer und Edelsteinen war erlaubt. 
seln bezeichmend. Denn niemand wird anf die Sicherheit, welehe die 3. Untersehrift bietet, rerzichten, wemn er diese Sicherheit unsehwer erlangen kamn. Aber gerade die Unmöglichkeit, eine 3. Unterseluift regehmäig - nicht blok ausnahmsweise - aufzutreiben, wird in nenen Ländern, die noch wenig entwickelten Handel und Verkehr haben, die Banken zwingen, sich - der Not gehorehend, nicht dem eigenen Triebe - mit 2 Untersehriften zu begnügen.

Den Kolonialbanken eigentïmlich sind anch die sogenamnten Aktiendarlehen. Sie finden sich nur in Gegenden, deren Bewohner neben ihren Aktien nicht viele andere Gegenstände des Realkiedits besitzen. Charakteristisch ist nieht die Verpfändung von Alitien überhaupt, sondern von Aktien der ausleihenden Bank. Diese Eigentïmlichkeit erkiät sich ans dem Gegenseitigkeitsverhältnis, das zwischen Aktionären und Kunden der Kolonialbanken bestand, indem fast jeder Aktionär anch Kunde der Bank war.

Darlehen anf Gegenstände ron Gold und Silber sind auch boi den Kontinentalbanken üblich. Dagegen werden Gegenstänle ron línper und Xiekel, sowie Edelstein e nur von líolonialbanken beliehen. Der oft schon betonte Sparkassencharaliter dieser Art Dartehen ist weniger störend bei einer Kóolonialbank als bei einer Kontinentalbank, und zwar aus dem Grunde, weil in der Kolonie der Geldumlauf langsamer geht als in den Kulturländern. Das hat zwei Folgen: die diskontierten Wechsel bleiben bis zur Verfallzeit in der Hand der Bank, sie zirkulieren nicht, es sei denn, daß sie auf das Ausland lauten. Die Wechsel sind also Kreditmittel, aber kein Zahlungsmittel. Zweitens mußte die Verfallzeit aler Wechsel in den Kolonien erhöht werden, nominell auf $4-6$ Monate, tatsïchlich auf S Monate. Diese hohen Fristen waren nu deshalb nötig, weil beim I)iskont der Kolonialhanken kein Unterschied zwischen Pflanzer und Kaufmamn gemacht wurde, obgteich doch offenbar der Pflanzer seine Kapitalien anf längere Zeit festlegt und dementsprechend längere Kredite braucht, als der Kaufmann.

Erwaihnenswert ist hier ferner, daf die Kolonialbanken den 
verschiedenen Formen des Realkreelits vor den Diskontgesehäften entsehieden den Vorzug gaben. Dies kam darin zum Ausdruck, daß sie den Lombardzinsfuß stets niedriger ansetzten als den Diskontsatz. Bei unseren liontinentalbanken ist umgekehrt der Lombardzins meist $1 \%$ höher als der Diskontsatz. Die Kolonialbanken baben für ihre Handlungsweise triftige Griunde. In den Kolonien, wo es neben Europäern so manche andore Bankkunden gibt, deren Begriffe rom Krodit recht unentwickelt und unklar sind, bieten die Pfänder tatsächlich eine größere sicherheit als die Persönlichkeit des Sehuldners. Dazu kummt, daß es sich bei den Eingeborenen und den Kolonisten meist um Leute handelt, die selbst wenig oder gar keine Kapitalien haben, sonderu sich solche erst erwerben wollen. Alles dies liegt in einem Kulturlande gerade umgekehrt, sodaß unsere Banken bei gleicher Sieherheit der Diskontgesehäfte gegenüber den Lombardgeschäften jenen wegen ihrer Bequemlichkeit und raseheren Realisierbarkeit den Vorzug geben.

Zu den besonderen Gesehäftsmethoden der Kolonialbanken gehört ferner die starke Reservebilıung, welche notwendig ist bei dem großen Risiko, das die Koloniabanken laufen, sorlann die Anlegung von Kapital und Reserven in Rentenbriefen, d. h. die Umwandlung ihres Grundkapitals aus einem Betriebskapital in ein Garantiekapital. Nicht überall ist es wje bei der Bank von Algerien Pflicht der Bank, iln Kapital in Rentenbriefen anzulegen. Aber überall ist dies mehr oder weniger streng beobachteter Brauch, ron dem höchstens die Bank ron Indochina abgeht. Bei ihr luat das Konto Rentes d'Etat mehr den finanziellen Zweek, die Einnahmen der Bank zu erhöhen und weniger die Bedeutung, die Bezahılung der Bankverbindlichkeiten zu sichern.

Die Geschäftstätigkeit der Kolonialbanken wird in besonderer Weise beeinflußt dureh ihre $A$ ufgabe, sowohl den inneren Geldumlauf der Kolonie als aneh die Weehselkurse zu regulieren. Wir erinnern an die großen und häufigen Goldsendungen, welehe die Zurückzahlung der Banknoten nötig machte, wenn das Metallgeld infolge ungünstiger Wechselkurse ins Ausland abfloß. 
Diese zentrale, das Geld- und Zahhungswesen der Kolonien, wemn nicht beherrschende, so doch maßgebend beeinflussende Stellung der Kolonialbanken, darf nicht übergangen werden, wemn wir ron ihmen ein vollständiges Bild beliommen wollen.

Zu den Aufgaben der Kolonialbanken, die ihren Sitz in Paris haben, gehört es auch, die einheimischen Kapitalien zu kolonialen Unternehmmmgen heranzuziehen: die Banken rermitteln dadurch zwischen dem heimischen Kapital und der kolonialen Arbeit. Diese Tätigkeit ist ebenso wichtig für die Kolonien wie berleutsam und charakteristisch für die Kolnnialhanken. Sie besteht nieht nur darin, daß die anf ihre Aktien gemachten Einzahlungen sowie die in Paris eingezahlten Depositen zu den kolonialen Geschäften der Banken verwendet werden, die Kolonialbanken bringen anch die Alitien und Obligationen von Kolonialgesellsehaften oder Koloniahregierungen auf dem heimischen Gieldmarkte unter oder beteiligen sich selbst an Unternehmungen, welche die Erschliefung der Kolonie zum Zweck haben. Sehlieflich sind in diesem /usammenhange noeh die rersehiedenen Dienstleistungen der Banken für den staat oder die kolonialen Regierungen zn erwähnen.

$$
\$ 37 .
$$

\section{DIE VERENIGUNG VON AGRAR- UND HANDELSBANK.}

Noch zu wenig hervorgehohen ist die merkwiurdige Tatsache, daß die Rolonialbanken Handels- und A grarbanken zugleich sind. Wïhrend in den kultivierten Staaten das Bestreben nach Spezialisicrung und Arbeitsteilung im Bankgewerbe rorherrscht und wenigstens die Trennung in Banken des Agrarkredits und in solche für Handel und Industrie durchgeführt ist, finden wir bei den Kolonialbanken alle verschiedenen Bankformen: Agrarbank. Depositenbank, Notenbank, Diskont- und Wechiethank, Pfandleihbank, Sparbank, Emissionshank.... in einem Bankinstitute rereinigt.

Die grunge wirtschaftliche Entwickelung der Kolonien bot wenigstens bei Grindung der Kolonialbanken nieht Raum und 
Beschäftigung genug für mehrere Spezialbanken. So muBte denn ein e Kolonialbank die Aufgaben versehiedener Banken gleiehzeitig zu erfüllen suehen. Das ging nicht ohne sehwierigkeiten ab. Wir erwähnen hier nur das Faktum, daß mit Rücksicht anf die agrarischen Kunden der Bank clie Verfallzeit der Wechsel anf 4 Monate erhöht werden muBte. Desgleichen erimnern wir wieder kurz an den Sparkassencharaliter der Darlehen anf Gegenstainde ron Gold, Silber, Kupfer und anf Edelsteine. Am dentlichsten zeigten sich die Folgen der mangehulen Arbeitsteilung im kolonialen Bankgewerbe in dem Mibrerhïltnis, wolches zw ischen den Aktiv- und Passirgesehäften der Banken besteht. Die Kolonialbanken rerfügen abgesehen von ihren (irundkapital nur über täglich fällige Kapitalien, die sie. sei es durch die Notenausgabe, sei es in Form ron Depositengeldern, erhalten haben. Die Bank leiht dagegen die so erhaltenen Kapitalien auf 4, 6, ja 8 Monate aus. Dieser Zustand ist bezeichnend für die Kolonialbanken, und zwar um so mehr, als biskang noeh kein praktischer Versuch gemacht wurde, diese Unstimmigkeit, ja diese Gefahr für die Banken zu heseitigen. An theoretisehen Vorschlägen hat es ja nicht gefehlt.

$$
38 .
$$

\section{DER SPEKULATIONSCHARAKTER DER KOLONIAL-} B.NKEN.

Das Mißrerhältnis zwisehen Alitiv- und Passivgesehäften der Kolonialbanken weist uns direkt anf ilnren Spckulationscharakter hin.

1. Die Kolonialhanken hoffen orler spekulieren daranf, dal nicht alle ilure Gläubiger, sondern vielleicht nur ein Drittel von ihnen ilure fälligen Forderungen sofort zuriiekbezahlt verdangen: ja noch mehr, sie erwarten, daf im Durehsehnitt die Einlagen mindestens 4 Monate in der Hand der Bank helassen und nicht eher zurückgezogen werden. Gesehïhe es doch, so wïre der Ruin der Bank da. 
2. Es gibt noch andere Zeichen für den aleatorischen Charakter der Kolonialbanken. Wir nenuen znnächst: ihre direkte Abhängigkeit ron Naturereignissen und Umständen, die anderhalb der mensclilichen Einflußsphäre liegen. Was diese direkte Abhängigkeit bedeutet, läßt sich ermessen, wenn man an die häufigen Wirbelstiirme. Zyklone, Orkane und Erdbeben in den Kolonien denkt. Sie zejat sieh bei allen Geschäften der Kolonialbanken, tritt aher besonders stark herror bei den Warenlombardrarlehen und vor allem bei den Erntedarlehen. Wie aleatorisch diese sind, ergibt die Tatsache, daf durch das im Bereich der Mögliehkeit liegende Znsammenwirken zweier Faktoren (einer schlechten Ernte und eines Preissturzes) das Beleihungsobjekt ${ }^{1 / 2}$ bis ${ }^{2}, 3$ seines Werts verlieren kann. Auch dadurch, daß die Kolonialbanken nur "2 Unterschriften beim Diskont verlangen, wirl ihre Abhüngigkeit ron den Konjunkturen rerstärkt. Der Produzent präsentiert der Bank direkt den Wreehsel seines Konsumenten ohne Vermittlung eines Privatbankiers. Alle Handelskrisen wirken deshalb direkt auf die Bank; sie mub den Ansturm aushalten, da keine dritte Unterschift sie dagegen selrützt.

3. Ein grobes Risiko erwäehst den Kolonialbanken aus rerschiedenen (ieschïften nur deshalb, weil es in den Kolonien fitst gar lieine Tersicherungsgesellschaften, speziell nicht solche gegen Erubeben und Feuersgefahr gibt.

Oft war das geringe wirtschaftliehe Verstiindnis der Eingeborenen für die Bank eine Quelle von Verlusten. Demn nicht jede Nichtzahlung einer Schuld beruhte auf Unvermögen oder schleehtem Willen. sondern oft nur auf Unkenntnis ron der Bedentung einer Wechsel- oder Darlehensverpfliehtung.

4. Dem spekulationscharakter der Kolonialbanken entspricht die Höhe des Leihzinses in den Kolonien, ebenso die außerordentlich sehwankenden Ergebnisse, wie wir sie besonders bei den 5 alten Kolonialbanken feststellen komnten. Sie treten dort dentlieher zutage als z. B. bei der Bank ron Indochina, weil jene Banken nieht wie die Bank ron Indochina den Branch befolgen. durch Zurüekhaltung eines Teils des Cewimes in 
guten Jahren sich die Mittel zu versehaffen, um den mageren Gewinn schlechter Jahre zu vermehren und dadurch die Dividenden guter und sehlechter Jahre anszugleichen.

Der stark wechselnde Metallbestand machte den Kolonialbanken ständige Sorge. Er war teilweise nur die Folge eines selur ungleichmäßigen Geldbedarfs des Kólonie, wie er allen Agrarländern eigen ist; zum Teil wurde er hervorgerufen dureh die oft abnormen Geldverhältnisse, die wir hesonders in ten Zuckerkolonien kennen lernten. Überall bildete aher der Wechselkurs eine Bedrohung des Metallbestandes der Bank und zugleich eine Ursache starker hursverluste.

5. Verluste erwuchsen den Kolonialbanken besonders clann, wenn sie in einem Konflikte zwischen ihren eigenen Interessen und denen der Kolonie letzteren folgten. Eine gewöhnliche Bank darf und wird unter gegebenen Unstïnden die Bediurfnisse des Verkehrs und Handels ihren eigenen Interessen und vor allem ihrer eigenen Sicherheit unterordnen. Nicht so eine Kolonialbank, dis dem Handel spine Wechsel diskontioren und dem Pflanzer die benötigten V'orschüsse liefern soll. Die Kolonialbank muß zu diesem Zwecke die Riicksicht auf die Einlösbarkeit ihrer Noten vereinigen mit den Bedürfnissen der kolonialen Volkswirtschaft. Daß hieraus, besonders bei abnormen Geldverhältnissen, den Kolonialbanken fortwährend schwere Gefahren drohen, liegt auf der Hand.

6. Auch die Beteilignng der Kolonialbanken an Enissionen und an finanziellen, kommerziellen oder industriellen Unternehmungen verrït ihren speknlativen Charakter, desgleichen ihr Handel mit Silber. ${ }^{1}$ )

Obgleich das Gesagte genïgt, un den Spekulationscharakter der Kolonialbanken zu erweisen, so sei noch darauf hingewiesen, daß gerade das große Risiko des kolonialen Kredits das private Kapital von einer Kolonialbankunternehmumg abgeschreckt hat, so daß der französische Staat die (iründung von Kolonialbanken in die Hand nehmen mußte. Wo Private sich dennoch zur selbständigen Gründung einer Kolonialbank entschlossen, wie

1) Vergl. oben S. 56. 
z. B. in Indochina, da taten sie es nur unter der Bedingung, dab ihnen als Entgelt für ihr anBerordentliches Risiko das Notenprivileg rerliehen wurde.

Der unleugbare spekulationscharakter der französischen Kolonialbanken rechtfertigt es, wenn wir sie zu den Spekulationsbauken zählen.

Dureh ihr Notenprivileg unterscheiden sie sich ron allen Banken, die nicht das Notenausuabereeht haben.

Durch ihren Spekulationscharakter treten sie aber auch zu den gewöhnlichen Notenbanken in einen Gegensatz, der um so größer wird, je mehr Eigentïmlichkeiten der oben besprochenen Art die Kolonialbank im Einzelfall aufweist.

Die Kolonialbanken sind also Spekulationsbanken mit Totenprivileg. Sie stehen zwischen den reinen Depositenbanken mit Notenausgaberecht und den reinen spekulationsbanken. Insofern könnte man die (französischen) Kolonialbanken als eine besondere Art ron Banken ansehen. Eins ist dabei aber nicht zu rergessen: die Kolonialbanken sind in ihrem Wesen nur ein spiegelbild der wirtschaftlichen Verhältnisse, unter denen sie arbeiten. Je primitiver diese Terhältnisse sind, desto mehr wird die Kolonialbank sich ron unseren Kontinentalbanken unterscheiden. Je mehr sich die Terhälnisse in ler Kolonie den Wirtschaftsbediugungen des Mutterlandes nähern, desto ähnlichel wird auch die Kolonialbank den einheimischen Banken sein.

2. Kapitel.

$$
\$ 39 .
$$

\section{DIE KOLONIALBANKEN III VERGLEICH MITEINANDER.}

Wenn wir nach diesem Gesiehtspunkt die hier besprochenen französischen Kólonialbanken mit Ausnahme der kurzlebigen Bank ron Neukaledonien gruppieren, so ergibt wich eine Entwicklungsreihe, die fast bis zur Bank ron Frankreich hinführt.

Die untersten Stufen bilden die Banken von Sénégal und Guyane. Beide haben das miteinander gemein, daß sie lieine Erntedarlehen und bis 1900 fast gar keine Warendarlehen gewährt haben. 
Der eigentliche Agrarkredit blieb ihnen ako fremd. Während aber die Bank ron Gurane neben ihren Diskontgeschäften durels ihre envois d'or natif Wechselgeschifte ron nicht bedeutender, aber immerhin beachtenswerter Höhə erzielte und ihren Notenumlauf stetig zunehmen sah, blieben die Wechselgeschifte der Bank ron Sénígal unerhehlich aus Mangel an Handelsrimessen. Noch geringfügiger als ihre Wechselgeschäfte waren ihre Diskontgeschäfte. Das zeigt, daß die Bank mehr auf dem Aubenhandel der Kolonie als auf dem Innenverkehr basierte. Damit steht in Einklang. daß der Kontokorrentrerkehr der Bank ron S'́nígal nur wenig Depositengelder zurVerfügung stellte. und dab der Notenumlauf der Bank oft niedriger war als iln Metallrorrat. Die Bank ron Súnégal stellte unter allen Kolonialbanken die unentwickeltste dar. Die Bank von Guyane weist höhere Geschäftsziffern auf, sowie hessere Ausnutzung ilures Kapitals und deshalb auch höhere Dividenden. Aber his 1901 stand aluch sie auf ziemlich primitiver Stufe. Teben einigen Diskont- und Wechselgeschäften war der Ankauf und die Terwahrung ron Rohgold das Hauptgeschäft und fast die einzige 'Tïtigkeit der Bank. Sie erimnerte an den primitiven Trpus der ersten Banken des 17. Jahrhunderts in Amsterdim und Hamburg, bei denen die Noten als genauer Gegenwert und mathematiseher Warrant des Metallbestandes der Bank angesehen wurke. Auch die Bank ron Guyane ist also in ihrer Entwicklung zuriuckgeblieben; sie ist aber noch stark entwicklungsfïhig. Anders verhält es sich mit den 3 Banken der Zuckerkolonien. Die Banken ron Guadeloupe und Réunion zeigen ein Überwiegen der Pfandrlarlehen über die Diskontgeschïfte mit dem Unterschiede, dah bei der Bank ron Guadeloupe die Erntedarlehen, bei der Bank ron Réunion die Wareudarlehen die Hauptrolle spielen. Im Gegensatz dazı nehmen bei der Bank ron Iartinique wie bei den nachfolgenden Kolonialbanken unter allen Torschubgeschäften die Diskontgeschäfte den breitesten Raum ein. Alle drei Banken der Zuckerkolonien scheinen den Höhepunkt ihrer Entwicklung schon erreicht zu haben, wohl infolge der zweifachen Beschränkung, der sie unterliegen, und die räumlicher sowie sachlicher Art 
ist. Da sie ihren sitz nicht in Paris haben, können sie nicht das einheimische Kapital kolonialen Unternehmmngen dienstbar machen: und ibr eigenes geringes hapital craubt es ibnen nicht, sich an größeren Finanzgeschäften zu beteiligen. Das gerade Gegenteil hierron gilt für die nächsten 3 Kolonialbanken, bei denen der Übergang ron einer kolonialen Lokatbank zu einem großen, resschiedene Länder umspamenden Kolonialbankinstitut rollzogen ist. Die Zahl der Bankstellen ist in dieser Hinsicht ein offenkundiger Fingerzeig.

Die Banken ron Westafrikal und Indochina sind mit fast gleichen Statuten bedacht, haben auch das Recht zu Erntedartehen. Beide dürfen Finanzgeschäfte großen stils machen. Aber das hapital der Bank ron Westafrika ist noch klein und die Bank noch in den ersten Anfüngen, wogegen die Bank ron Indochina ein glänzend entwickeltes Banlinstitut darstellt. das auf eine mehr als 30 jührige Vergangenheit zurükblickt. Nahe rerwandt mit ihr ist die Bank von Algerien in bezug anf Größe der Unternehmmng: der verfügbaren Mittel und auch der erzielten Erfolge. Doch fehlen der Bank ron Algerien die meisten Eirentümlichkeiten, die wir an den Kolonialbanken oben festgestellt haben. Das Bedentsanste hierbei ist, daf bei der Bauk ron Algerien die Trennung zwischen Agran- und Handelsbank rechtlich schon seit Gründung der Bank, tatsïchlich aber erst seit 1900 rollzogen ist. Die Bank ron Algerien gewährt mur noch handelsmäßigen Kredit, ist ako eine reine Handelshank. sie berührt sich darin. wie in vielen anderen Punkten, mit der Bank ron Frankreich und sondert sich dadurch gleichzeitig ron den ïbrigen Kolonialbanken ab, da das Kennzeichen der Kolonialbanken, ihr Spekulationscharakter. in gleichem Verhältnis wie ihr agrarischer Charakter verschwindet.

Daf anch die Bank ron Algerien noch keine Bank ron Frankreich in Kleinen darstellt, ist oben schon gesagt. 




IHC

3039

1337
Soltau, otto

Die französischen

Kolonialbanken

PLEASE DO NOT REMOVE

CARDS OR SLIPS FROM THIS POCKET

UNIVERSITY OF TORONTO LIBRARY 
